\title{
NOVEL GROOVED SUBSTRATA STIMULATE MACROPHAGE FUSION, CCL2 AND MMP-9 SECRETION
}

by

Hai-Sle Moon

B.Sc., The University of British Columbia, 2010

A THESIS SUBMITTED IN PARTIAL FULFILLMENT OF

THE REQUIREMENTS FOR THE DEGREE OF

\section{MASTER OF SCIENCE}

in

THE FACULTY OF GRADUATE AND POSTDOCTORAL STUDIES

(Craniofacial Science)

THE UNIVERSITY OF BRITISH COLUMBIA

(Vancouver)

December 2015

(C) Hai-Sle Moon, 2015 


\section{Abstract}

Monocyte-derived macrophages arrive early at a newly implanted device and affect the performance of implants by regulating immune responses. Macrophages are "plastic" cells that exhibit a spectrum of functions between two quintessential phenotypes: (1) the classically activated (M1) phenotype associated with classical inflammatory responses and (2) the alternatively activated (M2) phenotype involved in wound healing or immunoregulatory behavior. Rough surface topographies on implants attract macrophages but the influence of topography on macrophage fusion to produce multinucleated giant cells (MGCs) and foreign body giant cells (FBGCs) is unclear. Previous studies have shown topography induced macrophage polarization and changes in cell shape as well as differential activation of cell signaling pathways. In this study, the effects of novel grooved substrata, G1 and G2, on changes in cell shape, gene expression, cyto/chemokine secretion and cell fusion were studied. G1 and G2 surfaces were fabricated by anisotropic etching of silicon $<110>$ crystals, without the use of photolithographic patterning, and extensively characterized by optical profilometry to determine the roughness parameter $R_{a}$ and isotropy parameters $S_{t r}$ and $S_{a l}\left(\mathrm{G} 1: R_{a} 0.10 \mu \mathrm{m}, S_{t r} 0.03, S_{a l} 2.1\right.$ $\left.\mu \mathrm{m} ; \mathrm{G} 2: R_{a} 1.2 \mu \mathrm{m}, S_{t r} 0.08, S_{a l} 5.8 \mu \mathrm{m}\right)$. RAW 264.7 macrophages were cultured on G1, G2, and smooth control (Pol) epoxy substrata for one and five days. Cells on the grooved surfaces exhibited cell morphology similar to M2 macrophages that were produced by IL-4 treatment. Cell alignment with the grooves increased with surface directionality and roughness as well as time in culture. Expression of macrophage chemoattractants CCL2 and CCL4 increased at the gene and protein level and the secretion of fusion mediators CCL2 and MMP-9 increased with time on the grooved surfaces. Relative to the Pol surface, an increased proportion of multinucleated cells was observed on the grooved surfaces at Day 5. Collectively, these in vitro 
results demonstrated that topography dependent macrophage responses resulted in differential secretion of macrophage attractant chemokines and soluble mediators involved in cell fusion that may explain the observed accumulation of macrophages and MGCs on rough surfaced implants in vivo. 


\section{Preface}

This dissertation is the original work of the author, H. Moon and several collaborators:

- The identification and design of the research project was conceived by Dr. D. M. Brunette and Dr. J.D. Waterfield.

- Fabrication of the novel grooved surfaces, G1 and G2, was done and provided by Dr. A. Kulpa from Advanced Materials and Process Engineering Laboratory (AMPEL) Advanced Nanofabrication Facility (ANF), UBC.

- The characterization of the topography of the novel grooved surfaces, G1 and G2, was done by Dr. C.V.M. Cremmel from Laboratory for Surface Science and Technology, Department of Materials, ETH Zurich, Zurich, Switzerland.

- The general preparation of reagents for the conducted experiments was done by H. Moon and Ms. Quan Ho.

- Reverse transcription quantitative real-time PCR (RT-qPCR) was performed by H. Moon and Ms. Quan Ho.

- Scanning Electron Microscopy (SEM) sample preparation and SEM images were carried out by H. Moon, F. Kianoush, and Ms. Quan Ho at Centre for High-Throughput Phenogenomics, UBC

- Analysis of the SEM images was performed by H. Moon and F. Kianoush.

- Immunofluorescence (IF) images were taken by H. Moon, and Ms. Quan Ho at Centre for High-Throughput Phenogenomics, UBC. 
Material in this thesis was presented at 2014 Canadian Society of Biomaterials meeting in Halifax, Nova Scotia, 2015 International Association for Dental Research meeting in Boston, Massachusetts, and 2015 Canadian Society of Biomaterials meeting in Toronto, Ontario. 


\section{Table of Contents}

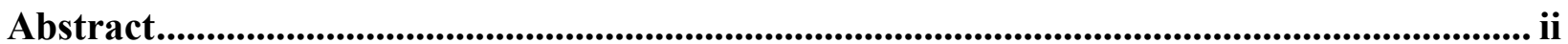

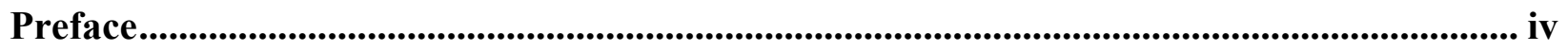

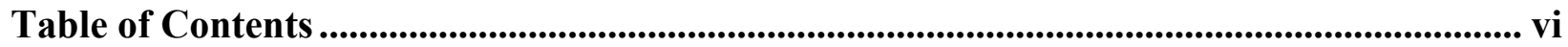

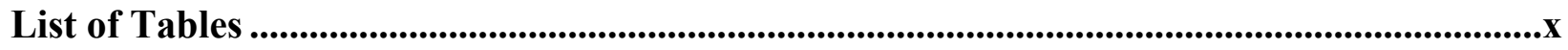

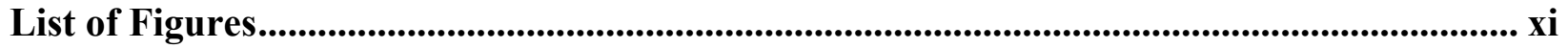

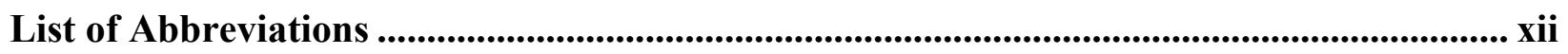

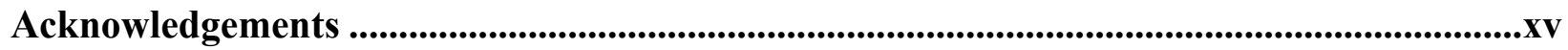

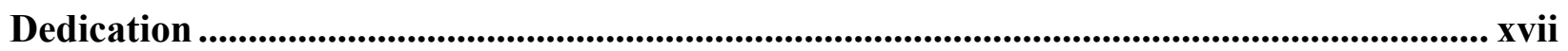

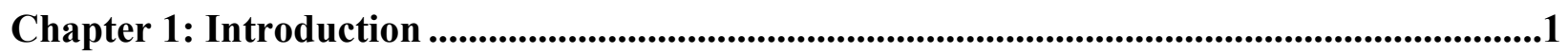

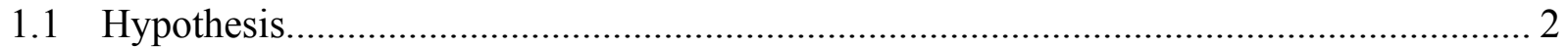

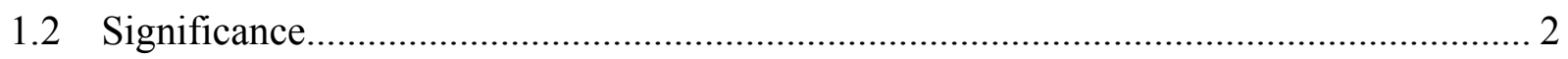

Chapter 2: Literature Review ......................................................................................................3

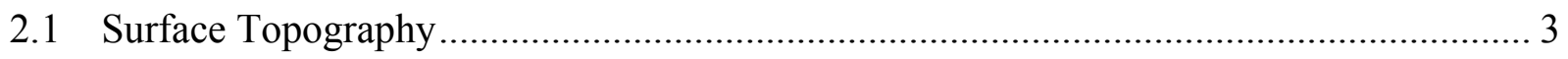

2.1.1 Surface Topography Characterization ............................................................ 4

2.1.2 Surface Topography Fabrication................................................................ 5

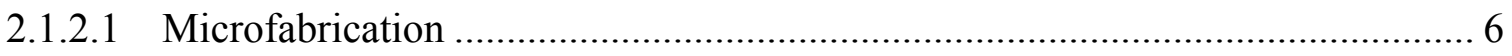

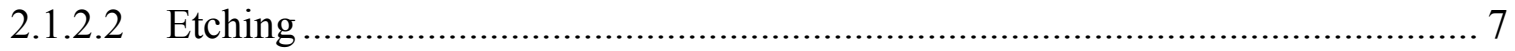

2.1.2.3 Novel Grooved Surface Topographies..................................................... 7

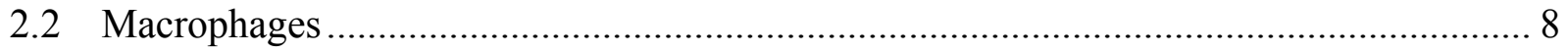

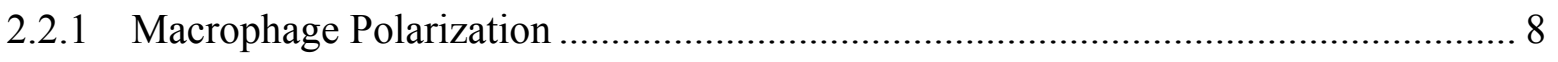

2.2.2 RAW 264.7 Macrophage Cell Line ............................................................. 11 
2.3 Surface Topography and Cell Behavior.................................................................... 12

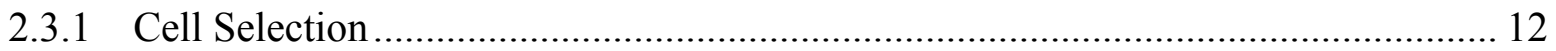

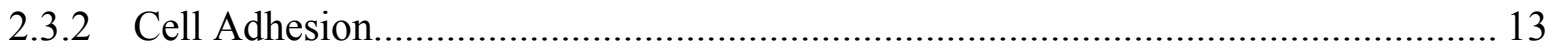

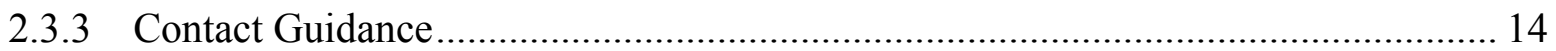

2.4 Effect of Microfabricated Grooved Surfaces on Cell Shape, Gene Expression and Protein

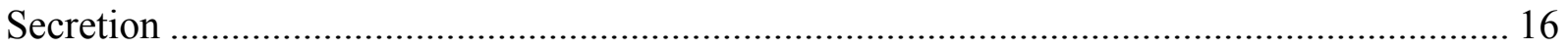

2.5 Production of Effector Molecules by Macrophages .................................................... 17

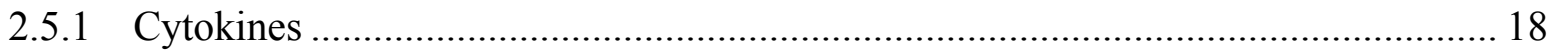

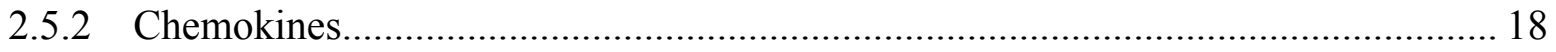

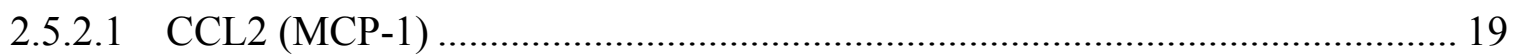

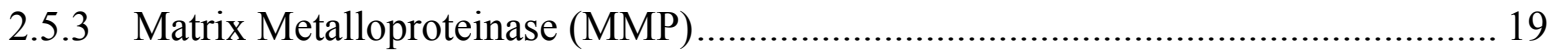

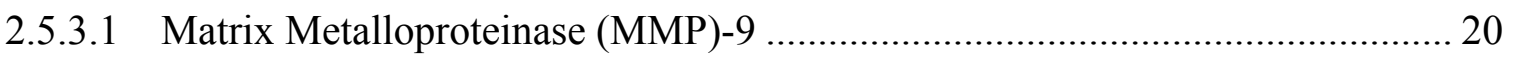

2.6 Macrophages, Foreign Body Giant Cell (FBGC) Formation and Cell Fusion ................. 21

2.6.1 Inflammatory Response Following Implantation .................................................. 21

2.6.2 Macrophage Fusion: Formation of Foreign Body Giant Cells (FBGCs).................. 22

Chapter 3: Material and Methods..................................................................................................24

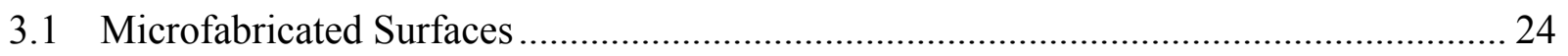

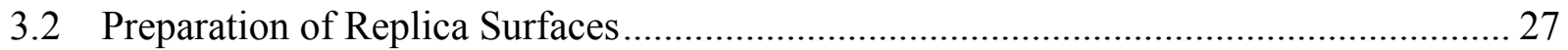

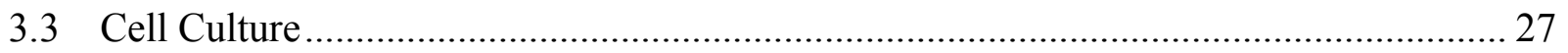

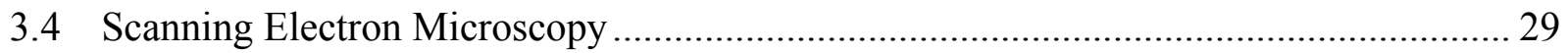

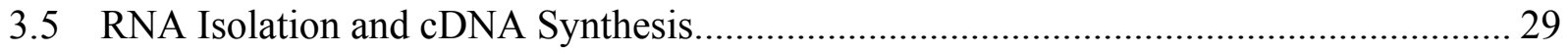

3.6 Reverse Transcription Quantitative Real-Time PCR (RT-qPCR) for Gene Expression in

RAW 264.7 Macrophages................................................................................................. 30 


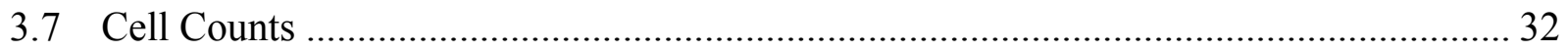

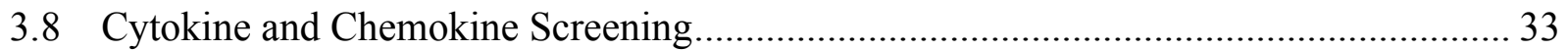

3.9 Quantification of Chemokine/protein Secretion Using ELISA …………………........... 33

3.10 Immunofluorescence (IF) and Analysis of Cell Fusion.................................................. 34

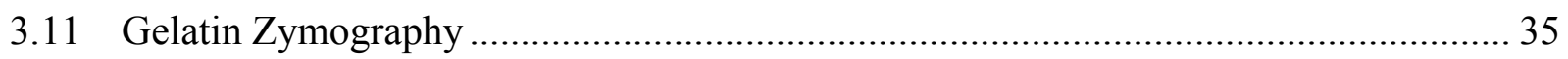

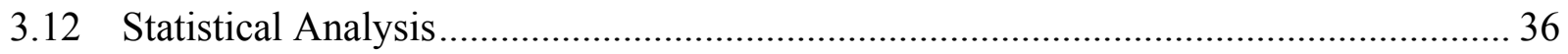

Chapter 4: Results....................................................................................................................................37

4.1 Effect of Surface Topography on Cell Morphology ………………………….............. 37

4.2 Effect of Grooved Surfaces on Macrophage Alignment................................................. 40

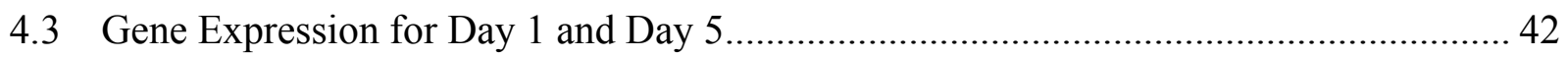

4.4 Cytokine/Chemokine Secretion for Day 1 and Day 5 .................................................. 45

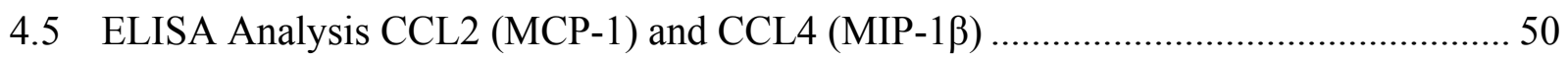

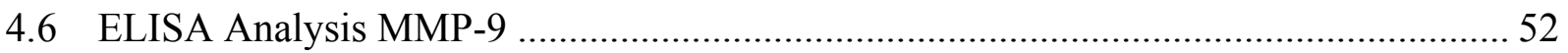

4.7 MMP-9 Expression and Activation Monitored by Zymography ..................................... 54

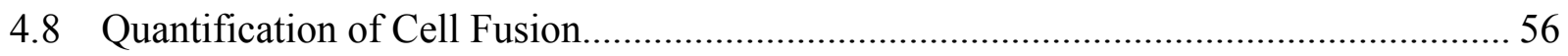

Chapter 5: Discussion ....................................................................................................................59

5.1 Alignment of Macrophages on the Grooved Surfaces ................................................. 59

5.2 Macrophage Phenotype and Shape on Grooved Surfaces ............................................... 60

5.3 Gene Expression and Cytokine/Protein Profile Produced by the Grooved Surfaces....... 61

5.4 Chemoattractant Cytokine CCL2/MCP-1 and Matrix Metalloproteinase-9 .................... 63

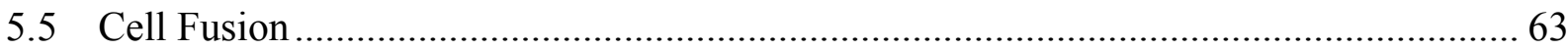

Chapter 6: Conclusions and Future Directions ..................................................................................67

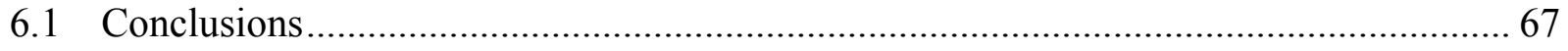




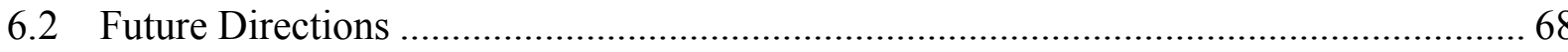

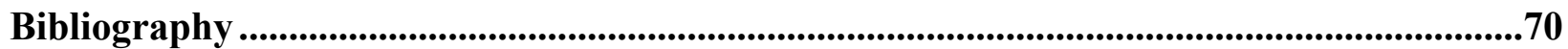

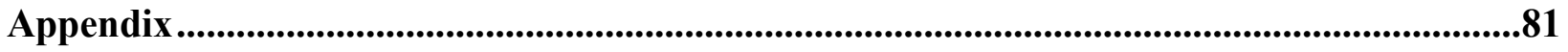

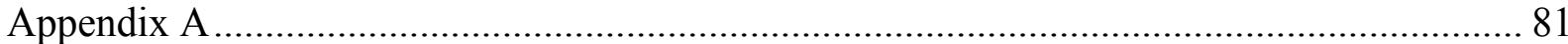

A.1 Preliminary Study on the Effect of Surface Topography on Canonical Wnt/ $\beta$-catenin Pathway in Macrophage—Role of E-cadherin/P120 (CTNND1) Complex in Macrophage-

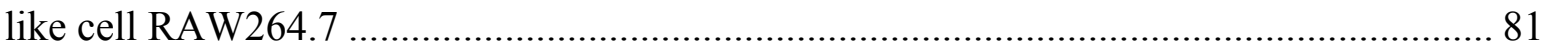




\section{List of Tables}

Table 2-1 Inducers and Indicators of Murine Macrophage Polarization. ................................ 10

Table 3-1 Surface Characterization ................................................................................ 26

Table 3-2 Primers used for Reverse Transcription Quantitative Real-Time PCR (RT-qPCR) .... 31

Table 4-1 Effect of G1 and G2 Grooved Surface Topographies on RAW 264.7 Macrophage Cell

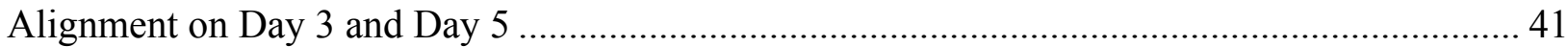




\section{List of Figures}

Figure 4-1 Topographic Effects on Macrophage Morphology …………………………........... 38

Figure 4-2 Elongation of RAW 264.7 by Grooved Substrata..................................................... 39

Figure 4-3 95\% Confidence Interval of Averaged Ratio Ct value (G1/Pol) for Day 1 and Day 543

Figure 4-4 95\% Confidence Interval of Averaged Ratio Ct value (G2/Pol) for Day 1 and Day 544

Figure 4-5 Cytokine and Chemokine Secretion Profile of RAW264.7 Macrophages Cultured on

G1 for Day 1 and Day 5 46

Figure 4-6 Analysis of the Cyto/Chemokine Secretion Profile of RAW264.7 Macrophages

Cultured on G1 for Day 1 and Day 5

Figure 4-7 Cytokine and Chemokine Secretion Profile of RAW264.7 Macrophages Cultured on

G2 for Day 1 and Day 5 48

Figure 4-8 Analysis of the Cyto/Chemokine Secretion Profile of RAW264.7 Macrophages

Cultured on G2 for Day 1 and Day 5. 49

Figure 4-9 CCL2 and CCL4 Secretion as Analyzed by ELISA ……………………............... 51

Figure 4-10 MMP-9 Secretion as Analyzed by ELISA …….................................................... 53

Figure 4-12 Immunofluorescent Images of RAW264.7 Macrophages Cultured on G1 and G2 on

Day 5 57

Figure 4-13 Cell Fusion on G1, G2, and Pol-as Analyzed by Number of Nucleus of Multinucleated Cells 58 


\section{List of Abbreviations}

ATCC

BLC

BMP2

$\mathrm{C} 5 \mathrm{a}$

$\mathrm{Ca}^{2+}$

$\mathrm{CaCl}_{2}$

CCL12

CCL2

CCL3

CCL4

CCL5

CCL7

CCR2

CI

CXCL2

DAPI

DC-STAMP

Eotaxin

ERK1/2

FBGC

G-CSF

GM-CSF

$\mathrm{H}_{2} \mathrm{O}_{2}$

HA

$\mathrm{HCl}$

$\mathrm{HF}$

HMDS

I-309

I-TAC

IL-1
American type culture collection

B lymphocyte chemoattractant

Also known as C-X-C motif chemokine 13 (CXCL13)

Bone morphogenetic protein-2

Complement component 5a

Calcium ion

Calcium chloride

Cysteine:cysteine $(\mathrm{C}: \mathrm{C})$ ligand 12 chemokine

Also known as MCP-5, monocyte chemotactic protein-5

Cysteine:cysteine $(\mathrm{C}: \mathrm{C})$ ligand 2 chemokine

Also known as MCP-1, monocyte chemotactic protein-1

$\mathrm{C}$ : $\mathrm{C}$ ligand 3 chemokine

Also known as MIP-1 $\alpha$, macrophage inflammatory protein alpha

$\mathrm{C}: \mathrm{C}$ ligand 4 chemokine

Also known as MIP-1 $\beta$, macrophage inflammatory protein beta

$\mathrm{C}: \mathrm{C}$ ligand 5 chemokine

Also known as RANTES, regulated on activation, normal T cell expressed and secreted

$\mathrm{C}: \mathrm{C}$ ligand 7 chemokine

Also known as MCP-3, monocyte chemotactic protein-3

$\mathrm{CC}$ chemokine receptor2

Confidence interval

C-X-C motif chemokine 2 (CXCL2)

Also known as MIP-2, Macrophage inflammatory protein-2

4', 6-diamidino-2-phenylindol

Dendritic cell-specific transmembrane protein

Cysteine:cysteine $(\mathrm{C}: \mathrm{C})$ ligand 11 chemokine

Extracellular signal-regulated protein kinases 1 and 2

Foreign body giant cell

Granulocyte-colony stimulating factor

Granulocyte-macrophage colony-stimulating factor

Hydrogen peroxide

Hydroxyapatite

Hydrochloric acid

Hydrofluoric acid

Hexamethyldisilazane

T lymphocyte-secreted protein I-309

Also known as $\mathrm{C}$ : $\mathrm{C}$ ligand 1 chemokine

Interferon-inducible $\mathrm{T}$ cell alpha chemoattractant

Also known as C-X-C motif chemokine 11 (CXCL11)

Interleukin-1 


\begin{tabular}{|c|c|}
\hline IL-10 & Interleukin-10 \\
\hline IL-12 p70 & Interleukin-12 p70 \\
\hline IL-13 & Interleukin-13 \\
\hline IL-16 & Interleukin-16 \\
\hline IL-17 & Interleukin-17 \\
\hline IL-1 ra & Interleukin-1 receptor antagonist \\
\hline IL- $1 \alpha$ & Interleukin-1 alpha \\
\hline IL-1 $\beta$ & Interleukin-1 beta \\
\hline IL-2 & Interleukin-2 \\
\hline IL-23 & Interleukin-23 \\
\hline IL-27 & Interleukin-27 \\
\hline IL-3 & Interleukin-3 \\
\hline IL-4 & Interleukin-4 \\
\hline IL-5 & Interleukin-5 \\
\hline IL-6 & Interleukin-6 \\
\hline IL-7 & Interleukin-7 \\
\hline INF $\gamma$ & Interferon gamma \\
\hline IP-10 & Interferon gamma inducible protein-10 \\
\hline $\mathrm{KC}$ & $\begin{array}{l}\text { Keratinocyte chemoattractant } \\
\text { Also known as } \mathrm{C}-\mathrm{X}-\mathrm{C} \text { motif chemokine } 1 \text { (CXCL1) }\end{array}$ \\
\hline $\mathrm{KOH}$ & Potassium hydroxide \\
\hline LPS & Lipopolysaccharide \\
\hline $\mathrm{M}-\mathrm{CSF}$ & Macrophage colony-stimulating factor \\
\hline M1 & Classically activated macrophages \\
\hline M2 & Alternatively activated macrophages \\
\hline MCP-1 & Monocyte chemotactic protein-1, also known as CCL2 \\
\hline MCP-3 & Monocyte chemotactic protein-3, also known as CCL7 \\
\hline MGC & Multinucleated Giant Cell \\
\hline MIG & $\begin{array}{l}\text { Monokine induced by interferon-g } \\
\text { Also known as C-X-C motif chemokine } 9 \text { (CXCL9) }\end{array}$ \\
\hline MIP-1 $\alpha$ & Macrophage inflammatory protein-1 alpha, also known as CCL3 \\
\hline MIP-1 $\beta$ & Macrophage inflammatory protein-1 beta, also known as CCL4 \\
\hline $\mathrm{mL}$ & Millilitre \\
\hline $\mathrm{mm}$ & Millimetre \\
\hline MMPs & Matrix metalloproteinases \\
\hline $\mathrm{NaCl}$ & Sodium chloride \\
\hline $\mathrm{NaOH}$ & Sodium hydroxide \\
\hline NGAL & Neutrophil gelatinase-associated lipocalin \\
\hline $\mathrm{NH}_{4} \mathrm{OH}$ & Ammonium hydroxide \\
\hline NO & Nitric oxide \\
\hline NOS2 & Nitric oxide synthase 2 , inducible \\
\hline OPN & Osteopontin \\
\hline $\mathrm{OsO}_{4}$ & Osmium tetroxide \\
\hline PBS & Phosphate buffered saline \\
\hline
\end{tabular}




$\begin{array}{ll}\text { Pol } & \text { Polished surface } \\ \mathrm{R}_{\mathrm{a}} & \text { Average roughness over all points on a profile } \\ \text { RNA } & \text { Ribonucleic acid } \\ \text { Sal } & \text { Auto-correlation length } \\ \text { SDF-1 } & \text { Stromal cell-derived factor-1 } \alpha \\ \text { SEM } & \text { Scanning electron microscope } \\ \text { sICAM } & \text { Soluble intercellular adhesion molecule-1 } \\ \text { SLA } & \text { Sandblasted Large-grit Acid-etched } \\ \text { STDEV } & \text { Standard deviation } \\ \text { Str } & \text { Texture aspect ratio } \\ \text { TARC } & \text { Thymus and activation regulated chemokine } \\ & \text { Also known as C:C ligand 17 chemokine } \\ \text { TGF } \beta & \text { Transforming growth factor beta } \\ \text { Th } & \text { T helper cell 1 } \\ \text { Th } & \text { T helper cell } 2 \\ \text { TIMP-1 } & \text { Tissue inhibitors of metalloproteinases }-1 \\ \text { TNF-a } & \text { Tumor necrosis factor alpha } \\ \text { TREM-1 } & \text { Triggering receptor expressed on myeloid cells-1 } \\ \mathrm{Zn}^{2+} & \text { Zinc ion } \\ \mu \mathrm{L} & \text { Microlitre } \\ \mu \mathrm{m} & \text { Micrometer }\end{array}$




\section{Acknowledgements}

I would like to thank my supervisor, Dr. D. M Brunette for his advice and continued patience throughout the course of my study. I would specially like to thank him for his support and guidance and I am very grateful for having to have an opportunity to learn and study under his supervision.

I would also like to thank my committee members, Dr. J.D. Waterfield, Dr. Clive Roberts, and Dr. Kim for their support and invaluable advice throughout the course of my thesis.

I would also like to thank Dr. Salem Ghrebi, Dr. Katrin Barth, Dr. Mandana Nematollahi, and Dr. Fumiko Sawada Kusuhara for being role models as well as their help and support throughout my study. Also, I would like to thank Mr. Andre Wong for teaching me the basics of fluorescence microscopy.

I am thankful for the membranes of the Brunette lab for their support and help. I would like to thank Ms. Quan Ho for her help with the RT-qPCR experiments and reagent preparations for the experiments and Dr. Mayu Kawase for her example of professionalism. I give many thanks to my colleague Ms. Fariba (Kiana) Kianoush for her moral support and contributions throughout this thesis.

I appreciate the kindness of the Dr. C. Schuler lab for allowing me to use their nanodrop spectrophotometer and PCR machine and the Dr. E. Putnins lab for allowing shared use of the ultrasonic machine, mastercycler, centrifuge, and scanner. 
I also would like to thank Dr. Reini Kappelhoff and Dr. Verena Goebeler for their help on zymography experiments and Dr. N.D. Spencer from Swiss Federal Institute of Technology Zurich for his help in providing access to the facilities of his lab and Dr. C.V.M Cremmel for the characterization of the topography of the novel grooved surfaces. Also, I would like to thank Dr. A. Kulpa and Dr. N.A.F. Jaeger for the fabrication of the novel grooved surfaces.

Finally, I would like to thank my family for all their encouragement, support, and understanding. 
For my family 


\section{Chapter 1: Introduction}

The optimal design of surfaces for implanted devices requires a thorough understanding of cell responses at the cell-implant interface. Currently there are several hundred dental implant systems available, varying in material composition, macro design and surface topography ${ }^{1,2}$. However, as a general rule implant designs were developed based on trial and error optimization, without knowledge of how cells would response to the surfaces ${ }^{3}$. Monocyte-derived macrophages are one of the first cell types to interact with implants. Macrophages are capable of responding to differences in surface topography through alterations in their shape and function ${ }^{4-}$ ${ }^{7}$ and are instrumental in inflammation, immunoregulation and wound healing. Functionally the two major phenotypes are (M1) macrophages associated with classical inflammatory responses, and alternatively activated (M2) macrophages involved in wound healing or immunoregulatory behavior ${ }^{8,9}$. Macrophages also undergo fusion to form multinucleated giant cells (MGC) that have long been recognized as a hallmark of granulomatous infections including foreign body response (FBR) ${ }^{10,11}$. Although several other stimuli may be involved, macrophage fusion can be induced by soluble mediators such as cytokines and growth factors ${ }^{12}$. The cytokine interleukin- 4 (IL-4), a mediator of macrophage alternative activation ${ }^{13}$, is known to induce macrophage fusion and formation of MGCs in vitro ${ }^{14,15}$. However, surface topography-induced expression of soluble mediators of cell fusion has not been studied extensively. Previous studies from our lab have shown that topography can modulate macrophage polarization ${ }^{16}$, changes in cell shape, and differential activation of signaling pathways that affect cell function ${ }^{7}$. In this study, novel grooved surface topographies were fabricated by anisotropic-etching of $\mathrm{Si}<110>$ crystals and found to affect gene expression, cyto-/chemokine secretion as well as cell fusion. The novel 
grooved surfaces promoted changes in macrophage cell shape similar to IL-4 induced M2 phenotype macrophages and showed time-dependent increase of cell fusion mediators, CCL2 and MMP-9 that resulted in an increase, relative to smooth control surfaces, in multinucleated cells.

\subsection{Hypothesis}

Surface topography would differentially affect macrophages' $: 1$ ) secretion of soluble mediators 2) cell alignment, 3) cell shape and polarization, and 4) gene expression and cyto/chemokine secretion.

\subsection{Significance}

The in vitro results from this study will help elucidate: 1) the effects of surface topography on changes in macrophage secretion pattern and responses, such as cell fusion, as well as 2) the possible role of surface topography in regulating foreign body giant cell (FBGC) formation on implants. This knowledge may lead to improved designs for the surface topography of biomedical devices that optimize desired macrophage response to implanted devices. 


\section{Chapter 2: Literature Review}

\subsection{Surface Topography}

Surface topography is defined by the degree of roughness of the surface and the orientation of its irregularities $^{2}$. A number of wavelength-dependent roughness evaluation techniques including non-contact laser profilometry (LPM) for micron to millimeter sized features, and interference microscopy (IM) and stereo-scanning electron microscopy (stereo-SEM) for nano-sized features are utilized to measure and characterize topographical features. Wavelength-dependent roughness evaluation techniques give more accurate measurements and provide a useful means of differentiating the effects of different surface treatment processes ${ }^{17}$. In addition, for precision profile and surface roughness measurements, optical profilometers have found widespread use. Optical profilometry refers to a non-contact interferometric-based method. Three most important measuring instruments based on optical techniques include optical stylus profilometry, confocal microscopy, and interferometry ${ }^{18}$. The confocal microscopy evaluation technique, relevant to this thesis, is based on the focus detection principle and is suitable for three-dimensional topography assessment when the reflected light is detected rather than the emitted fluorescence. For the technique, both the light source pinhole $\mathrm{P} 1$ and the detector pinhole $\mathrm{P} 2$ are focused on the sample specimen. The two pinholes allow the detection of light reflected back from the focal plane. In laser scanning confocal microscopy, one surface picture element (pixel) is imaged at a time and the final image is built by the reconstruction of a number of optical slices. All of the pixels where the reflection occurs contribute to the final image. Optical profilometers provide high radial and axial resolution that are based on nondestructive and noncontacting principle. ${ }^{18}$. 


\subsubsection{Surface Topography Characterization}

The characterization of surface topography is a complex branch of metrology with a large range of parameters. Characterization of surface textures can be divided into profile characterization and areal characterization. Only the surface parameters relevant to this study will be discussed.

Surface profile measurement is achieved by measuring a line laterally across the surface and representing that line mathematically as a height function with a lateral displacement, $\mathrm{z}(\mathrm{x})$. Manufacturers have carried out the use of profile methods to measure and characterize surface textures for some time. However, an analysis of the areal surface topography can provide much more information about surfaces ${ }^{19}$. For example, parameters $S_{a}$ and $R_{a}$ are commonly used to describe the average feature-height roughness of a surface. $S_{a}$ is a 3 dimensional parameter that gives a measurement of the average roughness over a surface in 3 dimensions (thus gives the average of the absolute values of the lateral displacement $\mathrm{z}$ in the measured area $(\mathrm{z}(\mathrm{x}, \mathrm{y}))$, whereas $R_{a}$ parameter gives the measurement over a profile in 2 dimensions ${ }^{20}$. Two surfaces may have different morphologies but still share a common $R_{a}$ value ${ }^{21}$. The $S_{a}$ parameter can differentiate between anisotropic and isotropic surfaces and Wennerberg (2004) suggested that the $S_{a}$ parameter calculated on an area may provide a more accurate representation of average surface roughness than the $R_{a}$ value.

Surfaces with some orientation of features such as micromachined surfaces are an example of an anisotropic surface, whereas surfaces in which the features lack a clear orientation, such as sandblasted large-grit acid-etched (SLA) surfaces, are referred to as an isotropic surface ${ }^{22}$. 
In this study, the two dimensional $R_{a}$ profile measurement was used to depict the average roughness of the studied surfaces Pol, G1 and G2. In addition, two areal field parameters $S_{a l}$ and $S_{t r}$ were used to characterize the anisotropy features of the grooved surfaces. $S_{a l}$ is the autocorrelation length referring to the quantitative distance of the surface where surface texture is statistically different from the original location. $S_{t r}$ is the texture aspect ratio that measures the directionality or spatial isotropy of the surface texture. An isotropic surface will have $S_{t r}$ value close to 1 and highly anisotropic surface will have $S_{t r}$ value close to 0 . For an in-depth understanding on characterization of areal surface texture refer to Characterisation of Areal Surface Texture, ed. R. Leach. $2013^{19}$.

\subsubsection{Surface Topography Fabrication}

Surface topographies can be produced by a myriad of fabrication techniques including plasma spraying, machining, particle blasting, acid etching, and combination of blasting and acid etching.

Additive procedures such as Ti plasma spraying or hydroxyapatite (HA) plasma spraying produce convex or bumpy surfaces. Plasma spraying technique will also introduce chemical changes to the surface topography. Surface characteristics, together with chemical modifications could affect cellular responses. For example, implants can be coated with Ti or HA particles to increase the speed and amount of bone formation ${ }^{23}$.

On the other hand, subtractive procedures such as blasting and acid etching that produce concave surfaces with pits or pores ${ }^{22}$. Combination of blasting and acid etching can be used to produce additional roughness within the pits created by the blasted particles. Sandblasted large-grit acid- 
etched (SLA) is an example of blasted and etched surface with 20 to $40 \mu \mathrm{m}$ pits and 0.5 to $2 \mu \mathrm{m}$ features within the pits ${ }^{17}$

There are also microfabricated surfaces with precisely defined surface characteristics that have allowed extensive studies on the effect of surface topographies on a wide variety of cell behaviors. Some of the examples of the microfabricated surfaces include simple structures such as single steps to much more sophisticated features like holes and pits ${ }^{24}$, grooves ${ }^{25-28}$, and pillars ${ }^{29}$.

\subsubsection{Microfabrication}

Microfabrication refers to the technologies that use integrated-circuit manufacturing technology to create objects with dimensions in the range of micrometers to millimeters. Microfabricaton uses a sequence of process steps and materials - e.g., silicon or titanium — that can lead to a large range of possible physical structures. Bulk micromachining refers to the fabrication of objects out of bulk material ${ }^{30}$ and surface micromachining refers to the fabrication of objects on its surface ${ }^{31}$. Often devices are built with a combination of both types of machining.

Typically microfabrication of silicon-grooved surfaces is done by the use of photolithographic technique, which is used to transfer a desired pattern into a substrate. Photolithography begins with a growth of a thin layer of oxide onto the wafer surface by heating the substrate. Then, a thin layer of photoresist, an organic polymer that is sensitive to ultraviolet radiation, is deposited on the oxide surface. Next the wafer is placed under a master mask (a metal pattern on a glass plate) through which it is exposed to radiation. The radiation causes chemical reactions in the 
exposed area and the wafer is rinsed in a developing solution that removes either the exposed area (positive photoresist) or the unexposed area of the photoresist (negative photoresist). Then the wafer is etched in an acid to remove exposed oxide and later on to strip off the remaining photoresist. The result is a transfer of a desired pattern into a substrate ${ }^{32}$

\subsubsection{Etching}

Etching is divided into wet (via liquid chemicals) and dry (via gas-phase chemistry) prcoesses. Either method can lead to isotropic or anisotropic etching. Isotropic etching etches in all directions equally and anisotropic etching is directional. Anisotropic etching can be induced either chemically or physically (sputter etching) ${ }^{33}$.

\subsubsection{Novel Grooved Surface Topographies}

Anisotropic etchants for crystalline silicon have been applied to produce a large variety of silicon structures in a highly controlled and reproducible manner. There is a strong dependence of the etch rate on crystal direction and on dopant concentration (for a general understating of anisotropic etching of crystalline silicon in alkaline solution see Seidel et al. (1990) ${ }^{34}$ ). Aqueous

alkaline solutions of $\mathrm{KOH}$ and $\mathrm{NaOH}$ have been widely used to etch silicon anisotropically ${ }^{35}$. In contrast to common microfabrication methods used to produce micro-scaled features that require photolithographic patterning and etching, this study utilized the anisotropic-etching of $\mathrm{Si}<110>$ crystals in aqueous alkaline solution $\mathrm{KOH}$ alone to produce novel grooved surfaces, designated as G1 and G2, with varying surface directionality and roughness. 


\subsection{Macrophages}

Macrophages are specialized phagocytes derived from blood monocytes. Blood monocytes, originate from the bone marrow, enter the blood circulation and remain in the circulation for several days before entering tissues, where they fully differentiate into resident macrophages 36,37 .

Macrophages carry out diverse biological functions such as activation of the immune response, antigen presentation, clearance of debris and pathogens via phagocytosis, wound healing, and fibrosis ${ }^{38}$. Depending on their location and microenvironment, macrophages acquire diverse morphology and a wide variety of biological functions ${ }^{39}$. Macrophage subtypes resident in different body tissues are known by different names and they perform specialized functions; for example alveolar macrophages resident in lungs identify and clear viruses and microorganisms in the lung 36 .

\subsubsection{Macrophage Polarization}

Upon stimulation with bacterial products, cytokines, chemokines, and growth factors in the environment, macrophages display functional changes ${ }^{40}$. Heterogeneity and plasticity are hallmarks of monocyte derived macrophages ${ }^{8,41,42}$ and macrophages polarize to functional phenotypes to adopt to changes in the environment ${ }^{8,9}$. Mirroring the two subsets of helper T cells Th1/Th2 nomenclature, polarized macrophages can be classified into two extremes of a spectrum of possible forms of functional phenotypes-M1 and M2. Classically activated (M1) macrophages are associated with classical inflammatory responses whereas alternatively activated (M2) macrophages are involved in wound healing or immunoregulatory behavior ${ }^{8,9}$. A 
classic inflammatory M1 phenotype is induced by IFN $\gamma$, and/ or microbial stimuli (e.g. LPS), whereas the alternative M2 phenotype is induced by IL-4 and IL-13 ${ }^{9,41,43}$.

Mantovani et al. (2004) ${ }^{44}$ proposed a more comprehensive and detailed classification on top of the M1/M2 paradigm to encompass a range of different subsets of alternatively activated macrophages (i.e., M2a, M2b, M2c), which includes not only the 'wound healing' macrophages but also the 'regulatory' macrophages. Generally, the nomenclature M2 is used as a generic name for the various alternatively activated macrophages other than the classically activated M1. Most common characteristics of murine M1 and M2 macrophage phenotypes are summarized in Table 2-1. 


\begin{tabular}{lll}
\hline Macrophage Phenotype & Main Inducers & Secretions and Cell Surface Receptors \\
\hline M1 & IFN- $\gamma$ & IL-1 $\beta, 6,23,12$ \\
& LPS & TNF-a, CCL-2 (MCP-1), iNOS (NOS2), COX-2 \\
& CXCL-9, 10,11 \\
& & IL-10, MRC1*, Arg1 \\
IL-4 & \\
& CCL-2 (MCP-1), CCL-7 (MCP-3) \\
& Ym ${ }^{*}$, Fizz- $1 *$ \\
\hline
\end{tabular}

Table 2-1 Inducers and Indicators of Murine Macrophage Polarization.

* indicates cell surface receptors 
M1 and M2 macrophages display distinctively different metabolism of iron, glucose, and amino acids. M1 macrophages promote Th1 differentiation of lymphocytes that secretes proinflammatory cytokines and prevent the growth of bacteria. M1 cells also metabolize glucose using the anaerobic glycolytic pathways. On the other hand, M2 macrophages obtain their energy through oxidative glucose metabolism ${ }^{45}$. M2 macrophages also secrete anti-inflammatory cytokines, such as IL-10, and express scavenger receptors and mannose receptors ${ }^{8}$, as well as display a high level of iron export aiding tissue remodeling ${ }^{46}$. The most profound distinguishing features between M1 and M2 macrophages are the production of nitric oxide (NO) and polyamines. M1 macrophages are capable of microbicidal activity characterized by the expression of nitric oxide synthase 2, inducible (NOS2) and production of $\mathrm{NO}^{45}$. In contrast, alternatively activated M2 macrophages express high levels of arginase I (Arg1), which catalyzes the production of polyamines required for cellular processes such as collagen synthesis, cell proliferation, tissue remodeling and fibrosis ${ }^{45,47}$.

\subsubsection{RAW 264.7 Macrophage Cell Line}

RAW 264.7 cell line is the most commonly used murine macrophage cell line in medical research. It was derived from adult male BALB/c mice transformed by the Abelson murine leukemia virus ${ }^{48}$. RAW 264.7 macrophages are sensitive to macrophage activating agents, such as lipopolysaccharide (LPS) and IL-4, and display some properties of characteristic normal macrophages. Although, murine RAW 264.7 macrophages display some discrepancies in expression of alternative activation markers when compared to human macrophages, (for example when stimulated, the M1 marker NOS2 and M2 markers Arg1, Fizz1 and Ym2 are expressed by murine but not in human macrophages ${ }^{49}$ ), conservation of function is apparent 
across the two species in that chemotactic activity of similar cell types is elicited by chemokines secreted by human and murine macrophages ${ }^{50}$. Unlike the variability in human macrophages arising from variations among donor sources, the RAW 264.7 macrophage cell line provides a stable and reproducible primary experimental system to examine various macrophage responses and behaviors to external stimuli such as surface topography and other treatments in vitro ${ }^{6,7,16,51}$.

\subsection{Surface Topography and Cell Behavior}

Cellular interactions with biomaterials are not only influenced by the macro structural design of biomedical devices, but also by the microscopic features (surface topography) of the biomedical devices. Microscopic features (surface topography) have been reported to affect a wide variety of cell behaviors (for a review see Titanium in Medicine, ed. D.M Brunette. $2001^{52}$ ). Some of the effects of surface topography on cell behaviors that influence the performance of implants will be discussed here:

\subsubsection{Cell Selection}

Topographic characteristics, such as roughness, may be varied to enhance cell adhesion and hence, promote attachment of certain cell types in selective regions of the implant surface. Cells vary in their adherent behaviors in response to roughness. For example, macrophages prefer rough surfaces, a behavior termed rugophilia ${ }^{53}$ while fibroblasts and epithelial cells prefer smooth topographies ${ }^{54}$, a behavior known as rugophobia. ${ }^{53}$.

Rugophilic behavior of macrophages was not only observed in vitro but also in vivo. In an in vivo study by Chehroudi et al. $(2010)^{55}$, newly recruited macrophage cells were found on the 
rough SLA surface and this high accumulation of macrophages was associated with faster and greater amount of bone formation.

Micro-machined topographies of different pits and pore sizes can also be employed in cell selection ${ }^{25,56}$. Also, cell traps fabricated by micropatterning can be utilized to direct and 'trap' the cells to a location where the cell's locomotion is restricted ${ }^{57}$.

\subsubsection{Cell Adhesion}

In order for anchorage dependent mammalian cell types to migrate, proliferate, differentiate and express certain genes, cells need to adhere to the surface ${ }^{58}$. Cells can attach to surfaces via large macromolecular assemblies, called focal adhesions (FAs), on the cell membrane. Integrins are the specialized attachment proteins in the FAs that interact with extracellular matrix (ECM) ${ }^{59}$ adhering to the biomaterial surface. Cells convey information about their microenvironment intracellularly through active engagement of membrane receptors, which results in signaling cascades that determine their function ${ }^{60}$. Integrins are involved in intracellular events regulating gene expression, cell proliferation, differentiation, migration and cell death ${ }^{61}$. Surface topography is known to modulate and affect adhesion molecules and it has been postulated that through proper manipulation of surface topography, optimum tissue device interactions can be achieved via selective cell adhesion, which could increase the success rate of implants ${ }^{24}$

Adhesion of macrophages to biomedical substrata is a complex process. Macrophages most likely recognize proteins adsorbed to the substratum and attach to surface adsorbed proteins via integrin mediated interactions ${ }^{62}$. Through their integrin receptors, macrophages can recognize 
fibronection, vitronectin of extra cellular matrix (ECM) as well as adsorbed blood proteins ${ }^{63}$. Surface topography can affect on macrophage adhesion. For example, Wojciak-Stothard and Curtis $(1996){ }^{4}$ found an increased number of macrophages on grooved substrata that was sensitive to groove depth, and pitch. Surface topography also has shown to affect macrophage attachment structure. Rough SLA surface exhibited greater amount of vinculin plaques localized at focal contacts and podosome-like structures compared to the smooth control surfaces ${ }^{7}$.

In addition, macrophages express highly dynamic dot-shaped adhesion structure called podosomes that represent "hotspots" of integrins, stretch-activated ion channels, and cytosolic proteins such as myosin and talin ${ }^{64}$. Podosomes are similar to focal adhesions (FAs) but they are short lived and undergo cycles of rapid assembly/disassembly with a life span of 2-4 $\min ^{65}$. Three dimensional micropatterned substrates have shown to align podosomes of dendritic cells along the edges of the substrata ${ }^{66}$.

\subsubsection{Contact Guidance}

Contact guidance (or topographic guidance) refers to directed cell alignment and locomotion by the features of the substratum such as grooves and ridges of substrata. This tendency of cells to orient themselves with topographical features was first discovered by Harrison in 1914 and later extensively studied by Weiss ${ }^{67}$. Surface features such as grooves, holes/pits, steps, fibers, tunnels/tubes, discontinuous surfaces, and pillars have been reported to show contact guidance of various cell types such as macrophages ${ }^{68}$, fibroblasts ${ }^{25,69}$, osteoblasts ${ }^{70}$, and epithelial cells ${ }^{56}$. 
Shallow micro grooves (called minor grooves) fabricated by the etching of $\mathrm{Si}<110>$ crystals were observed by Brunette (1986) ${ }^{26}$ as secondary feathers to the major grooves produced by photolithographic patterning. Fibroblasts were contact guided by the major grooves. The minor grooves were also capable of guiding the fibroblasts in the absence of any other influential factors. However, fibroblasts oriented themselves hierarchically with major grooves when the cells were exposed to both major and minor grooves. Brunette also showed alignment of fibroblasts and epithelial cells on grooves with depths as shallow as $0.5 \mu \mathrm{m}{ }^{1}$.

Macrophages can also be oriented by the grooves and showed spreading and migration along the groove/ridge edges. The speed of locomotion was also affected by the topographic features. Macrophages moved significantly faster and traveled for a longer distance on grooved surfaces when compared to the plain surfaces. The macrophage locomotion on grooves was depth dependent. Macrophages showed restricted locomotion and shorter travel distance on $5 \mu \mathrm{m}$ deep groves when compared $0.5 \mu \mathrm{m}$ deep grooves ${ }^{68}$

Several possible underlying mechanisms of contact guidance have been proposed. Ohara and Buck ${ }^{71}$ suggested rigidity of focal contacts governs the alignment of cells on narrow pitched grooves. Later Brunette ${ }^{56}$ showed focal contacts are capable of bending around the ridges and thus showed that the cell alignment is not solely the result of inflexibility of focal contacts. He suggested cell alignment is a result of cells' orientation based on the probability of formation of successful attachments. Oakley and Brunette (1993) ${ }^{28}$ observed microtubules as the first cytoskeletal element to align with micromachined grooves and suggested that microtubules are the prime cause of cell orientation and alignment on grooved surfaces. 


\subsection{Effect of Microfabricated Grooved Surfaces on Cell Shape, Gene Expression and}

\section{Protein Secretion}

Effects of grooved surfaces have been extensively studied in a variety of cell types. Cell orientation in turn affects extracellular matrix (ECM) orientation and deposition ${ }^{72}$, and is also known to alter gene expression ${ }^{73,74}$. Hong et al. (1987) ${ }^{75}$ studied the effect of grooves and adhesive substrata on relationship between cell proliferation, cell shape, and proteinase secretion in epithelial cells. Rounder epithelial cells, as observed on grooved substratum, secreted greater amount of proteinase compared to the more spread cells, demonstrating a correlation between cell shape for both neutral proteinase and plasminogen activator secretion. Cell proliferation, differentiation, and gene expression can also be affected by cell shape ${ }^{60,76}$. Gingival fibroblasts cultured on V shaped grooves showed significantly elongated shape and 1.5fold greater cell height as well as increased cell alignment when compared to gingival fibroblasts cultured on smooth controls. In addition, a two-fold increase in fibronectin secretion was observed for fibroblasts cultured on the grooved surface and the stability of fibronectin mRNA was also altered when compared to a smooth surface ${ }^{73}$.

Several in vitro studies have shown the effects of surface topography on macrophage gene and protein expressions. Macrophages cultured on rough surface topographies have been found to secrete pro and anti-inflammatory cytokines as well as pro-osteoinductive and pro-osteogenic growth factors in vitro ${ }^{5,16,77}$. Higher level of anti-inflammatory cytokine TGF $\beta$ and osteogenic growth factor BMP2 was found on macrophages cultured on a grit-blasted surface topography ${ }^{5}$. Similarly, Refai et al. (2004) ${ }^{6}$ showed surface topography modulated expression of the cytokines IL-1 and IL-6, and chemokines CCL2 and CCL3 by suboptimally stimulated 
macrophages in a surface roughness and time dependent manner. Barth et al. (2013) ${ }^{16}$ did not find any significant differences in gene expression of macrophage phenotype markers - NOS2 (M1 marker) and Arg1 (M2 marker) — between macrophages cultured on rough surface SLA and smooth control surfaces. However, relative increased secretion of CCL2 and CCL3, and decreased secretion of M1-associated chemokine IP-10 was observed on SLA when compared to the smooth control surfaces. The chemokine secretion pattern was similar to the M2 phenotype macrophages induced by IL-4 and thus indicated M2-like properties of macrophages cultured on SLA. Overall it appears that macrophages' responses to biomaterials do not fall clearly into the prototypical M1 or M2 phenotypes but rather exhibit a blended phenotypic signature ${ }^{16,77,78}$.

Surface topography can influence macrophage shape and function in vitro. For example, Ghrebi et al. (2013) ${ }^{7}$ found topography-dependent morphological changes were reflected in changes in the distribution of vinculin within focal contacts (FCs) and observed topography-dependent differentially activated components of the ERK1/2 signaling pathway. Similarly, McWhorter et $a l .{ }^{79}$ found changes in cell elongation, modulated by surface features, induced changes in expression of macrophage phenotype markers with a polarization toward a prohealing M2 phenotype.

\subsection{Production of Effector Molecules by Macrophages}

Macrophages release myriad substances including cytokines, chemokines, and effector molecules orchestrating the immune responses, immune regulation and wound repair after injury. Effector molecules most relevant to this project will be discussed. 


\subsubsection{Cytokines}

Cytokines encompass a broad group of signaling proteins that regulate cell functions under normal, developmental, and pathologic conditions ${ }^{80}$. They are produced transiently in response to environment-derived signals and initiate their actions via engaging with specific receptors expressed by their target cells ${ }^{81}$. Some of the large groups of cytokines include interleukins, interferons, colony stimulating factors, and tumor necrosis factors. Cytokines are involved in regulation of immune responses, inflammation, hematopoiesis, and wound healing ${ }^{82}$.

The cytokine network system demonstrates great redundancy; meaning different cytokines can carry out similar functions. For example, cell division in activated $\mathrm{T}$ cells can be stimulated by many different cytokines. Pleiotropism can also occur; a single cytokine can carry out different functions on different cell types or sometimes even on the same cell ${ }^{83}$.

\subsubsection{Chemokines}

Chemokines or chemotactic cytokines are subfamily of cytokines, whose main function is cell trafficking. Chemokines are classified into four families named $\mathrm{C}, \mathrm{CC}, \mathrm{CXC}$, and $\mathrm{CX} 3 \mathrm{C}$ based on the number and location of the cysteine residues at the N-terminus of the protein ${ }^{84}$. They perform a crucial role in immune responses by selectively recruiting monocytes, neutrophils, and lymphocytes. In response to chemokines produced in wounded tissue, migration of cells expressing the appropriate chemokine receptors are directed along the chemical ligand gradient known as the chemokine gradient. A Chemokine gradient directs cells to move toward high local concentrations of chemokines. Chemokines are involved in the induction of leukocyte migration, 
angiogenesis, collagen production, and the proliferation of hematopoietic precursors through the activation of G-protein coupled receptors ${ }^{84,85}$.

\subsubsection{CCL2 (MCP-1)}

The monocyte chemoattractant protein-1 (MCP-1/CCL2) is a member of the $\mathrm{C}-\mathrm{C}$ chemokine family. CCL2 is produced by a variety of cell types, including endothelial, fibroblasts, epithelial, smooth muscle, mesangial, astrocytic, monocytic, and microglial cells ${ }^{86-89}$.

Monocyte/macrophages are found to be the major source of CCL2 ${ }^{90,91}$. The expression of CCL2 is induced by inflammatory stimuli such as viruses, lipopolysaccharides (LPS) as well as cytokines such as tumor necrosis factor alpha (TNF- $\alpha$ ), interleukin-1 (IL-1), interferon gamma (IFN- $\gamma)$ and platelet-derived growth factor (PDGF) ${ }^{85,92-95}$. CCL2 regulates migration of monocytes/macrophages and lymphocytes ${ }^{85,93,95}$. CCL2 has also been shown to regulate Th1/Th2 lymphocyte differentiation by increasing IL-4 production and inhibiting IL-12 production, enhancing Th2 development ${ }^{96,97}$. The activities of CCL2 are mediated by the CC chemokine receptor2 (CCR2). All chemokine receptors are identified as G protein coupled receptors (GPCRs), belonging to the rhodopsin or serpentine receptor family ${ }^{98}$. CCR2 has two isoforms CCR2A and CCR2B, which differ only in their C-terminal tails ${ }^{99}$. CCR2A is the major isoform of CCR2 expressed by vascular smooth muscle cells ${ }^{100}$ whereas CCR2B isoform is predominantly expressed by monocytes and activated natural killer (NK) cells ${ }^{98}$.

\subsubsection{Matrix Metalloproteinase (MMP)}

Matrix metalloproteinases (MMPs) belong to a family of endopeptidases whose activities depend on metal ions, $\mathrm{Zn}^{2+}$ and $\mathrm{Ca}^{2+}$. MMPs act on a large range of substrates, including molecular 
components of extracellular matrix, growth factors, chemokines, and cell-surface proteins ${ }^{101,102}$ to activate latent forms of effector proteins or to alter protein functions. MMPs are involved in many physiological and pathological processes including wound healing, angiogenesis, inflammation, and cancer. MMPs can also regulate cell invasion, migration, apoptosis, and proliferation ${ }^{103,104}$.

Structurally, MMPs are comprised by a prodomain, a catalytic domain, which contains three conserved histidine metal ion, $\mathrm{Zn}^{2+}$, binding motifs ${ }^{105}$, a hinge region, and a hemopexin domain. Based on evolutionary relationships and structure of the catalytic domain, MMPs can be divided into six groups including collagenases, gelatinases, stromelysins, matrilysins, membrane-type MMPs (MT-MMPs), and seven MMPs that are not classified into the aforementioned categories ${ }^{101}$. Only MMP-9 of relevance to this thesis will be discussed.

\subsubsection{Matrix Metalloproteinase (MMP)-9}

Matrix metalloproteinase (MMP)-9 (gelatinase B), along with MMP-2 (gelatinase A), belong to the Gelatinases subfamily of MMPs. Structurally these enzymes have three repeats of a type II fibronectin domain in the catalytic domain, which can bind to gelatin, collagens, and laminin ${ }^{106}$. It has been shown that MMP-9 is responsible for the degradation of extracellular matrix components such as collagen I, IV, V, VII, X, and XI, elastin, fibronectin, and laminin ${ }^{103,107}$. MMP-9 also acts on number of non-matrix proteins such as cytokines, chemokines and growth factors including IL-1 and monocyte chemokine MCP-3/CCL7, and plasminogen by converting plasminogen to active antiangiogenic angiostatin ${ }^{108,109}$. MMP-9 has also been shown to modulate inflammatory signals by activating latent TGF- $\beta$ and by processing proinflammatroy 
protein interleukin -8 (IL-8) resulting in a 10 - to 27 -fold higher potency in neutrophil activation 110,111. The functional complexity of MMP-9 in inflammatory responses and the high level of MMP-9 observed in foreign body giant cells (FBGCs) in vivo and during macrophage fusion in vitro have implicated MMP-9 for a role in macrophage fusion and foreign body response (FBR) 112.

\subsection{Macrophages, Foreign Body Giant Cell (FBGC) Formation and Cell Fusion}

\subsubsection{Inflammatory Response Following Implantation}

Following the implantation of biomedical devices in vivo, a series of host reactions take place including blood-material interactions, provisional matrix formation, acute inflammation, chronic inflammation, and granulation tissue development ${ }^{10,113-115}$. In the early phase of implantation, blood/implant interactions occur concurrently with protein adsorption to the implant surface and the development of a blood-based transient provisional matrix that forms on and around the implant ${ }^{116,117}$. The provisional matrix is rich in cytokines, chemokines, growth factors, and chemoattractants that recruit cells of the innate immune system to the wound site ${ }^{118}$. Moreover, the provisional matrix also contains substances capable of modulating macrophage activities as well as proliferation and activation of other cells involved in the inflammatory and wound healing responses. Following provisional matrix formation, acute and chronic inflammation occurs sequentially. After the resolution of acute and chronic inflammatory responses, granulation tissue is seen that is the precursor to fibrous capsule formation. Granulation tissue is separated from the implanted device by the cellular component of foreign body reactions (FBR) consisting of macrophages and foreign body giant cells (FBGCs) at the implant interface ${ }^{119}$. 


\subsubsection{Macrophage Fusion: Formation of Foreign Body Giant Cells (FBGCs)}

Implant-surface-adherent macrophages can fuse to form foreign body giant cells (FBGCs). In order for macrophage fusion to occur, IL-4 induced molecules are needed on both fusing partners ${ }^{120}$. In vitro model induction of macrophage fusion and FBGC formation using IL-4 ${ }^{15}$ was confirmed in vivo using IL-4 neutralization antibody ${ }^{121}$. IL-13 was found to induce the monocyte-derived macrophage fusion as potently as IL-4 ${ }^{122}$. This finding indicates macrophage polarization resulted in phenotypically altered state of macrophages prior to cell fusion to form FBGCs by an IL-4 stimulus or other fusion inducing stimulus such as IL-13. For example, both IL-4 and IL-13 were found to up-regulate mannose receptors on fusing macrophages with localization of the receptor at fusion interface ${ }^{122}$. Inhibitors of mannose receptor activity resulted in prevention or reduced formation of fused macrophages ${ }^{123}$.

Several other fusion mediators other than mannose receptor have also been reported to be involved in macrophage fusion. For example, $\beta 1$ integrin receptors have been identified as a fusion mediator involved in IL-4 induced macrophage fusion ${ }^{124}$. Similarly, dendritic cellspecific transmembrane protein (DC-STAMP) appears to be necessary for fusion in the FBGC formation since macrophage fusion was completely abrogated in DC-STAMP deficient mice ${ }^{125}$.

The exact molecular mechanisms behind macrophage fusion have not been fully elucidated. However, it is anticipated that cell fusion involves tightly regulated steps. General overview of the macrophage fusion steps includes changes of macrophage status into fusion-competent status by fusion mediators, chemotaxis of the fusion competent cells towards each other, followed by 
cell-cell recognition and attachment, as well as merging of the cellular membranes resulting in multinucleated cells ${ }^{126}$.

In contrast to the clearly defined stimuli involved in osteoclastogenesis (osteoclast formation is stimulated by receptor activator of nuclear factor kappa B ligand (RANKL) and the growth factor macrophage colony stimulating factor (M-CSF) ${ }^{127}$ ), the stimuli involved in the formation of multinucleated cells are less well defined. Multinucleated cells seem to form in response to different cytokines and other stimuli. The chemokine CCL2 has been identified as a possible ligand for DC-STAMP receptor ${ }^{128}$. CCL2 null mice implanted with biomaterials $(0.45 \mu \mathrm{m}$ pore size, mixed cellulose ester and $6 \mathrm{~mm}$ diameter sponges) showed reduced formation of foreign body giant cells. Blockade of CCL2 in vitro also resulted in reduced FBGC formation further confirming CCL2 as a participant in macrophage fusion ${ }^{129}$. Also, osteopontin (OPN), an extracellular matrix protein that is upregulated at inflammatory sites, appears to play an inhibitory role in FBGC formation ${ }^{130}$. Macrophage fusion not only depends on the expression of necessary fusion promoting molecules but also depends on the material of biomaterial surfaces ${ }^{131}$. The surface must have an appropriate array of proteins adsorbed to implant surfaces that favors the fusion of macrophages ${ }^{12}$. McNally et al. ${ }^{132}$ found that polystyrene coated with vitronectin strongly supported macrophage adhesion as well as fusion and suggested surfaces that favor adsorption of vitronectin also favor macrophage fusion. FBGC formation thus depends on two main factors: first is the presence of appropriate stimuli that allow a macrophage polarization shift to undergo fusion and the second is the implant surface that favors the adsorption of appropriate proteins that favor macrophage fusion ${ }^{12}$. 


\section{Chapter 3: Material and Methods}

\subsection{Microfabricated Surfaces}

Grooved surfaces fabricated by anisotropic-etching of $\mathrm{Si}<110>$ crystals were fabricated at the Advanced Materials and Process Engineering Laboratory (AMPEL) Advanced Nanofabrication Facility (ANF), UBC. In brief, silicon wafers went through standard set of wafer cleaning steps called RCA clean (sometimes called "standard clean SC"). For the first step called RCA-1 or SC1, the wafers were soaked with a solution composed of 1 part $27 \% \mathrm{NH}_{4} \mathrm{OH}, 1$ part $30 \% \mathrm{H}_{2} \mathrm{O}_{2}, 5$ parts deionized water for the removal of organic residues and films form the silicon wafers. Then metal ions from the silicon wafers were removed by RCA-2 or SC-2 clean by soaking the silicon wafers in a solution composed of 1 part $27 \% \mathrm{HCl}, 1$ part $30 \% \mathrm{H}_{2} \mathrm{O}_{2}$ and 6 parts deionized water. Following the RCA cleaning, the silicon wafers were dipped in 47\% HF solution for $30 \mathrm{~s}$ followed by deionized water rinse and blow dry. Then the silicon wafers were placed in the condenser top beaker assembly and etched in freshly prepared $\mathrm{KOH}$ solution $(75 \mathrm{wt} \%$ of $\mathrm{KOH}$, $23.5 \mathrm{wt} \%$ of deionized water, $1.5 \mathrm{wt} \%$ of isopropyl alcohol) at $70 \sim 90{ }^{\circ} \mathrm{C}$ on a stirrer. During the etching process, the top part of the condenser was cooled with water. Anisotropic-etching of Si $<110>$ crystals produced grooved surfaces designated as $\mathrm{G} 1$ (fabricated at $70 \sim 90{ }^{\circ} \mathrm{C}$; for a general review of the wet-etching see Seidel et al. (1990) ${ }^{34}$ ) and G2 (fabricated in more vigorous condition by raising temperature to $165^{\circ} \mathrm{C}$ ) with different surface roughness. The characterization of these grooved surfaces was performed at ETH Zurich (ETHZ) using a Plu Neox (Sensofar, Terrassa, Spain) in the confocal mode. The analysis was executed using Sensomap (v. 6.1, Sensofar, Terrassa, Spain) and Matlab (v. R2014b, Mathworks, MA, USA) for 
the isotropy parameters, the threshold of the autocorrelation function was set to 0.3 . Roughness and isotropy parameters are given in Table 3.1. 


\begin{tabular}{lll}
\hline Surfaces & Roughness parameters & Isotropy parameters \\
\hline $\mathrm{G} 1$ & $R_{a}(\mu \mathrm{m}) 0.10 \pm 0.02$ & $S_{a l}(\mu \mathrm{m}) 2.1 \pm 0.4$ \\
& & $S_{t r} 0.03 \pm 0.003$ \\
G2 & $R_{a}(\mu \mathrm{m}) 1.2 \pm 0.25$ & $S_{a l}(\mu \mathrm{m}) 5.8 \pm 1.5$ \\
& & $S_{t r} 0.08 \pm 0.011$ \\
\hline
\end{tabular}

\section{Table 3-1 Surface Characterization}

Roughness and Isotropy parameters of the novel grooved surfaces, G1 and G2. Data represents median \pm standard deviation. $R_{a}$ is a commonly used parameter depicting the average feature-height roughness of a surface that provides the measurement over a profile in two dimensions. $S_{a l}$ is the auto-correlation length referring to the quantitative distance of the surface where surface texture is statistically different from the original location. $S_{t r}$ is the texture aspect ratio that measures the directionality or spatial isotropy of the surface texture. An isotropic surface will have $S_{t r}$ value close to 1 and highly anisotropic surface will have $S_{t r}$ value close to $0{ }^{19}$ 


\subsection{Preparation of Replica Surfaces}

Polished (Pol) titanium disks (15mm in diameter and $1 \mathrm{~mm}$ in thickness) with $R_{a}$ value of $0.06 \mu \mathrm{m}$ were provided by Institute Straumann (Basel, Switzerland). Epoxy replicates of Pol, G1 and G2 surfaces were prepared according to previously published methods, reproducing the original surface features with high fidelity ${ }^{27,133,134}$. Impressions of the surfaces were made with vinyl polysiloxane impression material (Flexitime Light Flow; Heraeus Kulzer, Hanau, Germany). These negative replica impressions were used to cast epoxy-resin (Epo-TEK 302-3; Epoxy Technology, MA, USA) positive replicas. Positive replicas were then cured overnight at $37{ }^{\circ} \mathrm{C}$ for initial polymerization, followed by $6 \mathrm{~h}$ at $58^{\circ} \mathrm{C}$ and $2 \mathrm{~h}$ at $80{ }^{\circ} \mathrm{C}$ to complete polymerization. There was apparent batch-to-batch variation in the epoxy resin that could result in incompletely cured epoxy and cells cultured on the incompletely cured epoxy proliferated more slowly. Thus, if a new batch of resin is used in replicating the experiments, a first step is to test the replicas for their ability to support growth. The epoxy replicas were cleaned by ultrasonication in a $50 \%$ diluted detergent 7X (MP Biomedicals, CA, USA) for 30 min, washed extensively with water, followed by $10 \mathrm{~min}$ sonication in distilled water then $10 \mathrm{~min}$ sonication in ultrapure water (NANOpure Diamond; Barnstead, USA). Directly before cell seeding, the epoxy resins were cleaned and sterilized by 4 min exposure to an argon plasma (Plasma Cleaner/Sterilizer PDC32G; Harrick Scientific, NY, USA).

\subsection{Cell Culture}

The commercially available murine macrophage-like cell line RAW 264.7 (ATCC, VA, USA) used in this study is well established in the literature as a convenient homogenous population suitable for the analysis of macrophage activation and function ${ }^{135}$. RAW 264.7 was selected for 
this study in particular as it builds on previously conducted studies carried out by our group studying the effects of surface topography on macrophages ${ }^{6,7,16,51}$. The cells were cultured in $75 \mathrm{~cm}^{2}$ tissue culture flasks (Corning; VWR International, ON, Canada) in Dulbecco's modified Eagle's medium (STEMCELL Technologies, BC, Canada) supplemented with 10\% heatinactivated bovine growth serum (BGS) (Fisher Scientific, MA, USA) and antibiotics [66ug/mL penicillin G (Sigma-Aldrich, MO, USA), 33ug/mL gentamycin (Gibco, MA, USA), 0.7ug/mL Amphotericin B (Gibco, MA, USA)] at $37{ }^{\circ} \mathrm{C}$ in a humidified $5 \% \mathrm{CO}_{2}$ atmosphere. Cells were routinely passaged and sub-cultured by harvesting using a cell scraper and kept for a maximum of 15 passages. For the gene expression studies, cells passaged less than nine times after purchase were used. Cells were plated onto the epoxy replicas at a population density of $2 \times 10^{5}$ cells/mL/well (Corning Costar; VWR International, ON, Canada) for 1-day and $2 \times 10^{4}$ cells $/ \mathrm{mL} /$ well for 5 -day experiments. Theses cell population densities were chosen based on previous studies ${ }^{7,16,136}$ so that the cells were grown to confluence at Day 1 and 5. For gelatin zymography studies, cells were plated on the epoxy replicas at a population density of $6 \mathrm{x}$ $10^{5} \mathrm{cells} / \mathrm{mL} /$ well for 1 -day, $1.5 \times 10^{5}$ cells $/ \mathrm{mL} /$ well for 3 -day, and $6 \times 10^{4}$ cells $/ \mathrm{mL} /$ well for 5 day experiments so that sufficient cells for analysis were available. For the cytokine and chemokine analysis on Day 5, the culture medium was changed on Day 4, $24 \mathrm{~h}$ before the supernatant samples were collected to ensure that only the cytokines and chemokines secreted between Day 4 and 5 were analyzed. Collected supernatants were centrifuged at 13,000rpm for 7 $\min$ for the removal of cell debris and stored in aliquots at $-80{ }^{\circ} \mathrm{C}$.

For M2 phenotype controls, RAW 264.7 cells were stimulated with $40 \mathrm{ng} / \mathrm{mL}$ IL-4 (Peprotech, NJ, USA) 30 min after seeding on Pol substrata ${ }^{137}$. 


\subsection{Scanning Electron Microscopy}

The morphology of RAW 264.7 cells plated on G1, G2, polished (Pol) as well as Pol+ IL4 (M2 phenotype control) for $24 \mathrm{~h}$ were observed by scanning electron microscopy (SEM). Cells were first fixed with 2.5\% glutaraldehyde (Fisher Scientific, MA, USA) for $45 \mathrm{~min}$, then rinsed with PBS, followed by staining with $1 \% \mathrm{OsO}_{4}$ for $30 \mathrm{~min}$ and $1 \%$ Tannic acid staining for $20 \mathrm{~min}$. Lastly, samples were re-stained in $1 \% \mathrm{OsO}_{4}$ for $15 \mathrm{~min}$. The subsequent dehydration steps were performed using a microwave (PELCO 3470 Hornet Microwave System; Pelco International Redding, CA, USA). The specimens were sequentially rinsed in 50, 60, 70, 80 and 90\% ethanol for $1 \mathrm{~min}$ each and 2 min twice for 100\% ethanol. Finally $100 \%$ ethanol was exchanged with 100\% hexamethyldisilazane (HMDS) (Sigma-Aldrich, MO, USA) for three times 10 min each at room temperature. Samples were sputter-coated with Iridium using Leica EM MED020 coating system (Leica, Wetzlar, Germany) and observed using Helios NanoLab ${ }^{\mathrm{TM}}$ DualBeam ${ }^{\mathrm{TM}}$ scanning electron microscope (FEI, OR, USA) at $1 \mathrm{kV}$ accelerating voltage.

\subsection{RNA Isolation and cDNA Synthesis}

On Day 1 and Day 5, cells were lysed and RNA was isolated using RNeasy Mini Kit (Qiagen, ON, Canada) according to the manufacturer's instructions. RNA quality and quantity was assessed with Nanodrop ND-1000 Spectrophotometer (Thermo Scientific, MA, USA). Samples

were considered pure if 260/280 ratios and 260/230 ratios were $>1.8{ }^{138}$. RNA was reverse transcribed into cDNA using iScript cDNA Synthesis Kit (Bio-Rad Laboratories, CA, USA) and a Mastercycler gradient thermal cycler (Eppendorf, Hamburg, Germany) according to manufacturer's instructions. 


\subsection{Reverse Transcription Quantitative Real-Time PCR (RT-qPCR) for Gene Expression in RAW 264.7 Macrophages}

Reverse transcription quantitative real-time PCR was carried out using a RG-3000 Rotor Gene

PCR cycler (Corbett Research, NSW, Australia) and Sso Fast ${ }^{\mathrm{TM}}$ EvaGreen ${ }^{\circledR}$ Supermix (Bio-Rad Laboratories, CA, USA). After an initial denaturation step for 1 min at $95{ }^{\circ} \mathrm{C}, 40$ cycles were performed for $10 \mathrm{~s}$ at $95{ }^{\circ} \mathrm{C}$ and $60 \mathrm{~s}$ at $60{ }^{\circ} \mathrm{C}$. At the end of each cycling protocol, melt curves were acquired by heating the samples from $72{ }^{\circ} \mathrm{C}$ to $95{ }^{\circ} \mathrm{C}$ in $1{ }^{\circ} \mathrm{C}$ increment for $45 \mathrm{~s}$ for the first step and $5 \mathrm{~s}$ for the remaining steps to ensure the formation of a single product after amplification. Two controls were included for each run; nontemplate controls without cDNA to check for primer dimers as well as contaminants and non-RT controls from mock reverse transcriptions without the enzyme to ensure the absence of contaminating genomic DNA. Each sample was run in 3 biological and 3 technical replicates. The primer pairs (Integrated DNA Technologies, IA, USA) used for the study are given in Table 3-2. 


\begin{tabular}{|c|c|c|c|}
\hline Primer & Sequence & Orientation & Source \\
\hline \multirow{2}{*}{$\begin{array}{l}\text { CCL2 } \\
\text { (MCP-1) }\end{array}$} & 5'- AGG TGT CCC AAA GAA GCT GTA-3' & Forward & \multirow[t]{2}{*}{139} \\
\hline & 5'-ATG TCT GGA CCC ATT CCT TCT-3' & Reverse & \\
\hline CCL3 & 5'-TGA CAC TCT GCA ACC AAG TCT TC-3' & Forward & \multirow[t]{2}{*}{140} \\
\hline$(\mathrm{MIP}-1 \alpha)$ & 5'-AAC GAT GAA TTG GCG TGG AA-3' & Reverse & \\
\hline CCL4 & 5'-TTC TCT TAC ACC TCC CGG CAG-3' & Forward & \multirow[t]{2}{*}{141} \\
\hline$(\mathrm{MIP}-1 \beta)$ & 5'-GTA CTC AGT GAC CCA GGG CTC A-3' & Reverse & \\
\hline CCL5 & 5'-TGC CCA CGT CAA GGA GTA TTT C-3' & Forward & \multirow[t]{2}{*}{142} \\
\hline (RANTES) & 5'-AAC CCA CTT CTT CTC TGG GTT G-3' & Reverse & \\
\hline CCL7 & 5'-AGC TAC AGA AGG ATC ACC AG-3' & Forward & \multirow[t]{2}{*}{143} \\
\hline (MCP-3) & 5'-CAC ATT CCT ACA GAC AGC TC-3' & Reverse & \\
\hline \multirow[t]{2}{*}{ GAPDH } & 5'-TGG CAA AGT GCA GAT TGT TGC C-3' & Forward & \multirow[t]{2}{*}{16} \\
\hline & 5'-AAG ATG GTG ATG GGC TTC CCG-3' & Reverse & \\
\hline
\end{tabular}

Table 3-2 Primers used for Reverse Transcription Quantitative Real-Time PCR (RT-qPCR) 
Amplification plots showed that the expression of housekeeping gene GAPDH was invariant throughout all treatments, thus validating its use as an internal control. Relative quantification of target transcript abundance between two surfaces was analyzed by the comparative $2^{-\Delta \Delta \mathrm{Ct}}$ method ${ }^{144}$ using GAPDH as the reference gene. For each target gene studied, threshold cycle Ct, the PCR cycle at which fluorescent first rises above threshold background fluorescence, was averaged from experiments done with sample sets prepared from a minimum of two separate cell platings and the ratio $\mathrm{Ct}(\mathrm{Ct}(\mathrm{G}) / \mathrm{Ct}(\mathrm{Pol}))$ was calculated. Comparison of gene expression between two conditions, typically $\mathrm{G}$ and Pol surfaces, was considered statistically significant if the $95 \%$ confidence interval calculated for averaged ratio $\mathrm{Ct}$ value $(\mathrm{Ct}(\mathrm{G}) / \mathrm{Ct}(\mathrm{Pol}))$ did not include the value of one.

\subsection{Cell Counts}

To express the results on a per cell basis, the number of viable cells on the Pol, G1, and G2 samples was quantified using the metabolic MTS based CellTiter $96^{\circledR}$ cell proliferation assay (Promega, WI, USA). After harvesting the supernatants on Day 1 and Day 5, sample substrata were placed into a new 24-cell culture well plate (Falcon, NY, USA) and cultured in $1 \mathrm{~mL}$ of fresh cell culture medium supplemented with $0.2 \mathrm{~mL}$ of the MTS reagent as specified in the manufacturer's instructions. Then the sample substrata were incubated at $37^{\circ} \mathrm{C}$ in a humidified $5 \% \mathrm{CO}_{2}$ atmosphere for $2 \mathrm{~h}$. After incubation, $130 \mu \mathrm{L}$ of the supernatants were transferred to a 96 well plate (Nalgene, NY, USA) in triplicate and the absorbance of the formazan formed by the cultured cells on sample substrata was measured at $490 \mathrm{~nm}$ using a microplate reader (FLUOstar Optima; BMG Labtech, Ortenberg, Germany). The number of cells cultured on each substratum was determined by comparing the absorbance from the calibration curve obtained by 
seeding RAW264.7 cells with known cell concentration in the range of 0 cells $/ \mathrm{mL}$ to $1 \times 10^{6}$ cells $/ \mathrm{mL}$. The cell concentrations were also confirmed by observing DAPI (Sigma-Aldrich, MO, USA)-stained cells under UV-2E-C filter per unit area of $1.4 \mathrm{~mm}^{2}$ using an Axioskop 2 fluorescent microscope (Zeiss, Jena, Germany).

\subsection{Cytokine and Chemokine Screening}

To screen for the influence of surface topography on cytokine and chemokine secretion, a commercially available antibody array kit based on a sandwich ELISA principle with 40 murine cytokines and chemokines capture antibodies (Proteome Profiler, Panel A; R\&D Systems, MN, USA) was used to analyze supernatants harvested on Day 1 and Day 5. Captured proteins were labeled with an IR-Dye (IRDye 800CW Streptavidin; LI-COR, NE, USA) and scanned using a LI-COR Odyssey Infrared Imaging System according to the manufacturer's instructions. The software ImageJ (Version 1.48s, Image J, MD, USA) was used to determine, after background subtraction, the integrated density of the spots on the array pictures. The antibodies for the following chemokines are spotted on the membrane: BLC, C5a, G-CSF, GM-CSF, I-309, Eotaxin, sICAM-1, IFN- $\gamma$, IL-1 $\alpha$, IL-1 $\beta$, IL-1ra, IL-2, IL-3, IL-4, IL-5, IL-6, IL-7, IL-10, IL-13, IL-12 p70, IL-16, IL-17 IL-23, IL-27, CXCL10 (IP-10), I-TAC, KC, M-CSF, CCL2 (MCP-1), CCL12 (MCP-5), MIG, CCL3 (MIP-1 $\alpha$ ), CCL4 (MIP-1ß), CXCL2 (MIP-2), CCL5 (RANTES), SDF-1, TARC, TIMP-1, TNF- $\alpha$, TREM-1.

\subsection{Quantification of Chemokine/protein Secretion Using ELISA}

To confirm the microarray data that indicated higher secretion levels of CCL2/MCP-1 and CCL4/MIP-1 $\beta$ on grooved surfaces compared to Pol surface, the secretion levels of 
CCL2/MCP-1, CCL4/MIP-1 $\beta$ and matrix metalloproteinese9 (MMP-9) were measured with sandwich ELISAs in accordance with the manufacturer's instructions (QuantikineTM; R\&D Systems, MN, USA). The optical density of each well was determined using a microplate reader (FLUOstar Optima; BMG Labtech, Ortenberg, Germany) set at $450 \mathrm{~nm}$ and corrected at $550 \mathrm{~nm}$. A standard curve for the determination of the amount of secreted chemokines/protein was obtained by a four parameter logistic curve-fit with the BMG microplate reader software MARS (Version 1.10). All samples were assayed in triplicate.

\subsection{Immunofluorescence (IF) and Analysis of Cell Fusion}

To characterize the distribution of vinculin and actin, samples were simultaneously fixed and permeabilized in $4 \%$ formaldehyde (Fisher Scientific, MA, USA) with $0.1 \%$ Triton X-100 (Fisher Scientific, MA, USA) prepared in PBS for $10 \mathrm{~min}$ at room temperature. Simultaneous permeabilization/fixation avoids the staining of cytosolic focal adhesion proteins (Dr. D.M. Cohen, personal communication). Blocking of non-specific binding was performed for $1 \mathrm{~h}$ at room temperature using 10\% goat serum (Sigma-Aldrich, MO, USA) in 1\% bovine serum albumin (BSA) (Sigma-Aldrich, MO, USA) prepared in PBS. Cells were incubated with primary rabbit anti-mouse vinculin (Santa Cruz Biotechnology Inc, TX, USA) (1:100 dilution) overnight at $4{ }^{\circ} \mathrm{C}$ and rinsed with PBS twice before incubated in Alexa Fluor 488 goat anti rabbit secondary antibody (Invitrogen, NY, USA) (1:200 dilution) for $1 \mathrm{~h}$ at room temperature. Cells were then stained for actin by applying phalloidin-TRITC labeled (Sigma-Aldrich, MO, USA) (1:500 dilution) for $40 \mathrm{~min}$ at room temperature. All samples were counter-stained with DAPI prepared at $5 \mu \mathrm{g} / \mathrm{mL}$ (Sigma-Aldrich, MO, USA) for $30 \mathrm{~min}$ at room temperature to demonstrate cell nuclei. Samples were washed with PBS five times for 2 min each before mounted on a slide in 
Fluoromount ${ }^{\circledR}$ (SouthernBiotech, AL, USA).

Multinucleated Cell (2 6 nuclei) formation was analyzed using confocal images observed with Nikon Confocal Microscope C1 and EZ-C1 3.50 software version 1.0. Images were captured with a RETIGA 2000R camera (Q Imaging, BC, Canada). Pictures of randomly selected fields (left, right, top, bottom, and centre of the sample surface) were captured under identical parameter settings (60x magnification with 3x digital zoom).

\subsection{Gelatin Zymography}

To determine whether MMP-9 secreted from cells cultured on Pol, G1 and G2 was active, RAW264.7 cells were seeded on Pol, G1 and G2 surfaces and cultured in complete cell culture media containing $10 \%$ BGS for $24 \mathrm{~h}$. After cells were attached to the sample substrata, the cells were rinsed in DMEM (STEMCELL Technologies, BC, Canada) without any added serum three times for 2 min each to harvest MMP-9 secreted by cells cultured on sample substrata. Then cells were cultured in fresh DMEM media for specific time points Day 2, 3 and 5. The medium was exchanged $24 \mathrm{~h}$ before the harvesting of the supernatants to ensure the collection of MMP-9 secreted between Day 1-2, Day 2-3 and Day 4-5. The supernatants were concentrated by a factor of 30 by using ultracentrifugal filter devices with a 30kDa cut off size (Amicon Ultra- $0.530 \mathrm{~K}$; Millipore, MA, USA). Equal volumes of sample supernatants were separated on $10 \%$ SDSPAGE gel containing $1 \mathrm{mg} / \mathrm{mL}$ gelatin (Bio-Rad Laboratories, CA, USA) under non-reducing conditions at $4{ }^{\circ} \mathrm{C}$. After gel-electrophoresis, gels were washed in 1x Renaturing buffer $(2.5 \%$ Triton X-100 prepared in deionized water) three times 20 min each at room temperature. Then gels were washed three times 10 min each with 1x Digestion buffer (10mM Tris, $40 \mathrm{mM}$ Tis$\mathrm{HCl}, 0.2 \mathrm{M} \mathrm{NaCl}, 7 \mathrm{mM} \mathrm{CaCl}_{2}$, and $10 \%$ BriJ35) before gelatinolytic reactions were induced by 
incubating the gel in 1x Digestion buffer for overnight at $37{ }^{\circ} \mathrm{C}$. Gels were stained with EZBlue $^{\mathrm{TM}}$ Gel Staining Reagent (Sigma-Aldrich, MO, USA) and destained according to the manufacturer's instructions.

\subsection{Statistical Analysis}

Data from at least two separate experiments are represented as the mean and $95 \%$ confidence interval or standard deviation. The antibody array was repeated with two independent sample sets from different cultures. Tests for statistical significance of the data were performed using SPSS (Version 19, IBM Corp, NY, USA). Statistical comparison of the cell morphology and the effect of surface topography on multinucleated cell formation were done using one-way analysis of variance (ANOVA) followed by post hoc Tukey's test. For ELISA studies, multiple sample analysis was carried out using Kruskal-Wallis $\mathrm{H}$ test to determine if there were statistically significant differences in the non-normally distributed secretion levels of CCL2/MCP-1, CCL4/MIP-1 $\beta$ and MMP-9 among the cells cultured on Pol, G1 and G2. Differences were considered statistically significant for $\mathrm{p}<0.05$. 


\section{Chapter 4: Results}

\subsection{Effect of Surface Topography on Cell Morphology}

Macrophages cultured on G1 and G2 exhibited elongated morphology similar to IL-4 (an activator of the M2 phenotype)—stimulated macrophage cells (Figure 4-1). In contrast, cells cultured on Pol surface tended to be round. RAW264.7 macrophages demonstrated a statistically significant increase in elongation, compared to the Pol control, for both G1 and G2 surfaces (Figure 4-2). 

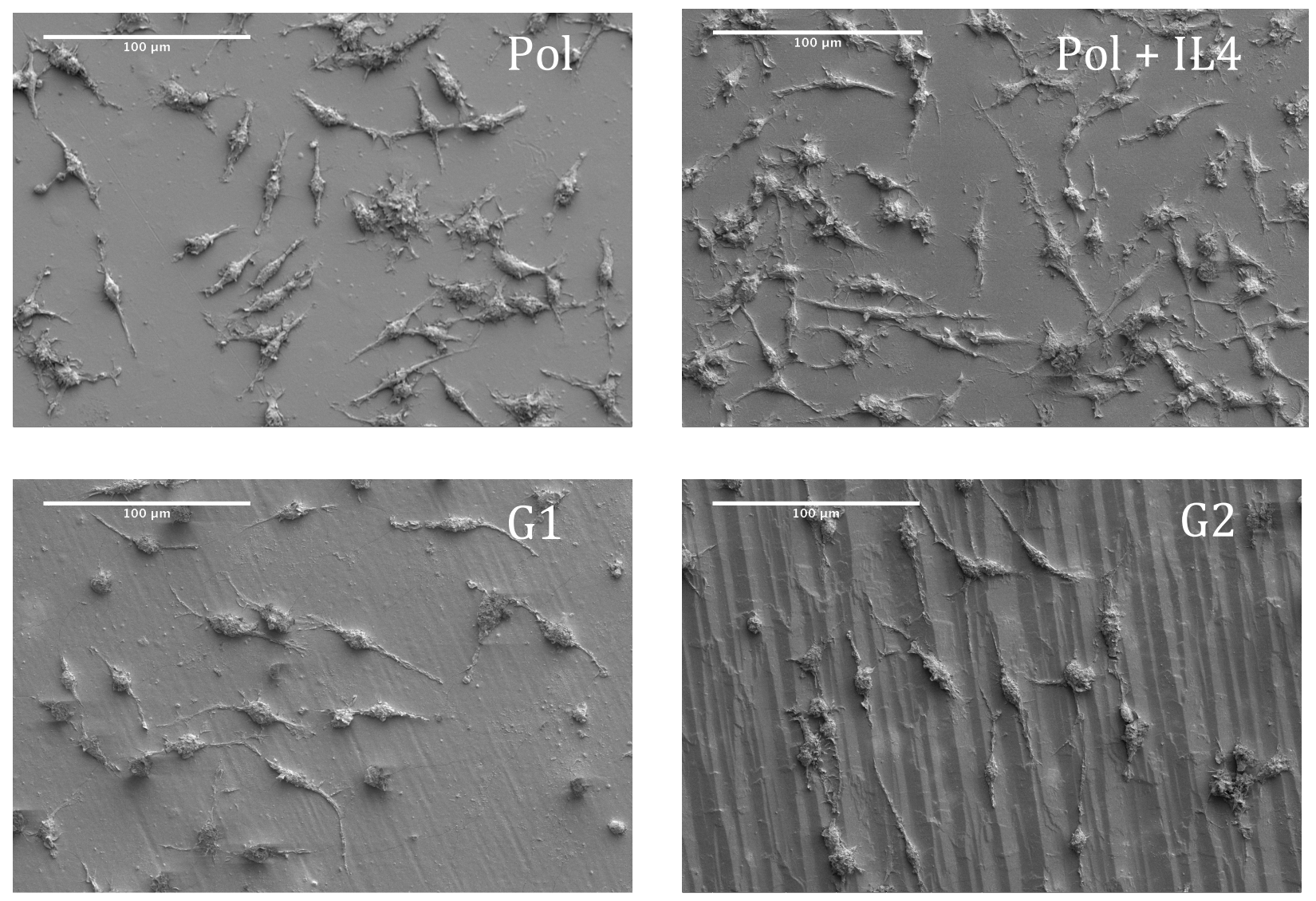

\section{Figure 4-1 Topographic Effects on Macrophage Morphology}

RAW 264.7 cells were cultured for $24 \mathrm{~h}$ on Pol, Pol+IL-4, $(40 \mathrm{ng} / \mathrm{mL})$ (to activate macrophage cells into the M2 phenotype), G1, and G2 grooved surfaces. Cells on the grooved surfaces and the IL-4 treated cells were elongated. 


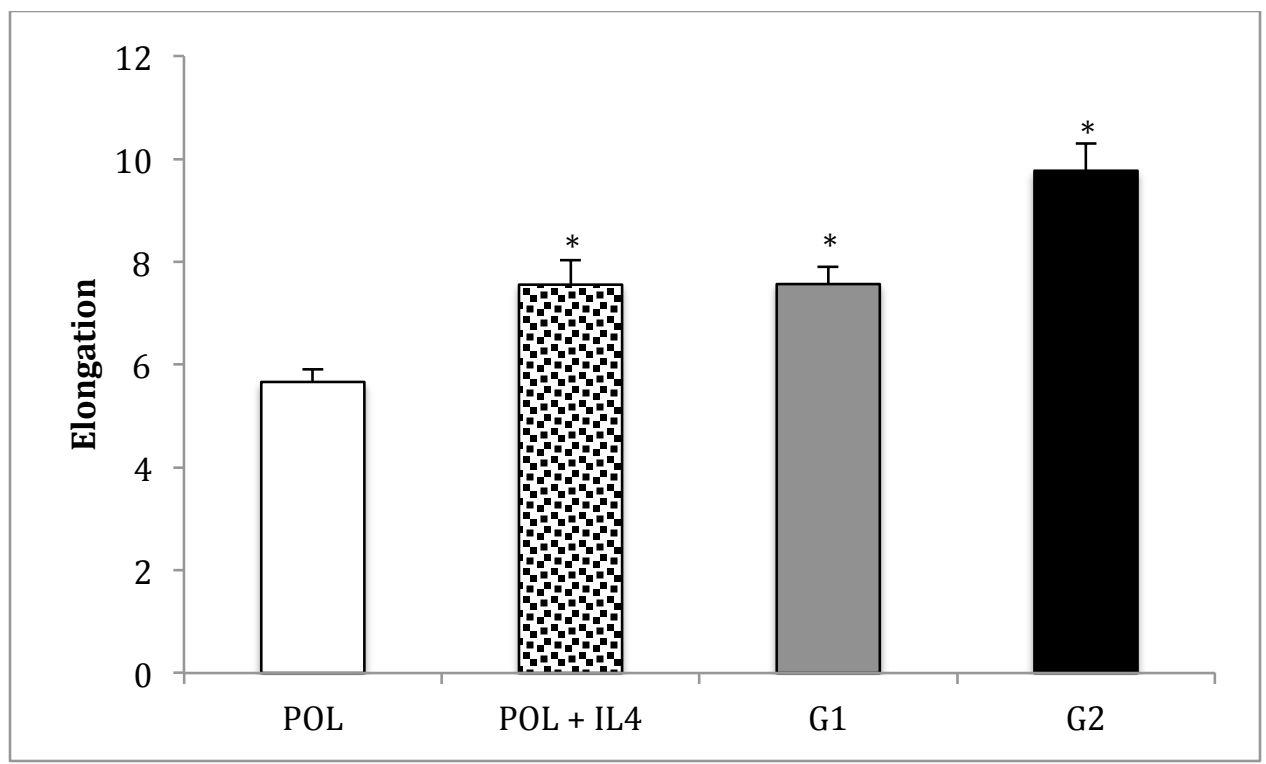

Figure 4-2 Elongation of RAW 264.7 by Grooved Substrata

Elongation is defined by the length of the long axis divided by the length of the short axis at the widest part of the cell. Pol was used as a control and Pol + IL4 was used as a M2 phenotype control. One hundred and fifty-four cells were analyzed per each surface. Data represent mean $\pm 95 \%$ CI (confidence interval). Statistically significant differences relative to Pol control was determined by one-way ANOVA ( $\mathrm{p}=0.05)$ followed by Tukey's test. * indicates $\mathrm{p}<0.05$. 


\subsection{Effect of Grooved Surfaces on Macrophage Alignment}

Cell orientation increased with increase in surface directionality, roughness, and duration of cell culture time. This is demonstrated by the decrease in mean orientation angle of the cells cultured on grooved surfaces G1 and G2 at time point Day 3 and Day 5 (Table 4-1). 


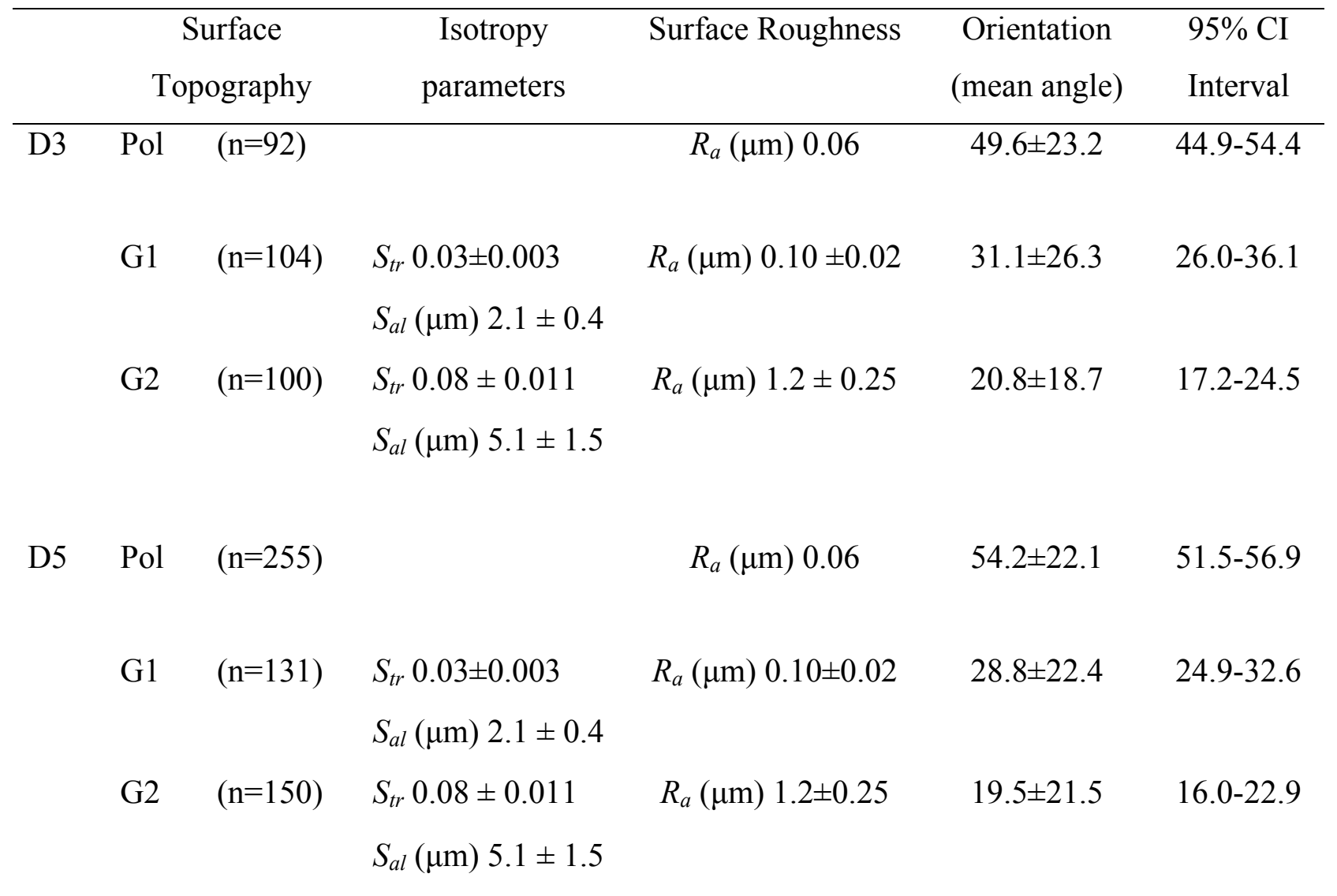

Table 4-1 Effect of G1 and G2 Grooved Surface Topographies on RAW 264.7 Macrophage Cell Alignment on Day 3 and Day 5

Surface Topographies: Pol represents polished surfaces. G1 and G2 represent grooved surfaces prepared by anisotropic etching of $\mathrm{Si}<110>$ crystals; all were replicated in epoxy. Cell alignment analysis was done by measuring the cell angle to the orientation of the topography. $0^{\circ}$ represents perfect alignment. Expected value of orientation angle in the absence of orientating features is $45^{\circ}$. 


\subsection{Gene Expression for Day 1 and Day 5}

The influence of surface topography on gene expression had been previously studied in our laboratory using whole genome microarray that identified a number of macrophage attractant

chemokines candidates whose expression was altered by culture on rough topography ${ }^{136}$. The gene expression levels of macrophage attractant chemokines CCL2/MCP-1, CCL3/MIP-1 $\alpha$, CCL4/MIP-1 $\beta$, CCL5/RANTES, CCL7/MCP-3 ${ }^{145,146}$ were measured using RT-qPCR at Day 1 and Day 5. A significant increase in gene expression of RAW264.7 on G1 vs. Pol surface was detected on Day 1 for CCL2/MCP-1, CCL3/MIP-1 $\alpha$, CCL4/MIP-1 $\beta$ whereas on Day 5, CCL2/MCP-1, CCL4/MIP-1 $\beta$, CCL5/RANTES, and CCL7/MCP-3, but not CCL3/MIP-1 $\alpha$, increased significantly. For G2 surface, all the analyzed genes, except CCL5, were increased significantly relative to the Pol surface on Day 1 and Day 5. Hence, for both G1 and G2 surfaces, time dependent changes in gene expression were observed (Figure 4-3 and 4-4). 


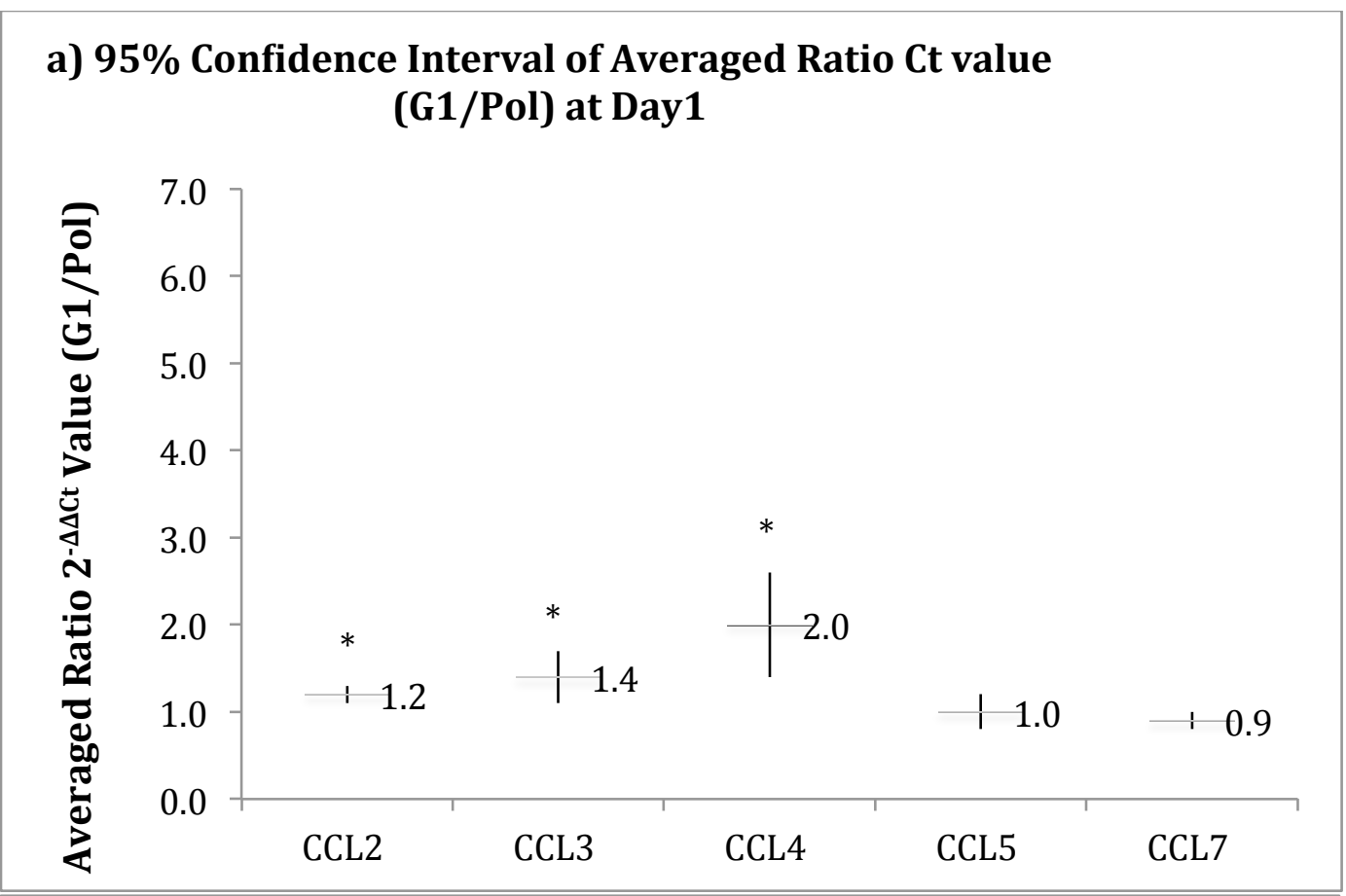

b) $95 \%$ Confidence Interval of Averaged Ratio Ct value (G1/Pol) at Day5

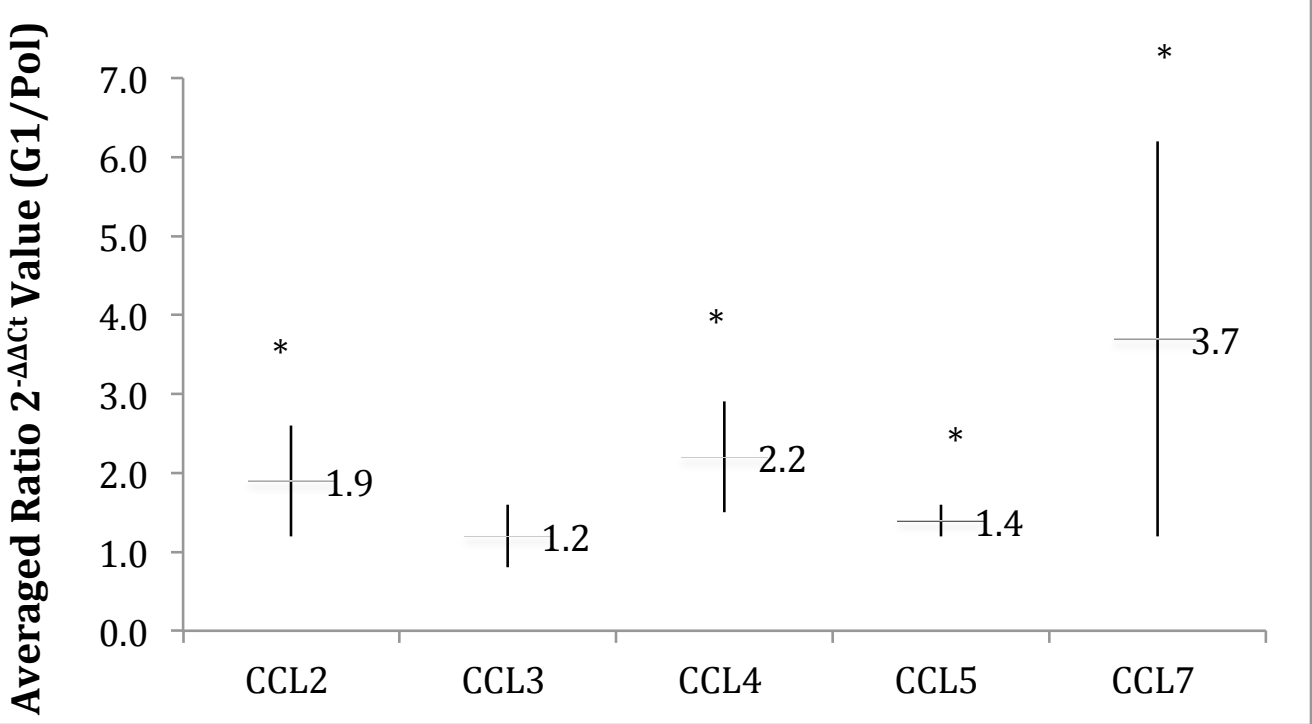

Figure 4-3 95\% Confidence Interval of Averaged Ratio Ct value (G1/Pol) for Day 1 and Day 5 Average ratio $\mathrm{Ct}$ values (G1/Pol) and 95\% CI calculations of the genes expressed by RAW264.7 cells cultured on G1 for Day 1 (a) and Day 5 (b). Values show averaged ratio Ct (G1/Pol) $\pm 95 \%$ CI (confidence interval), * indicates $95 \%$ CI that did not include the value of one. 


\section{a) $\mathbf{9 5 \%}$ Confidence Interval of Averaged Ratio Ct value (G2/Pol) at Day1}

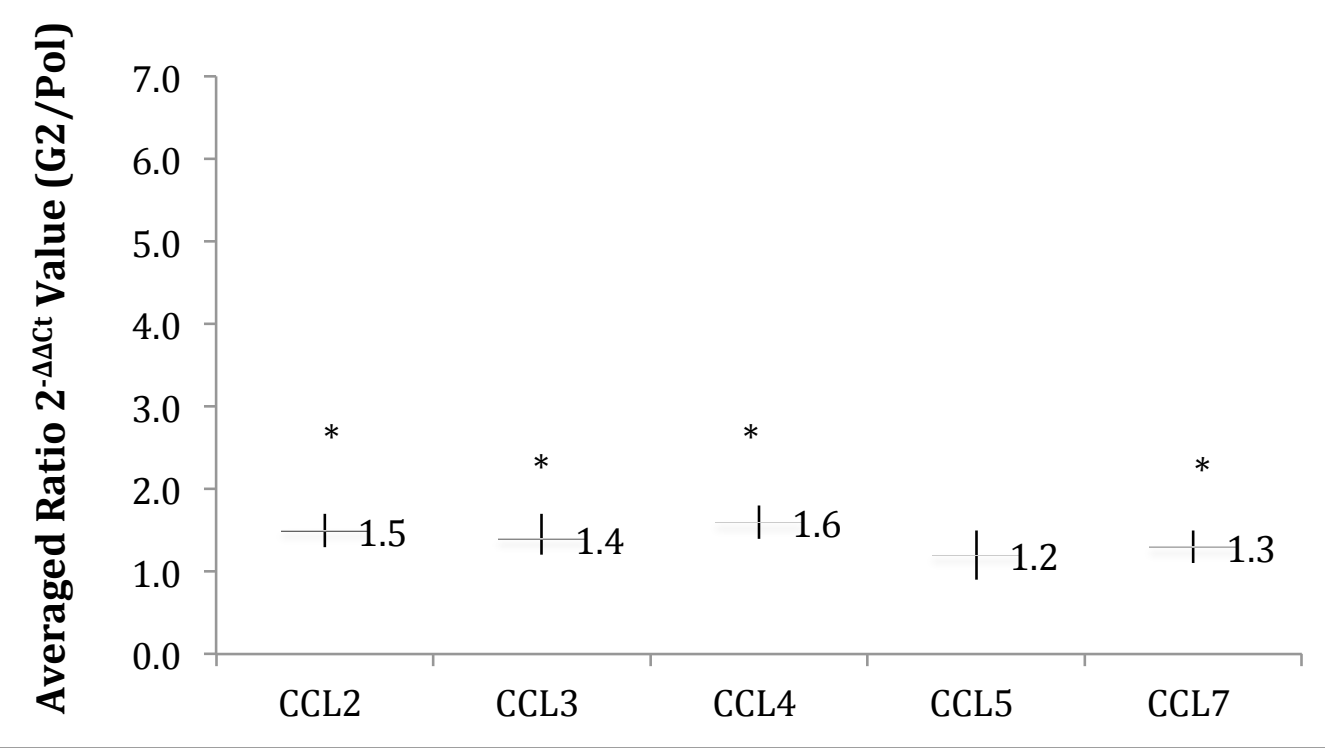

\section{b) $95 \%$ Confidence Interval of Averaged Ratio Ct value (G2/Pol) at Day5}

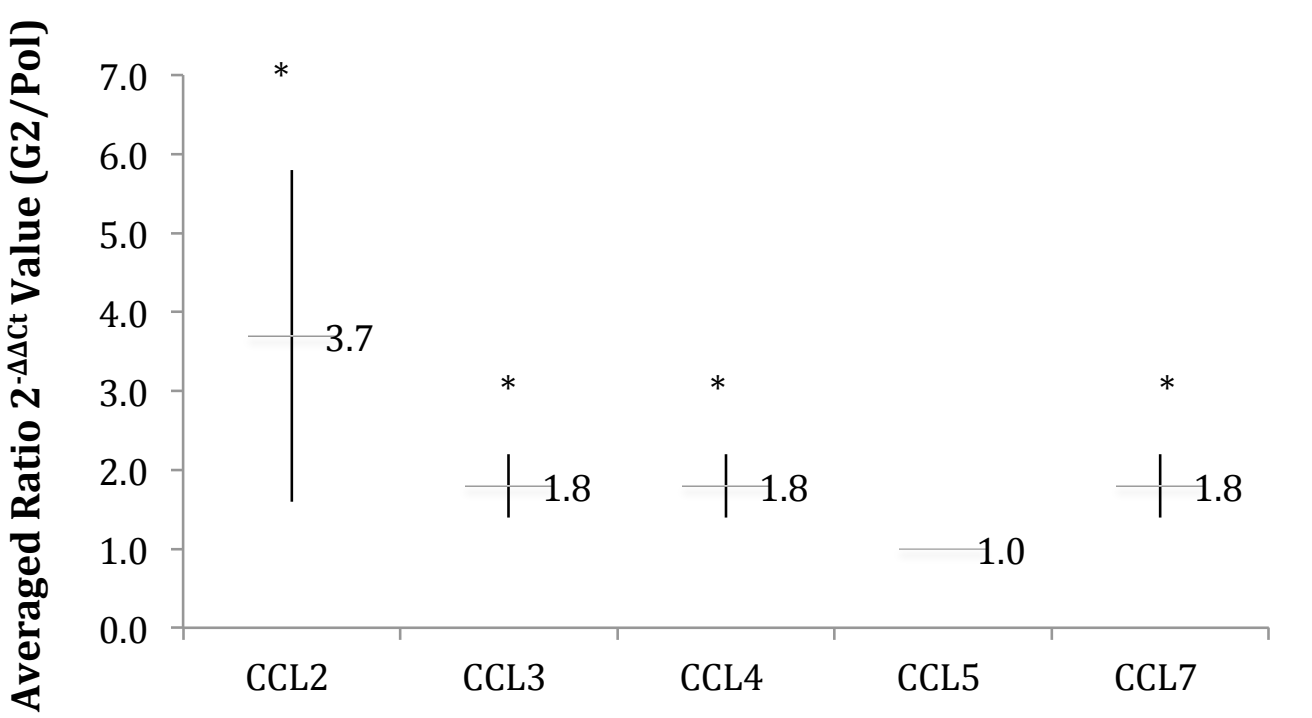

Figure 4-4 95\% Confidence Interval of Averaged Ratio Ct value (G2/Pol) for Day 1 and Day 5 Average ratio Ct values (G2/Pol) and 95\% CI calculations of the genes expressed by RAW264.7 cells cultured on G2 for Day 1 (a) and Day 5 (b). Values show averaged ratio Ct (G2/Pol) $\pm 95 \%$ CI (confidence interval), * indicates $95 \%$ CI that did not include the value of one. 


\subsection{Cytokine/Chemokine Secretion for Day 1 and Day 5}

Cytokine and chemokine secretion profiles of RAW 264.7 cells cultured on Pol, G1 and G2 were measured using antibody microarray involving 40 cytokine and chemokines for the cell culture supernatants harvested on Day 1 and Day 5. Cell medium containing 10\% heat-inactivated serum was incubated with the antibody-bound membrane from the array kit and showed no significant signal over background. Day 1 secretion profiles of RAW264.7 cultured on Pol, G1, and G2 surfaces showed higher secretion of CCL3/MIP-1 $\alpha$ and CCL4/MIP-1 $\beta$ on both G1 and G2 surfaces relative to the Pol surface. On Day 5, CCL2/MCP-1 and CCL4/MIP-1 $\beta$ secretion level increased on G2. In addition, on Day 1, a lower secretion level of the anti-inflammatory cytokine IL-1ra was observed on the G1 surface, but on Day 5, IL-1 ra secretion level was increased on the G1 surface. In contrast, pro-inflammatory chemokine IP-10/CXCL10 level increased on Pol surface on Day 5 compared to the G1 surface (Figure 4-5, 4-6, 4-7 and 4-8). 


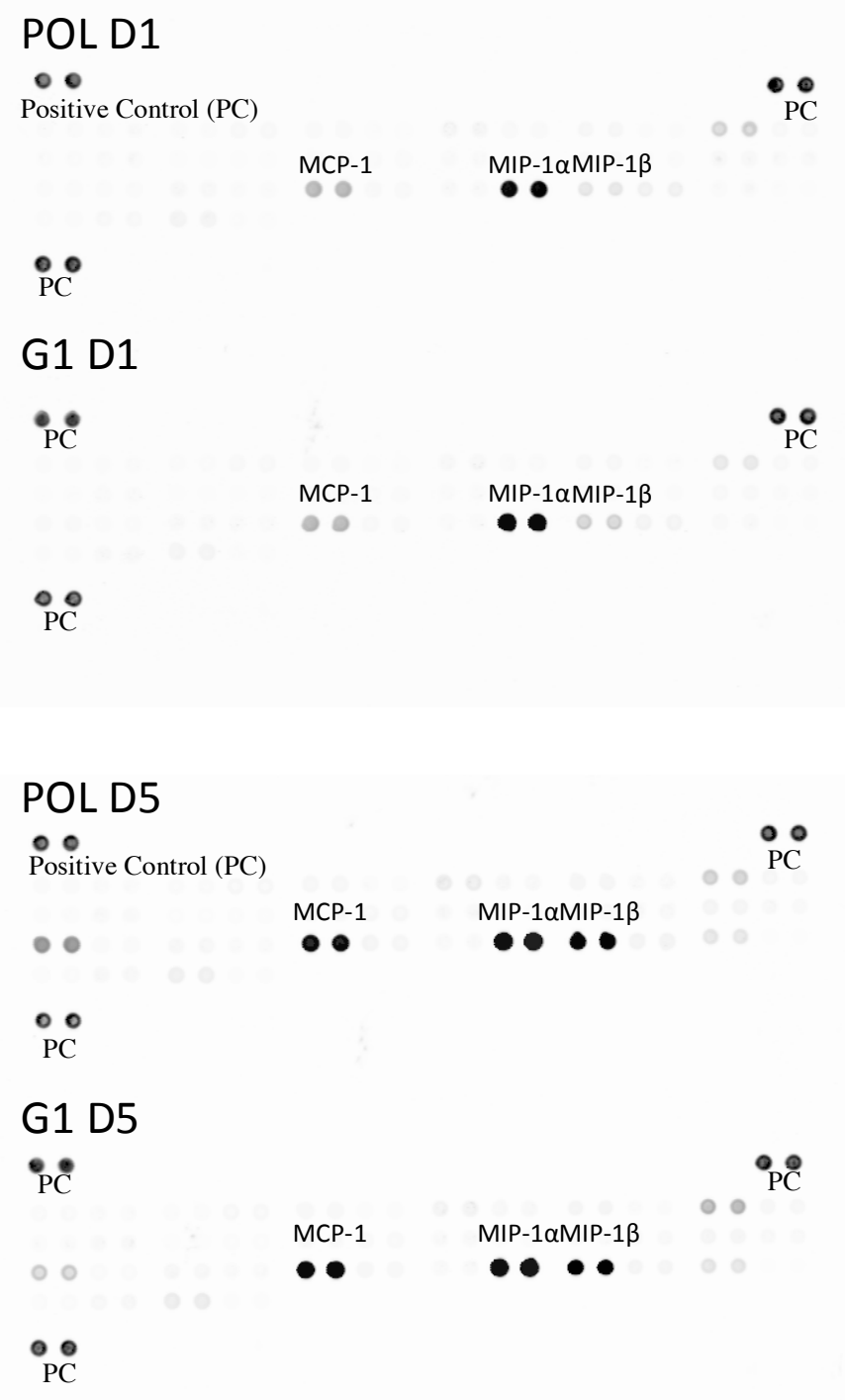

Figure 4-5 Cytokine and Chemokine Secretion Profile of RAW264.7 Macrophages Cultured on G1 for Day 1 and Day 5

Cytokine and chemokine secretion profile detected by antibody array of RAW264.7 macrophages cultured on Pol and G1 surfaces for Day 1 and Day 5. The amount of cell culture medium used for the microarray assay was normalized to the number of cells present on the surfaces. Three sets of duplicate dots in the corners of each membrane (labeled PC) are kit positive controls. The assay was repeated with two independent sample sets from different cultures showing similar results. (Pol represents polished substrata, G1 presents grooved substrata, D1 = Day 1, D5 = Day 5) 


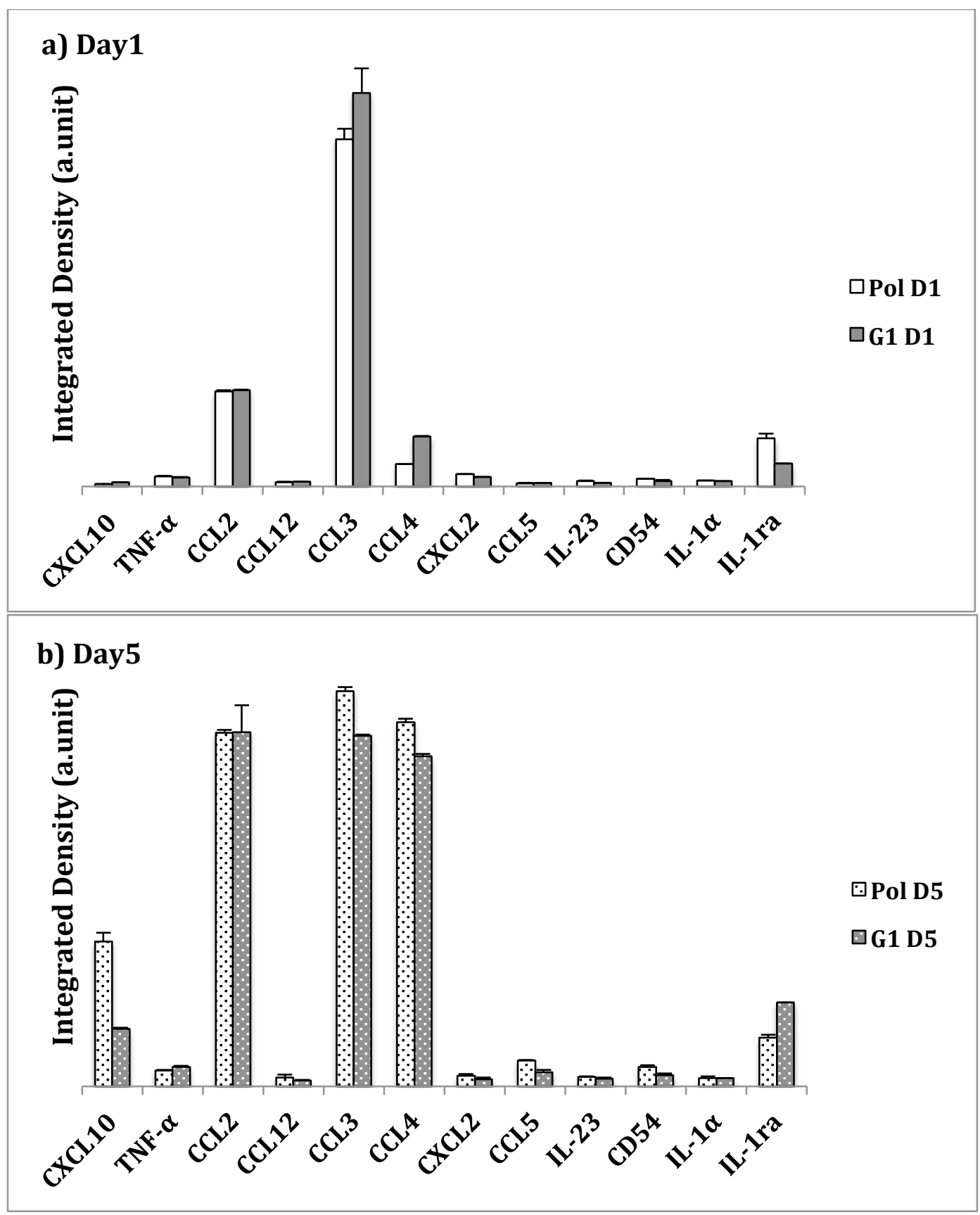

Figure 4-6 Analysis of the Cyto/Chemokine Secretion Profile of RAW264.7 Macrophages Cultured on G1 for Day 1 and Day 5

Integrated densities of the cyto-/chemokine secretion profile from the antibody microarray of media from RAW264.7 macrophages cultured on Pol and G1 surfaces on Day 1 (a) and Day 5 (b). Data represents mean \pm standard deviation of the integrated densities of the duplicate spots on the respective arrays. 


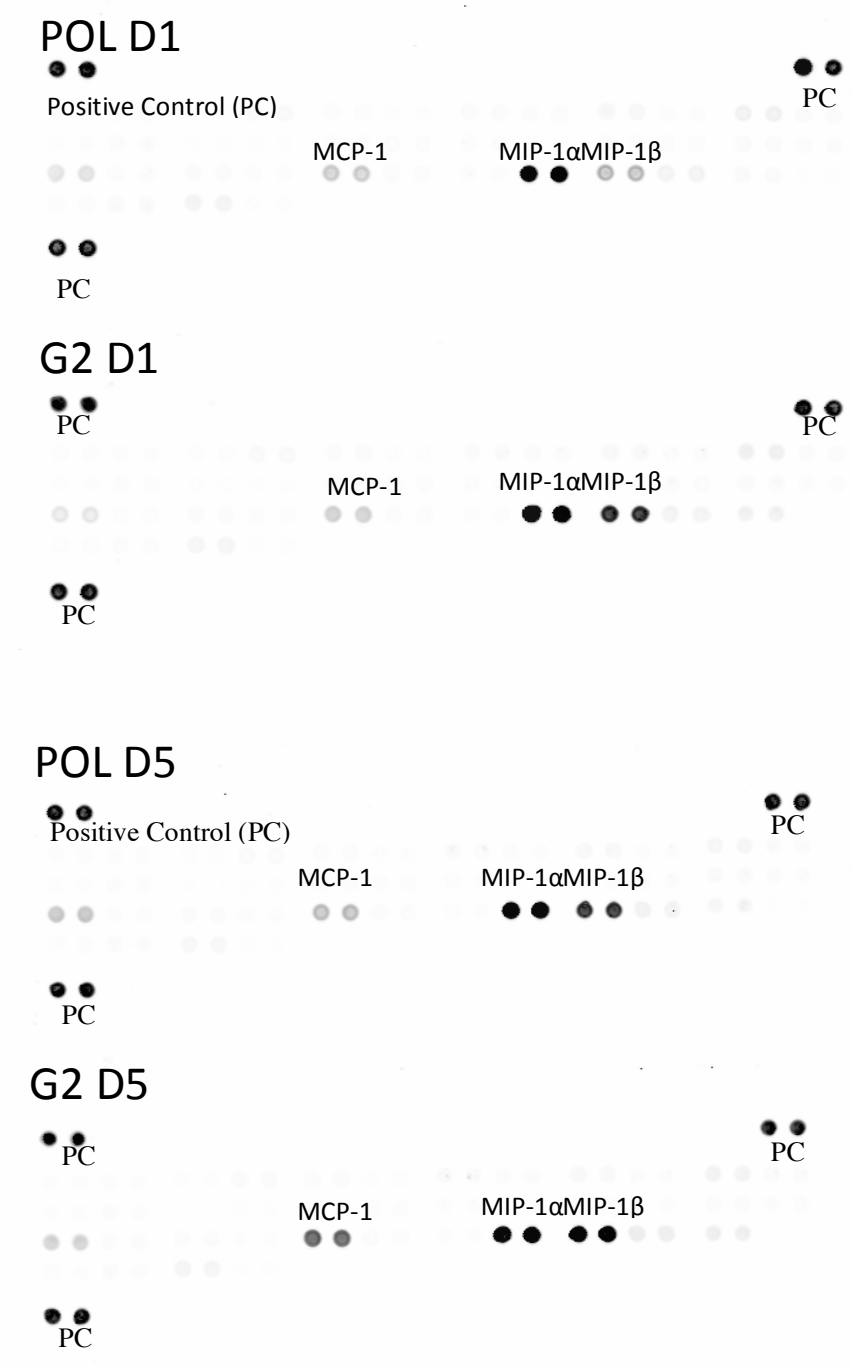

Figure 4-7 Cytokine and Chemokine Secretion Profile of RAW264.7 Macrophages Cultured on G2 for Day 1 and Day 5

Cytokine and chemokine secretion profile detected by antibody array of RAW264.7 macrophages cultured on Pol and G2 surfaces for Day 1 and Day 5. The amount of cell culture medium used for the microarray assay was normalized to the number of cells present on the surfaces. Three sets of duplicate dots in the corners of each membrane (labeled PC) are kit positive controls. The assay was repeated with two independent sample sets from different cultures showing similar results. (Pol represents polished substrata, G2 presents grooved substrata, D1 = Day 1, D5 = Day 5) 


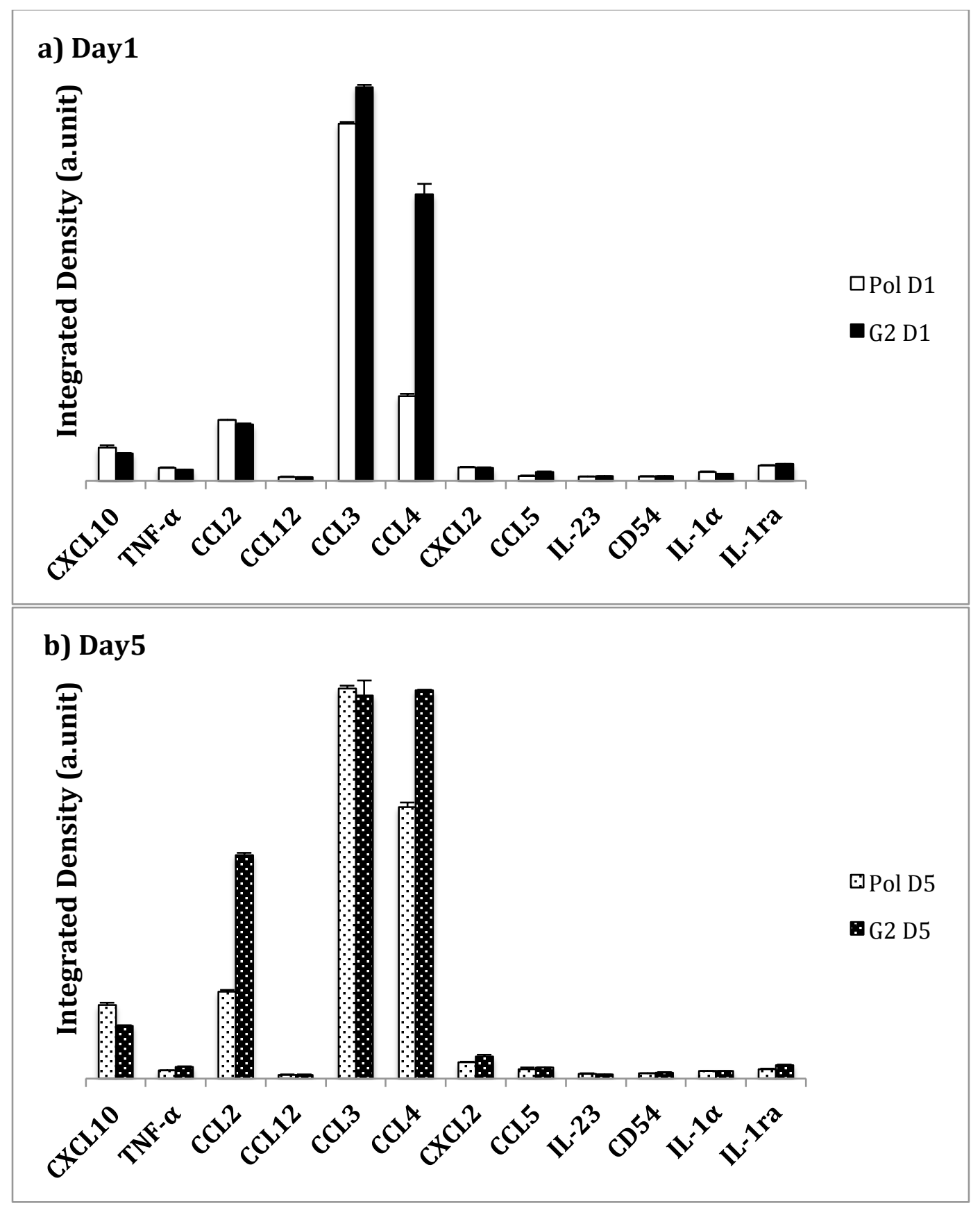

Figure 4-8 Analysis of the Cyto/Chemokine Secretion Profile of RAW264.7 Macrophages Cultured on G2 for Day 1 and Day 5

Integrated densities of the cyto-/chemokine secretion profile from the antibody microarray of media from RAW264.7 macrophages cultured on Pol and G2 surfaces on Day 1 (a) and Day 5 (b). Data represents mean \pm standard deviation of the integrated densities of the duplicate spots on the respective arrays. 


\subsection{ELISA Analysis CCL2 (MCP-1) and CCL4 (MIP-1ß)}

The expression of CCL2/MCP-1 and CCL4/MIP-1 $\beta$ was quantitatively analyzed by sandwich ELISA to confrim the microarray data.. For all the ELISA assays, cell culture medium containng $10 \%$ heat inactivated serum did not produce a signal above the minimum detection level of $\sim 2$ $\mathrm{pg} / \mathrm{mL}$. The averaged ELISA results for both monocyte-attractants CCL2 and CCL4 showed significant increase in the secretion level with respect to time for all 3 surfaces. Only CCL4 exhibited significantly different secretion level among sufaces P, G1 and G2 at Day 1 and Day 5 (Kruskal-Wallis H test, $\mathrm{p}<0.05$ ) (Figure 4-9). 


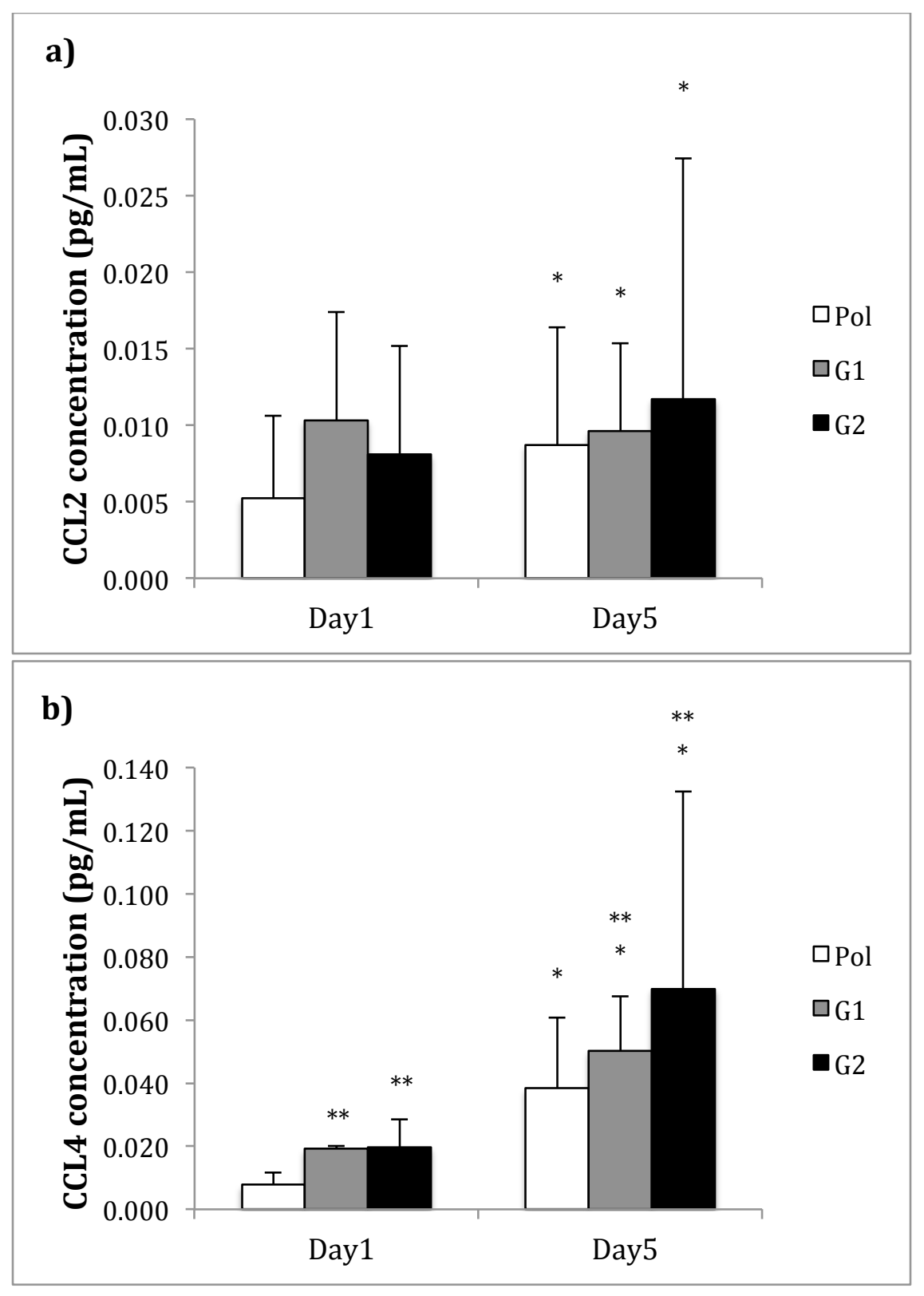

Figure 4-9 CCL2 and CCL4 Secretion as Analyzed by ELISA

ELI SA analysis of averaged CCL2/MCP-1 (a) and CCL4/MIP-1ß (b) secretion per cell by RAW 264.7

macrophages cultured on Pol, G1 and G2 surfaces on Day 1 and Day 5. Values show mean $\pm 95 \%$ CI (confidence interval). Results were averaged for 3 experiments. Kruskal-Wallis $\mathrm{H}$ test was used to determine the statistically significant differences between the studied time points on one surface type $(*$ indicates $p<0.05$ comparisons between Day1 and Day 5) and statistically significant differences relative to Pol control (** indicates $p<0.05$ comparisons between the surfaces within the same day) 


\subsection{ELISA Analysis MMP-9}

As the analysis of CCL2 expression at gene and protein level indicated an influence of topography on CCL2 expression level in time dependent manner, it was of interest to examine the effect of surface topography on the secretion level of another soluble mediator involved in macrophage cell fusion-matrix metalloproteinase (MMP)-9 ${ }^{112}$. MMP-9 was detected uisng sandwich ELISA by analying cell supernatants on Day 1 and Day 5. Similar to CCL2, MMP-9 did not exhibit significant differences in secretion level among the surfaces. However, the secretion level of MMP-9 showed significant difference with respect to time on G2 surface (Figure 4-10). 


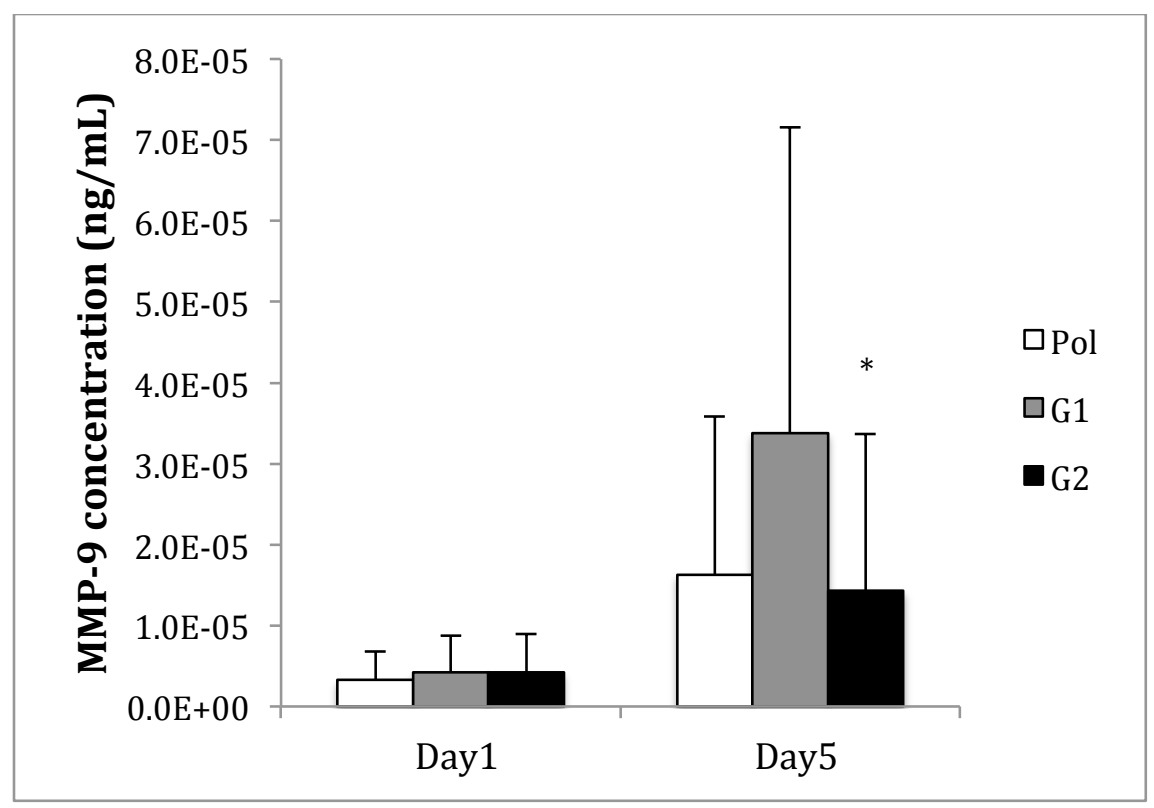

Figure 4-10 MMP-9 Secretion as Analyzed by ELISA

ELISA analysis of averaged MMP-9 secretion per cell by RAW 264.7 macrophages cultured on Pol, G1 and G2 surfaces on Day 1 and Day 5. Values show mean $\pm 95 \%$ CI (confidence interval). Results were averaged from 3 experiments. For the effect of time on the secretion level, Kruskal-Wallis $\mathrm{H}$ test was used to determine the statistically significant differences between the studied time points on one surface type. * indicates $p<0.05$ 


\subsection{MMP-9 Expression and Activation Monitored by Zymography}

The results from the MMP-9 ELISA assay were supported by gelatin zymography that detected MMP-9 expression and activity at Day 2, Day 3 and Day 5 (Figure 4-11). Similar to MMP-9 ELISA assay, the band pattern of the zymograpy also showed time dependent expression of MMP-9. The strongest MMP-9 activity was detected at Day 5 with media from RAW 264.7 macrophages cultured on G1 and G2 surfaces compared to Day 2 and Day 3 samples. Digestion of the gel was found at a higher molecular weight $(\sim 125 \mathrm{kDa})$ than the usual pro-form of MMP-9 (92 kDa) indicating formation of a MMP-9 and neutrophil gelatinase-associated lipocalin (NGAL) complex ${ }^{147}$. 


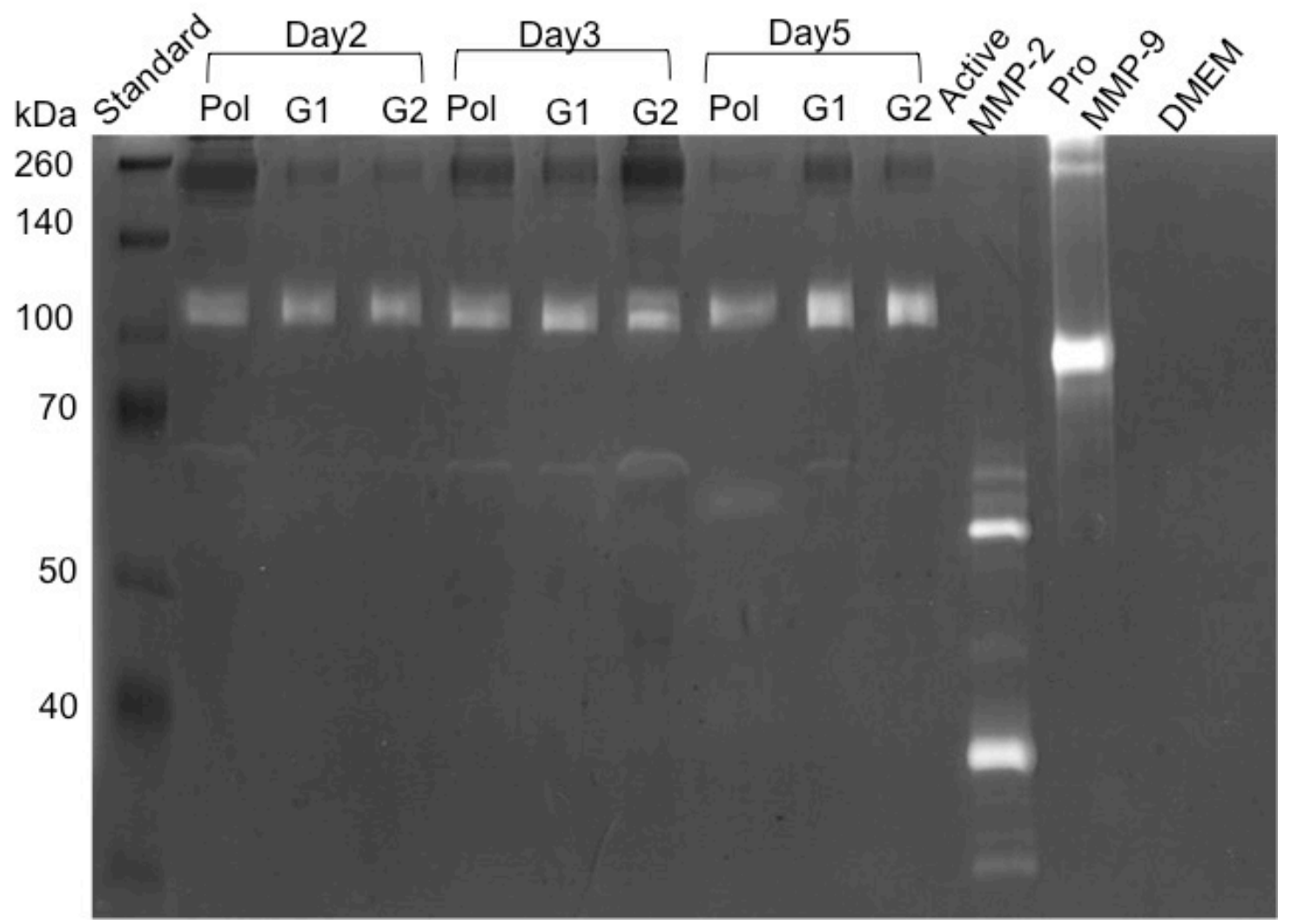

Figure 4-11 MMP-9 Activity as Demonstrated by Gelatin Zymography

Zymography gel showing gelatinase activity (visualized as lighter bands against the non-degraded darker gelatin backgrounds) of the cell culture media harvested from the macrophages cultured on Pol, G1 and G2 surfaces for two, three and five days. The harvested cell culture media were analyzed on $10 \%$ SDS-PAGE gel containing 1mg/mL gelatin. Active MMP-2 (68kDa) and proMMP-9 (92kDa) were loaded as a comparison. DMEM media, without any added serum, used to harvest zymography samples did not show any observable gelatinase activity as shown in the last lane. 


\subsection{Quantification of Cell Fusion}

As MMP-9 and CCL2 production by RAW 264.7 cells increased on the grooved surfaces with time, it was of interest to determine if cell fusion was enhanced on these surfaces. For the quantification of cell fusion, confocal images of cells cultured on Pol, G1 and G2 for Day 1 and Day 5 were used. As nuclei at different levels can overlap in projected images, three dimensional computational reconstruction of the cells cultued on the Pol, G1 and G2 surfaces was used to identify and count the number of nuclei per cell. Analysis of multinucleated cells stained for actin and vinculin and counter-stained with DAPI to demonstrate cell nuclei showed significant increase $(\mathrm{p}<0.05)$ in number of multinucleated cells on rough surface topographies G1 and G2 relative to Pol surface on Day 5 (Figure 4-12 and 4-13). Also, increase in cell height was observed from the reconstructed three-dimensional images of multinucelated cells formed on the G1and G2 surfaces (Figure 4-12). 


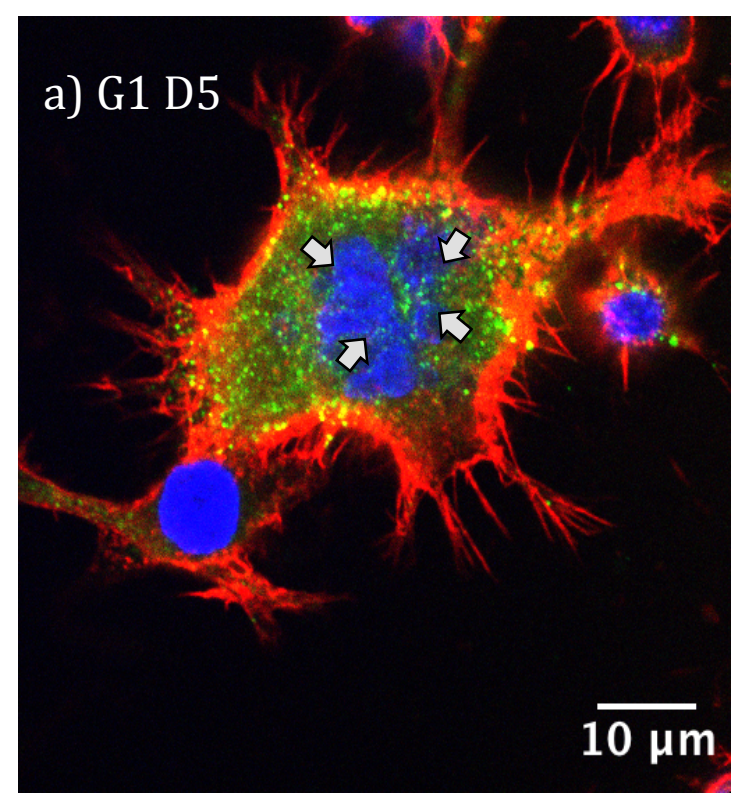

c) G1 D5
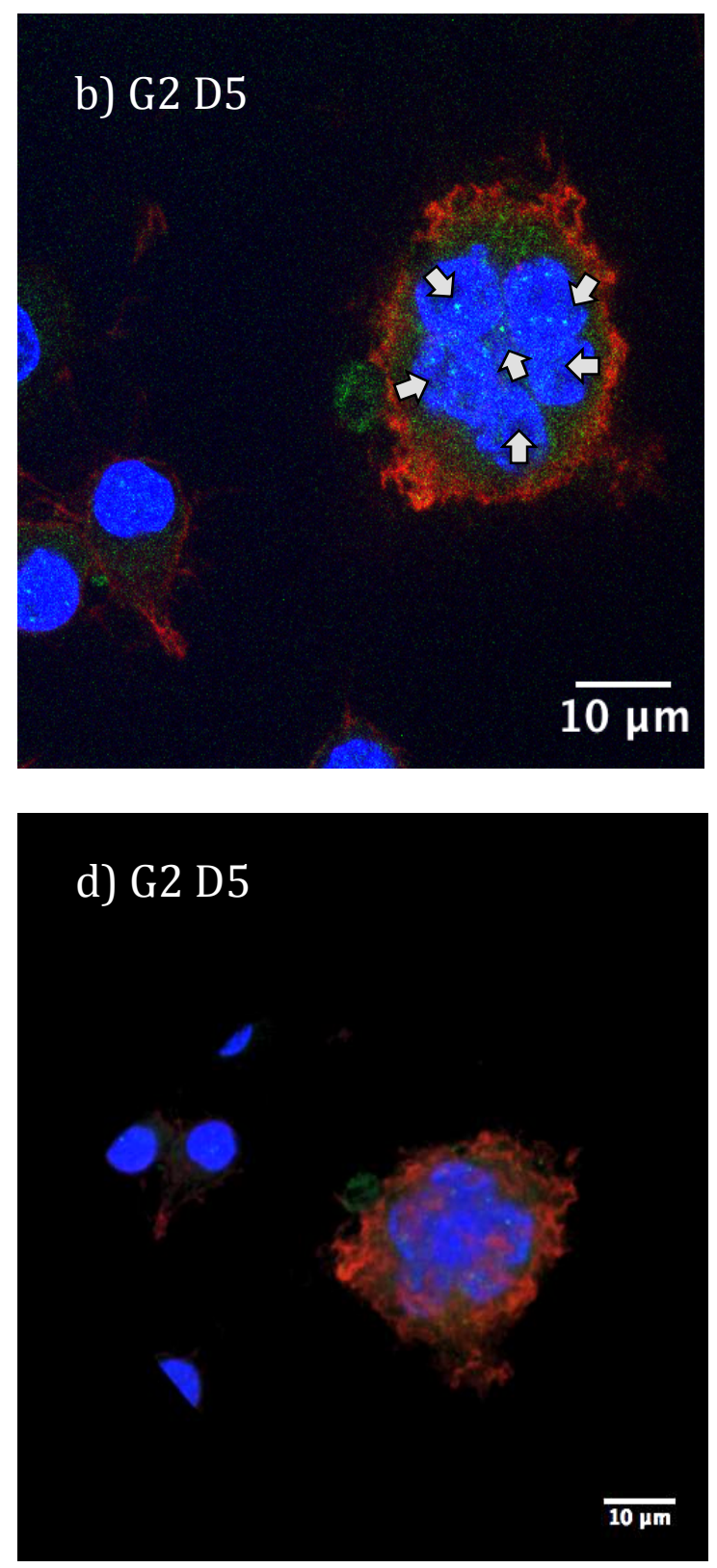

Figure 4-12 Immunofluorescent Images of RAW264.7 Macrophages Cultured on G1 and G2 on Day 5

Representative fluorescence images of topographical effects on multinucleated cell (MC) formation in RAW264.7 macrophages cultured on G1 (a) and G2 (b) on Day 5. Cells were stained for vinculin (green), F-actin (red) and counter-stained with DAPI to demonstrate cell nuclei. Arrow indicates nuclei in multinucleated cells. Threedimensional images of macrophages cultured on G1 (c) and G2 (d) on Day5 were reconstructed from the multiple fluorescent z-stack images 


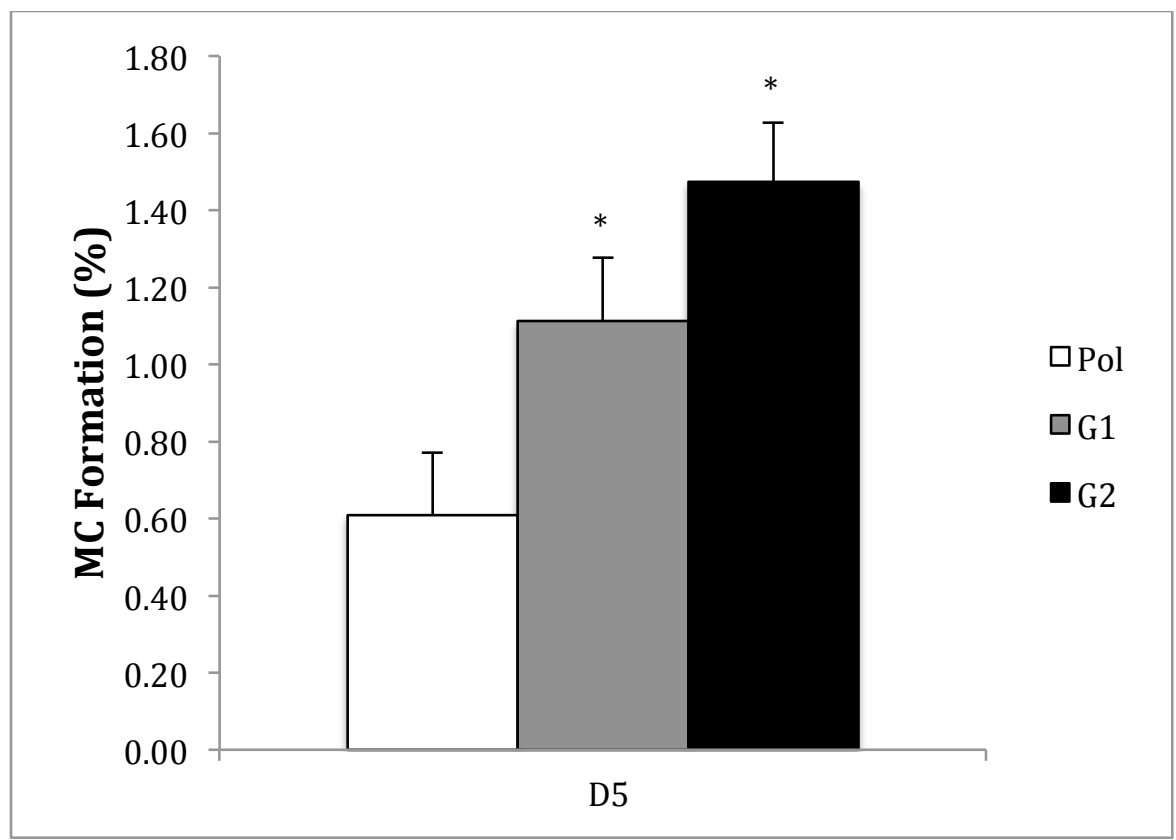

Figure 4-13 Cell Fusion on G1, G2, and Pol-as Analyzed by Number of Nucleus of Multinucleated Cells Analysis of multinucleated cell formation of RAW264.7 macrophages cultured on G1 and G2 on Day 5 was done using confocal images. Results are the mean \pm standard deviation. Statistically significant differences relative to Pol control was determined by one-way ANOVA $(\mathrm{p}=0.05)$ followed by Tukey's test. * indicates $p<0.05$.The experiment was repeated with two independent sample sets from different cultures and showed similar results. 


\section{Chapter 5: Discussion}

In contrast to common microfabrication methods used to produce micro-scaled features that require photolithographic patterning and etching, this study utilized the anisotropic etching process alone to produce micron scale $(\sim 0.1-1.0 \mu \mathrm{m})$ grooves, designated as G1 and G2, with varying surface directionality and roughness.

\subsection{Alignment of Macrophages on the Grooved Surfaces}

Anisotropic topographical surface features have been shown to induce cell alignment and migration along the direction of the anisotropic features, a phenomenon called contact guidance, for many cell types. Similar shallow micron scale grooves (called minor grooves), fabricated by etching of $\mathrm{Si}<110>$ crystals, were observed by Brunette $(1986)^{26}$ in the bottom of large grooves (called major grooves) produced using photolithographic processes. Minor grooves were able to orient fibroblast in the absence of any other orienting influence. But when the fibroblasts were exposed to both major and minor grooves, fibroblasts aligned with the major (larger) grooves and largely ignored the minor (smaller) grooves demonstrating an example of hierarchy of cell guidance cues.

Little is known about the mechanisms underlying contact guidance but micro-scaled grooved surface topographies have been shown to affect localization of focal adhesions and actin microfilaments for macrophages ${ }^{4}$ and fibroblasts ${ }^{69}$ as well as alignment of microtubules and microfilaments in fibroblasts ${ }^{148,149}$. In this study, increased macrophage orientation was observed with increased surface directionality, roughness and cell culture time compared to the 
Pol. This alignment induced by anisotropic topographic features of G1 and G2 was expected based on previous studies, which demonstrated wide range of grooved topography-mediated cellular orientation and migration of fibroblast and epithelial cells ${ }^{56,69,150}$ as well as macrophages ${ }^{4,151}$. Cellular behaviors other than contact guidance can also produce alignment. Elsdale and Bard (1972) ${ }^{152}$ observed that parallel arrays of cells often found in dense fibroblast cultures could form as a result of contact inhibition of movement and that this process could explain the small but significant alignment of macrophages observed at Day 5 in highly dense cell cultures formed on the isotropic Pol surface.

\subsection{Macrophage Phenotype and Shape on Grooved Surfaces}

Traditionally, macrophages were known as a driving force of chronic inflammation; however, over the past two decades, their role in immune regulation and wound healing has been recognized ${ }^{153}$. Macrophages are now considered as plastic cells capable of exhibiting a continuum of functional phenotypes between classically activated M1 phenotype involved in inflammation and alternatively activated M2 phenotype involved in wound healing and immunoregulation ${ }^{44,153-155}$. Previous studies have shown surface topography modulated cell shape and its effect on cell signaling and secretion pattern of diverse cell types including macrophages, epithelial cells, and fibroblast ${ }^{7,73,75}$. A recent study by McWhorter et al. (2013) ${ }^{79}$ reaffirmed topography induced cell shape and demonstrated topography-dependent macrophage polarization mediated via cell shape. RAW264.7 macrophages cells grown on rough surfaces G1 and G2 exhibited a significantly higher degree of elongation compared to the smooth Pol surface, and were similar in cell shape to macrophages treated with IL4, a known inducer of the wound 
healing M2 phenotype (Figure 4-1 \& 4-2) ${ }^{13}$. McWhorter et al. $(2013){ }^{79}$ suggested cell elongation modulates macrophage phenotype more towards an M2 phenotype.

The topography-induced adaptation exhibited by macrophages cultured on the grooved surfaces, as observed in morphology and cellular orientation studies, confirms previous in vitro studies that demonstrated the role of surface topography in regulation of macrophage shape and functions ${ }^{4,716}$. Sand-blasted, large grit, acid-etched (SLA) surface showed changes in macrophage morphology and attachment structures when compared to the Pol surface ${ }^{7}$. The most likely molecules involved in modulating topography-induced changes in cell shape and alignment observed on the novel grooved substrata would be integrins as the downstream of integrin signal transduction is known to affect cytoskeletal organization as well as adhesion structure formation ${ }^{156}$.

\subsection{Gene Expression and Cytokine/Protein Profile Produced by the Grooved Surfaces} Consistent with previous studies, which showed the influence of cell shape on gene expression and other cellular responses on grooved surfaces for other cell types ${ }^{73,75}$, the novel grooved surfaces, which are rougher than the Pol surface, showed significant up-regulation of genes that are involved in the recruitment of macrophages ${ }^{145,146}$. Macrophages exhibit rugophilia; that is a preference for rough surface topographies ${ }^{53}$. The increased expression of macrophage-attractant genes on grooved surfaces explains the accumulation of macrophages found on the rough surfaced SLA implant ${ }^{55}$. Chehroudi et al. (2010)'s in vivo rat model study was associated with greater accumulation of macrophages and enhanced bone formation on the rough SLA implant surface, relative to smooth surfaces, suggesting a possible role of macrophages in osseointegration. 
The cyto-/chemokine secretion profile was similar to the gene expression profile. Both grooved surfaces showed increase in secretion of macrophage-attractant chemokines relative to Pol surface. The secretory profile of macrophages cultured on the grooved surfaces indicated a shift towards an M2 phenotype similar, but not identical, to that of IL-4 primed macrophage cells ${ }^{16}$.

An in vitro study by Paul et al. (2008) ${ }^{77}$ who investigated the effects of different polyvinylidene fluoride (PVDF) surface topography on gene expression of human macrophages concluded that the microstructured surface induced changes in gene expression profile that had properties of both M1 and M2 phenotypes. Barth et al. $(2013)^{16}$, who studied the influence of surface topography on the phenotype of RAW264.7 macrophages, found that RAW264.7 macrophages exposed to surface topography alone, without any stimulus such as LPS or IL-4, did not activate cellular pathways to produce NOS2 (M1 marker) or Arg1 (M2 marker). Although, Barth et al. $(2013)^{16}$ could not observe significant up-regulation of traditional M1 or M2 markers of macrophages cultured Pol and SLA surfaces using RT-qPCR, they found cytokine secretion of macrophages cultured on SLA surface more closely resembled the activity of an M2-like phenotype compared to Pol surface.

The results from this study also support previous studies that concluded rough topographies can induce a phenotype intermediate between M1 and M2 but shifted towards M2 ${ }^{16}$, thereby demonstrating a blended phenotypic signature ${ }^{77,78}$. 


\subsection{Chemoattractant Cytokine CCL2/MCP-1 and Matrix Metalloproteinase-9}

CCL2/MCP-1 is a chemoattractant for monocytes/macrophages ${ }^{145,146}$ and is also known to play a role in the regulation of Th1/Th2 lymphocyte differentiation by increasing IL-4 production and inhibiting IL-12 production, enhancing Th2 development as a result. Interestingly, CCL2/MCP-1 is a critical participant in macrophage fusion ${ }^{129}$. An increase in CCL2/MCP-1 and MMP-9 secretion level at Day 5 was observed using ELISA and increased number of multinucleated cells was found on the grooved surfaces relative to the Pol surface. Although, the precise role of CCL2/MCP-1 in the regulation of MMP-9 expression in macrophages requires further investigation, CCL2/MCP-1 deficiency has been shown to lower mRNA expression level of MMP-9 ${ }^{112}$. MMP-9 modulates ECM proteins and activates a number of cytokines, chemokines, and growth factors such as IL-1 and CCL7/MCP-3 ${ }^{103,107-109}$. As an increased secretion of CCL2/MCP-1 was observed concomitantly with increased formation of multinucleated cells, it was of interest to analyze the secretion level of MMP-9, which is not only characteristically expressed by foreign body giant cells (FBGC) ${ }^{12}$ but also required for IL-4 induced macrophage fusion in vitro and in vivo ${ }^{112}$.

\subsection{Cell Fusion}

The time-dependent increased secretion level of CCL2 (MCP-1) and MMP-9 explains the enhanced cell fusion found at Day 5. The MMP-9 secretion pattern from the ELISA assay and immunofluorescent cell fusion study were also supported by the zymography results.

MacLauchlan et al. (2009) ${ }^{112}$ studied the role of MMP-9 in bone marrow derived murine macrophage fusion and observed strong induction of pro-MMP-9 expression level concomitantly with macrophage fusion. They also observed reduced fusion of IL-4 stimulated wide type (WT) 
bone marrow derived macrophages when MMP-9 function-blocking antibodies were present. The expression pattern of pro-MMP-9 observed by the zymography from this study (Figure 4-11) was similar to that observed by MacLauchlan et al. (2009) ${ }^{112}$. The expression of pro-MMP-9 was detected as a heterodimer pro-MMP-9 and neutrophil gelatinase-associated lipocalin (NGAL) complex $(125 \mathrm{kDa}){ }^{147}$. It has been suggested that the complex could increase the enzyme activity of pro-MMP-9 via an autocatalytic process ${ }^{157}$. However, it is not clear how the different forms of pro-MMP-9 or the enzymatic activity of MMP-9 affect the macrophage fusion. Further studies on functional and structural components of MMP-9 in the context of macrophage fusion are required.

Expression of MMP-9 prior to the occurrence of cell fusion suggests possible role of MMP-9 in pre-fusion events such as modulation of cell adhesion, which has been shown to be crucial in the context of integrin-ECM (ECM proteins adsorbed to surfaces) mediated fusion ${ }^{124}$. However, MacLauchlan et al. (2009) did not observe an adhesion defect in MMP-9 null macrophages.

Jay et al. (2007) ${ }^{158}$ demonstrated the importance of cytoskeletal rearrangements prior to macrophage fusion. MacLauchlan et al.(2009) ${ }^{112}$ observed irregular remodeling of the cytoskeleton in MMP-9 null FBGCs and showed possible role of MMP-9 in cytoskeletal rearrangement prior to macrophage fusion. The delayed cytoskeletal rearrangement and irregular actin assembly observed during fusion in MMP-9 null macrophage support the possible role of MMP-9 in cytoskeletal rearrangement prior to fusion as it indicates that MMP-9 null macrophages are capable of responding to fusogenic stimulus but unable to carry out proper rearrangements of cytoskeleton necessary for cell fusion ${ }^{112}$. 
In order for cell fusion to occur, IL4 induced molecules need to be present on both pre-fusing cells ${ }^{120}$. Their finding may suggest the need for macrophages to undergo phenotypic change, similar to the M2 phenotype, prior to cell fusion. In this study, IL-4 secretion could not be detected from both Day 1 and Day 5 microarray results. Hence, enhanced cell fusion observed on the grooved surfaces at Day 5 relative to smooth surface Pol indicates the phenotypic change of macrophages produced by topography is independent of the presence of IL-4 in the media in our system; however, differences in functional surface bound IL-4 may have been present.

Difference in cell/substrata interactions and subsequent cytokine mediators secreted by the cells on different surfaces may have resulted in difference in surface-modulated polarization state of macrophages. In any case, G1 and G2 topographies resulted in distinctive profiles of macrophage secretions and behaviors, such as cell fusion and time dependent CCL2 (MCP-1) and MMP-9 production on the $\mathrm{G} 2$ substrata.

One plausible mechanism behind time-dependent macrophage phonotypical change observed on the novel grooved surfaces G1 and G2 is the alternative activation of macrophages via transmembrane glycoprotein CD98 and $\beta 1$ integrin mediated activation of PI3K ${ }^{159}$. Mackinnon et al. (2008) ${ }^{159}$ concluded that PI3K activation mediated through the association of CD98 with $\beta 1$ integrin ${ }^{160,161}$ is the key mediator for the alternative activation of macrophages. Studies on PI3K mediated macrophage alternative activation on G1 and G2 surfaces have been demonstrated by Kianoush (Kianoush.F MSc Thesis in progression).

Further study is required on topography-induced expression of $\beta 1$ integrin as $\beta 1$ integrin is not only involved in alternative activation of macrophages as a key mediator of PI3K activation 
${ }^{160,161}$ but it is also involved in IL-4 induced cell fusion ${ }^{124}$ that might have resulted in differences in surface-modulated macrophage responses. Consistent with this perspective, IL-4 induced cell fusion can be inhibited by function-blocking antibodies and inhibitors of PI3K ${ }^{124}$. In addition, time dependent expression of $\beta 1$ integrins on adherent monocytes, fusing macrophage cells and foreign body giant cells ${ }^{124}$ may explain the enhanced cell fusion, relative to Pol surface, observed on the G1 and G2 surfaces at Day 5, but not at Day 1, as the secretion levels of CCL2/MCP-1 and MMP-9 increased with time.

Macrophages most likely recognize proteins adsorbed to the substratum and attach to surface adsorbed proteins via integrin mediated interactions ${ }^{62}$. Macrophages can recognize fibronection, vitronectin of extra cellular matrix (ECM) as well as adsorbed blood proteins through their integrin receptors ${ }^{63}$. Interestingly, FBGC formation has shown to be related to proteins such as plasma fibronectin, vitronectin, and osteopontin ${ }^{130,132,162}$. Hence, one possible explanation behind the increased proportion of fused cells formed on G1 and G2 surfaces at Day 5 relative to smooth Pol surfaces is the differences in adsorbed proteins between the surfaces. Anderson $(2008)^{12}$ proposed that macrophage fusion requires an appropriate array of proteins favoring cell fusion adsorbed to the surfaces. There is a possibility that the profile of surface proteins produced and adsorbed in the grooved and smooth surfaces differed. 


\section{Chapter 6: Conclusions and Future Directions}

\subsection{Conclusions}

This study investigated the influence of novel grooved surfaces, fabricated by anisotropic etching of $\mathrm{Si}<110>$ crystals on cell morphology, gene expression, cyto-/chemokine secretion and its association with cell fusion.

The following conclusions can be made from this study:

1) The novel grooved topographies appeared to induce changes in the expression of the gene and the secretion of cyto-/chemokines in a time-dependent manner, that are involved in the recruitment of macrophages

2) The novel grooved topographies increased the secretion level of soluble mediatorsCCL2 (MCP-1) and MMP-9, relative to the smooth control topography Pol, in timedependent manner.

3) Cells with an increased elongated morphology reminiscent of M2 macrophage phenotype on the novel grooved surfaces, relative to Pol surface, were observed.

4) More bi-nucleated or multinucleated cells with increased cell culture time on the novel grooved surfaces, relative to Pol surface, were observed.

5) Increased cell alignment with increase in surface directionality, roughness and cell culture time was observed. 
Collectively, our in vitro data suggests importance of surface topography in regulating macrophage responses and hence, regulating foreign body giant cell (FBGC) formation on implants. Ultimately, a better understanding of macrophage responses at cell-substrate interface may lead to a more rational approach to designing surfaces for biomedical devices.

\subsection{Future Directions}

1. Analysis of adsorbed protein layers on the novel grooved surfaces, G1 and G2, and smooth control surface Pol to further elucidate the effect of surface topography on the types, levels, and surface conformations of the adsorbed proteins that results in increased proportion of fused cells on the rougher surfaces.

Proteomic analysis of the adsorbed protein layers could be attempted as stated below $^{163,164}$ :

1) Elution of proteins adsorbed onto the surfaces

2) Run 2-D PAGE

3) Silver staining of the gel for the visualization of the gel

4) Analysis of the 2-D gel to identify the adsorbed proteins by:

a. Comparing the scanned gel image with the 2-D reference map of mouse plasma proteins.

b. Performing the mass spectrometry ${ }^{164}$

2. Analysis of focal adhesion sites of macrophages using immunogold staining to detect the expression and localization of vinculin ${ }^{165}$ on different surface topographies to further 
elucidate cell/substrate interactions that may have resulted in difference in subsequent gene, and cytokine expressions

3. Determine the effect of surface topography on the expression of different forms of MMP9 proteins (for example, homo-dimer form or hetero-dimer form such as MMP-9/NGAL complex) using commercially available ELISA kits.

In addition, an antibody against secreted NGAL would be used ${ }^{166}$ (at present no specific NGAL inhibitors are available ${ }^{167}$ ) to prevent the formation of MMP-9/NGAL complex and its effect on macrophage fusion will be studied.

4. Determine the effect of surface topography on $\beta 1$ integrin expression. $\beta 1$ integrin expression by RAW264.7 macrophages cultured on G1, G2, and Pol surfaces will be studied by immunofluorescence ${ }^{124}$. 


\section{Bibliography}

1. Brunette, D. M. The effects of implant surface topography on the behavior of cells. Int. J. Oral Maxillofac. Implants 3, 231-46 (1988).

2. Albrektsson, T. \& Wennerberg, A. Oral implant surfaces: Part 1--review focusing on topographic and chemical properties of different surfaces and in vivo responses to them. Int. J. Prosthodont. 17, 536-43 (2004).

3. Brunette, D. M. in Titanium in Medicine (ed. Brunette, D. M.) 486-512 (Springer, 2001). doi:10.1007/978-3-642-56486-4

4. Wójciak-Stothard, B., Curtis, A., Monaghan, W., MacDonald, K. \& Wilkinson, C. Guidance and activation of murine macrophages by nanometric scale topography. Exp. Cell Res. 223, 426-35 (1996).

5. Takebe, J., Champagne, C. M., Offenbacher, S., Ishibashi, K. \& Cooper, L. F. Titanium surface topography alters cell shape and modulates bone morphogenetic protein 2 expression in the J774A.1 macrophage cell line. J. Biomed. Mater. Res. A 64, 207-16 (2003).

6. Refai, A. K., Textor, M., Brunette, D. M. \& Waterfield, J. D. Effect of titanium surface topography on macrophage activation and secretion of proinflammatory cytokines and chemokines. J. Biomed. Mater. Res. A 70, 194-205 (2004).

7. Ghrebi, S., Hamilton, D. W., Waterfield, J. D. \& Brunette, D. M. The effect of surface topography on cell shape and early ERK1/2 signaling in macrophages; linkage with FAK and Src. J. Biomed. Mater. Res. Part A 101, 2118-28 (2013).

8. Mantovani, A. et al. The chemokine system in diverse forms of macrophage activation and polarization. Trends Immunol. 25, 677-86 (2004).

9. Mosser, D. M. \& Edwards, J. P. Exploring the full spectrum of macrophage activation. Nat. Rev. Immunol. 8, 958-69 (2008).

10. Anderson, J. M. Multinucleated giant cells. Curr. Opin. Hematol. 7, 40-7 (2000).

11. Boros, D. L. Immunopathology of Schistosoma mansoni infection. Clin. Microbiol. Rev. 2, 250-69 (1989).

12. Anderson, J. M., Rodriguez, A. \& Chang, D. T. Foreign body reaction to biomaterials. Semin. Immunol. 20, 86-100 (2008).

13. Stein, M., Keshav, S., Harris, N. \& Gordon, S. Interleukin 4 potently enhances murine macrophage mannose receptor activity: a marker of alternative immunologic macrophage activation. J. Exp. Med. 176, 287-292 (1992).

14. McInnes, A. \& Rennick, D. M. Interleukin 4 induces cultured monocytes/macrophages to form giant multinucleated cells. J. Exp. Med. 167, 598-611 (1988). 
15. McNally, A. K. \& Anderson, J. M. Interleukin-4 induces foreign body giant cells from human monocytes/macrophages. Differential lymphokine regulation of macrophage fusion leads to morphological variants of multinucleated giant cells. Am. J. Pathol. 147, 1487-99 (1995).

16. Barth, K. A., Waterfield, J. D. \& Brunette, D. M. The effect of surface roughness on RAW 264.7 macrophage phenotype. J. Biomed. Mater. Res. A 101, 2679-88 (2013).

17. Wieland, M., Textor, M., Spencer, N. D. \& Brunette, D. M. Wavelength-dependent roughness: a quantitative approach to characterizing the topography of rough titanium surfaces. Int. J. Oral Maxillofac. Implants 16, 163-81 (2001).

18. Horst, C., Tetsuya, S. \& Smith Leslie. Springer Handbook of Metrology and Testing. (Springer, 2011).

19. Blateyron, F. Characterisation of Areal Surface Texture. (Springer, 2013). doi:10.1007/978-3-642-36458-7

20. Wennerberg, A. \& Albrektsson, T. On implant surfaces: a review of current knowledge and opinions. Int. J. Oral Maxillofac. Implants 25, 63-74 (2009).

21. Cooper, L. F. A role for surface topography in creating and maintaining bone at titanium endosseous implants. J. Prosthet. Dent. 84, 522-534 (2000).

22. Wennerberg, A. \& Albrektsson, T. Effects of titanium surface topography on bone integration: a systematic review. Clin. Oral Implants Res. 20 Suppl 4, 172-84 (2009).

23. Ong, J. L., Carnes, D. L. \& Bessho, K. Evaluation of titanium plasma-sprayed and plasma-sprayed hydroxyapatite implants in vivo. Biomaterials 25, 4601-6 (2004).

24. Hamilton, D. W., Chehroudi, B. \& Brunette, D. M. Comparative response of epithelial cells and osteoblasts to microfabricated tapered pit topographies in vitro and in vivo. Biomaterials 28, 2281-93 (2007).

25. Brunette, D. M., Kenner, G. S. \& Gould, T. R. Grooved titanium surfaces orient growth and migration of cells from human gingival explants. J. Dent. Res. 62, 1045-8 (1983).

26. Brunette, D. M. Fibroblasts on micromachined substrata orient hierarchically to grooves of different dimensions. Exp. Cell Res. 164, 11-26 (1986).

27. Chehroudi, B., Gould, T. R. \& Brunette, D. M. Effects of a grooved epoxy substratum on epithelial cell behavior in vitro and in vivo. J. Biomed. Mater. Res. 22, 459-73 (1988).

28. Oakley, C. \& Brunette, D. M. The sequence of alignment of microtubules, focal contacts and actin filaments in fibroblasts spreading on smooth and grooved titanium substrata. $J$. Cell Sci. 106 ( Pt 1, 343-54 (1993).

29. Nematollahi, M., Hamilton, D. W., Jaeger, N. J. \& Brunette, D. M. Hexagonal micron scale pillars influence epithelial cell adhesion, morphology, proliferation, migration, and cytoskeletal arrangement. J. Biomed. Mater. Res. A 91, 149-57 (2009).

30. Kovacs, G. T. A., Maluf, N. I. \& Petersen, K. E. Bulk micromachining of silicon. Proc. IEEE 86, 1536-1551 (1998). 
31. Bustillo, J. M., Howe, R. T. \& Muller, R. S. Surface micromachining for microelectromechanical systems. Proc. IEEE 86, 1552-1574 (1998).

32. Angell, J., Terry, S. \& Barth, P. Silicon Micromechanical Devices. Sci. Amerian, INC 248, 44-55 (1983).

33. Voldman, J., Gray, M. L. \& Schmidt, M. a. Microfabrication in Biology and Medicine. Annu. Rev. Biomed. Eng 01, 401-425 (1999).

34. Seidel, H., Csepregi, L., Heuberger, A. \& Baumgärtel, H. Anisotropic Etching of Crystalline Silicon in Alkaline Solutions. J. Electrochem. Soc. 137, 3612-3626 (1990).

35. Holmes, P. . The Electrochemistry of Semiconductors. (Academic Press, Ltd, 1962).

36. Gordon, S. \& Taylor, P. R. Monocyte and macrophage heterogeneity. Nat. Rev. Immunol. 5, 953-64 (2005).

37. Hume, D. A. The mononuclear phagocyte system. Curr. Opin. Immunol. 18, 49-53 (2006).

38. Fairweather, D. \& Cihakova, D. Alternatively activated macrophages in infection and autoimmunity. J. Autoimmun. 33, 222-30 (2009).

39. Morrissette, N., Cold, E. \& Aderem, A. The macrophage - A cell for all seasons. Trends Cell Biol. 9, 199-201 (1999).

40. Stout, R. D. \& Suttles, J. Functional plasticity of macrophages: reversible adaptation to changing microenvironments. J. Leukoc. Biol. 76, 509-513 (2004).

41. Gordon, S. Alternative activation of macrophages. Nat. Rev. Immunol. 3, 23-35 (2003).

42. Mantovani, A., Sozzani, S., Locati, M., Allavena, P. \& Sica, A. Macrophage polarization: tumor-associated macrophages as a paradigm for polarized M2 mononuclear phagocytes. Trends Immunol. 23, 549-555 (2002).

43. Mantovani, A., Sica, A. \& Locati, M. Macrophage Polarization Comes of Age. Immunity 23, 344-346 (2005).

44. Mantovani, A. et al. The chemokine system in diverse forms of macrophage activation and polarization. Trends Immunol. 25, 677-686 (2004).

45. Mantovani, A., Biswas, S. K., Galdiero, M. R., Sica, A. \& Locati, M. Macrophage plasticity and polarization in tissue repair and remodelling. J. Pathol. 229, 176-85 (2013).

46. Recalcati, S. et al. Differential regulation of iron homeostasis during human macrophage polarized activation. Eur. J. Immunol. 40, 824-35 (2010).

47. Classen, A., Lloberas, J. \& Celada, A. Macrophage activation: classical versus alternative. Methods Mol. Biol. 531, 29-43 (2009).

48. Hartley, J. W. et al. Expression of infectious murine leukemia viruses by RAW264.7 cells, a potential complication for studies with a widely used mouse macrophage cell line.

Retrovirology 5, 1 (2008). 
49. Murray, P. J. \& Wynn, T. A. Protective and pathogenic functions of macrophage subsets. Nat. Rev. Immunol. 11, 723-37 (2011).

50. Martinez, F. O., Helming, L. \& Gordon, S. Alternative activation of macrophages: an immunologic functional perspective. Annu. Rev. Immunol. 27, 451-83 (2009).

51. Waterfield, J. D., Ali, T. A., Nahid, F., Kusano, K. \& Brunette, D. M. The effect of surface topography on early NFאB signaling in macrophages. J. Biomed. Mater. Res. A 95, 837-47 (2010).

52. Brunette, D. M., Tengvall, P., Textor, M. \& Thomsen, P. Titanium in Medicine. (Springer Berlin Heidelberg, 2001). doi:10.1007/978-3-642-56486-4

53. Rich, A. \& Harris, A. K. Anomalous preferences of cultured macrophages for hydrophobic and roughened substrata. J. Cell Sci. 50, 1-7 (1981).

54. Chehroudi, B., Gould, T. \& Brunette, D. Titanium-coated micromachined grooves of different dimensions affect epithelial and connective-tissue cells differently in vivo. $J$. Biomed. Mater. Res. 24, 1203-19 (1990).

55. Chehroudi, B. et al. Bone formation on rough, but not polished, subcutaneously implanted Ti surfaces is preceded by macrophage accumulation. J. Biomed. Mater. Res. Part A 93, 724-737 (2010).

56. Brunette, D. M. Spreading and orientation of epithelial cells on grooved substrata. Exp. Cell Res. 167, 203-17 (1986).

57. Dow, J. A., Clark, P., Connolly, P., Curtis, A. S. \& Wilkinson, C. D. Novel methods for the guidance and monitoring of single cells and simple networks in culture. J. Cell Sci. Suppl. 8, 55-79 (1987).

58. Bershadsky, A. D., Balaban, N. Q. \& Geiger, B. Adhesion-dependent cell mechanosensitivity. Annu. Rev. Cell Dev. Biol. 19, 677-95 (2003).

59. Hynes, R. O. Integrins: bidirectional, allosteric signaling machines. Cell 110, 673-87 (2002).

60. Gundersen, G. G., Kreitzer, G., Cook, T. \& Liao, G. Microtubules as determinants of cellular polarity. Biol. Bull. 194, 358-60 (1998).

61. Humphries, M. J., Travis, M. A., Clark, K. \& Mould, A. P. Mechanisms of integration of cells and extracellular matrices by integrins. Biochem. Soc. Trans. 32, 822-5 (2004).

62. Phillips, J. M. \& Kao, W. J. Macrophage adhesion on gelatin-based interpenetrating networks grafted with PEGylated RGD. Tissue Eng. 11, 964-73 (2005).

63. Labat-Robert, J., Bihari-Varga, M. \& Robert, L. Extracellular matrix. FEBS Lett. 268, 386-93 (1990).

64. Block, M. R. et al. Podosome-type adhesions and focal adhesions, so alike yet so different. Eur. J. Cell Biol. 87, 491-506 (2008). 
65. Destaing, O., Saltel, F., Géminard, J.-C., Jurdic, P. \& Bard, F. Podosomes display actin turnover and dynamic self-organization in osteoclasts expressing actin-green fluorescent protein. Mol. Biol. Cell 14, 407-16 (2003).

66. van den Dries, K. et al. Geometry sensing by dendritic cells dictates spatial organization and PGE(2)-induced dissolution of podosomes. Cell. Mol. Life Sci. 69, 1889-901 (2012).

67. Brunette, D. M. \& Chehroudi, B. The effects of the surface topography of micromachined titanium substrata on cell behavior in vitro and in vivo. J. Biomech. Eng. 121, 49-57 (1999).

68. Wójciak-Stothard, B., Madeja, Z., Korohoda, W., Curtis, A. \& Wilkinson, C. Activation of macrophage-like cells by multiple grooved substrata. Topographical control of cell behaviour. Cell Biol. Int. 19, 485-90 (1995).

69. Brunette, D. M. Fibroblasts on micromachined substrata orient hierarchically to grooves of different dimensions. Exp. Cell Res. 164, 11-26 (1986).

70. Brunette, D. M. et al. in Bio-Implant Interface: Improving Biomaterials and Tissue Reactions (eds. Ellingsen, J. E. \& Lyngstadaas, S. P.) 103-122 (CRC Press, 2003).

71. Ohara, P. T. \& Buck, R. C. Contact guidance in vitro. A light, transmission, and scanning electron microscopic study. Exp. Cell Res. 121, 235-49 (1979).

72. Abiko, Y. \& Brunette, D. M. Immunohistochemical investigation of tracks left by the migration of fibroblasts on titantium surfaces. Cell Mater 3, 161-170 (1993).

73. Chou, L. S., Firth, J. D., Uitto, V. J. \& Brunette, D. M. Substratum Surface-Topography Alters Cell-Shape and Regulates Fibronectin Messenger-Rna Level, Messenger-Rna Stability, Secretion and Assembly in Human Fibroblasts. J. Cell Sci. 108, 1563-1573 (1995).

74. Wong, N. et al. Effects of interleukin-10 on titanium particle-induced macrophage transcription factor activation and cytokine expressionin vitro. J. Biomed. Mater. Res. 69A, 40-46 (2004).

75. Hong, H. L. \& Brunette, D. . Effect of cell shape on proteinase secretion by epithelial cells. J. Cell Sci. 87, 259-267 (1987).

76. Ben-Ze'ev, A. Differential control of cytokeratins and vimentin synthesis by cell-cell contact and cell spreading in cultured epithelial cells. J. Cell Biol. 99, 1424-33 (1984).

77. Paul, N. E. et al. Topographical control of human macrophages by a regularly microstructured polyvinylidene fluoride surface. Biomaterials 29, 4056-64 (2008).

78. Jones, J. A. et al. Proteomic analysis and quantification of cytokines and chemokines from biomaterial surface-adherent macrophages and foreign body giant cells. J. Biomed. Mater. Res. A 83, 585-96 (2007).

79. McWhorter, F. Y., Wang, T., Nguyen, P., Chung, T. \& Liu, W. F. Modulation of macrophage phenotype by cell shape. Proc. Natl. Acad. Sci. U. S. A. 110, 17253-8 (2013). 
80. Dinarello, C. A. The Physiological and Pathological Effects of Cytokines (Progress in Leukocyte Biology). (John Wiley \& Sons, Inc., 1990).

81. Miyajima, A., Kitamura, T., Harada, N., Yokota, T. \& Arai, K. Cytokine receptors and signal transduction. Annu. Rev. Immunol. 10, 295-331 (1992).

82. Foster, J. R. The functions of cytokines and their uses in toxicology. Int. J. Exp. Pathol. 82, 171-92 (2001).

83. Abbas, A. K., Lichtman, A. H. \& Pober, J. S. Cellular and molecular immunology. (1997).

84. Locati, M. et al. Regulation of the chemokine system at the level of chemokine receptor expression and signaling activity. Immunobiology 204, 536-42 (2001).

85. Luster, A. D. \& Rothenberg, M. E. Role of the monocyte chemoattractant protein and eotaxin subfamily of chemokines in allergic inflammation. J. Leukoc. Biol. 62, 620-33 (1997).

86. Cushing, S. D. et al. Minimally modified low density lipoprotein induces monocyte chemotactic protein 1 in human endothelial cells and smooth muscle cells. Proc. Natl. Acad. Sci. U. S. A. 87, 5134-8 (1990).

87. Standiford, T. J., Kunkel, S. L., Phan, S. H., Rollins, B. J. \& Strieter, R. M. Alveolar macrophage-derived cytokines induce monocyte chemoattractant protein-1 expression from human pulmonary type II-like epithelial cells. J. Biol. Chem. 266, 9912-8 (1991).

88. Brown, Z. et al. IL-1 receptor antagonist inhibits monocyte chemotactic peptide 1 generation by human mesangial cells. Kidney Int. 42, 95-101 (1992).

89. Barna, B. P. et al. Regulation of monocyte chemoattractant protein-1 expression in adult human non-neoplastic astrocytes is sensitive to tumor necrosis factor (TNF) or antibody to the 55-kDa TNF receptor. J. Neuroimmunol. 50, 101-7 (1994).

90. Yoshimura, T. et al. Human monocyte chemoattractant protein-1 (MCP-1). Full-length cDNA cloning, expression in mitogen-stimulated blood mononuclear leukocytes, and sequence similarity to mouse competence gene JE. FEBS Lett. 244, 487-93 (1989).

91. Yoshimura, T., Robinson, E. A., Tanaka, S., Appella, E. \& Leonard, E. J. Purification and amino acid analysis of two human monocyte chemoattractants produced by phytohemagglutinin-stimulated human blood mononuclear leukocytes. J. Immunol. 142, 1956-62 (1989).

92. Rollins, B. J., Morrison, E. D. \& Stiles, C. D. Cloning and expression of JE, a gene inducible by platelet-derived growth factor and whose product has cytokine-like properties. Proc. Natl. Acad. Sci. U. S. A. 85, 3738-42 (1988).

93. Luo, Y. et al. Serologic analysis of the mouse beta chemokine JE/monocyte chemoattractant protein-1. J. Immunol. 153, 3708-16 (1994).

94. Van Damme, J. et al. Production and identification of natural monocyte chemotactic protein from virally infected murine fibroblasts. Relationship with the product of the mouse competence (JE) gene. Eur. J. Biochem. 199, 223-9 (1991). 
95. Gu, L. et al. In vivo properties of monocyte chemoattractant protein-1. J. Leukoc. Biol. 62, 577-80 (1997).

96. Karpus, W. J. et al. Differential CC chemokine-induced enhancement of T helper cell cytokine production. J. Immunol. 158, 4129-36 (1997).

97. Lukacs, N. W. et al. C-C chemokines differentially alter interleukin-4 production from lymphocytes. Am. J. Pathol. 150, 1861-8 (1997).

98. Deshmane, S. L., Kremlev, S., Amini, S. \& Sawaya, B. E. Monocyte chemoattractant protein-1 (MCP-1): an overview. J. Interferon Cytokine Res. 29, 313-26 (2009).

99. Charo, I. F. et al. Molecular cloning and functional expression of two monocyte chemoattractant protein 1 receptors reveals alternative splicing of the carboxyl-terminal tails. Proc. Natl. Acad. Sci. U. S. A. 91, 2752-6 (1994).

100. Bartoli, C., Civatte, M., Pellissier, J. F. \& Figarella-Branger, D. CCR2A and CCR2B, the two isoforms of the monocyte chemoattractant protein-1 receptor are up-regulated and expressed by different cell subsets in idiopathic inflammatory myopathies. Acta Neuropathol. 102, 385-92 (2001).

101. Visse, R. \& Nagase, H. Matrix metalloproteinases and tissue inhibitors of metalloproteinases: structure, function, and biochemistry. Circ. Res. 92, 827-39 (2003).

102. Ra, H.-J. \& Parks, W. C. Control of matrix metalloproteinase catalytic activity. Matrix Biol. 26, 587-96 (2007).

103. Mott, J. D. \& Werb, Z. Regulation of matrix biology by matrix metalloproteinases. Curr. Opin. Cell Biol. 16, 558-64 (2004).

104. Parks, W. C., Wilson, C. L. \& López-Boado, Y. S. Matrix metalloproteinases as modulators of inflammation and innate immunity. Nat. Rev. Immunol. 4, 617-29 (2004).

105. Bode, W., Gomis-Rüth, F. X. \& Stöckler, W. Astacins, serralysins, snake venom and matrix metalloproteinases exhibit identical zinc-binding environments

(HEXXHXXGXXH and Met-turn) and topologies and should be grouped into a common family, the 'metzincins'. FEBS Lett. 331, 134-40 (1993).

106. Allan, J. A. et al. Binding of gelatinases A and B to type-I collagen and other matrix components. Biochem. J. 309 ( Pt 1, 299-306 (1995).

107. Niyibizi, C., Chan, R., Wu, J. J. \& Eyre, D. A 92 kDa gelatinase (MMP-9) cleavage site in native type V collagen. Biochem. Biophys. Res. Commun. 202, 328-33 (1994).

108. Schönbeck, U., Mach, F. \& Libby, P. Generation of biologically active IL-1 beta by matrix metalloproteinases: a novel caspase-1-independent pathway of IL-1 beta processing. J. Immunol. 161, 3340-6 (1998).

109. Patterson, B. C. \& Sang, Q. A. Angiostatin-converting enzyme activities of human matrilysin (MMP-7) and gelatinase B/type IV collagenase (MMP-9). J. Biol. Chem. 272, 28823-5 (1997). 
110. Yu, Q. \& Stamenkovic, I. Cell surface-localized matrix metalloproteinase-9 proteolytically activates TGF-beta and promotes tumor invasion and angiogenesis. Genes Dev. 14, 163-76 (2000).

111. Van den Steen, P. E., Proost, P., Wuyts, A., Van Damme, J. \& Opdenakker, G. Neutrophil gelatinase B potentiates interleukin-8 tenfold by aminoterminal processing, whereas it degrades CTAP-III, PF-4, and GRO-alpha and leaves RANTES and MCP-2 intact. Blood 96, 2673-81 (2000).

112. MacLauchlan, S. et al. Macrophage fusion, giant cell formation, and the foreign body response require matrix metalloproteinase 9. J. Leukoc. Biol. 85, 617-26 (2009).

113. Anderson, J. M. Biological Responses to Materials. Annu. Rev. Mater. Res. 31, 81-110 (2001).

114. Gretzer, C., Emanuelsson, L., Liljensten, E. \& Thomsen, P. The inflammatory cell influx and cytokines changes during transition from acute inflammation to fibrous repair around implanted materials. J. Biomater. Sci. Polym. Ed. 17, 669-87 (2006).

115. Luttikhuizen, D. T., Harmsen, M. C. \& Van Luyn, M. J. A. Cellular and molecular dynamics in the foreign body reaction. Tissue Eng. 12, 1955-70 (2006).

116. Latour, R. . Biomaterials: Protein-surface interactions. Encycl. Biomater. Biomed. Eng. 28, 1-15 (2005).

117. Wilson, C. J., Clegg, R. E., Leavesley, D. I. \& Pearcy, M. J. Mediation of biomaterial-cell interactions by adsorbed proteins: a review. Tissue Eng. 11, 1-18 (2005).

118. Hu, W. J., Eaton, J. W., Ugarova, T. P. \& Tang, L. Molecular basis of biomaterialmediated foreign body reactions. Blood 98, 1231-8 (2001).

119. Williams, D. F. Tissue-biomaterial interactions. J. Mater. Sci. 22, 3421-3445 (1987).

120. Helming, L. \& Gordon, S. Macrophage fusion induced by IL-4 alternative activation is a multistage process involving multiple target molecules. Eur. J. Immunol. 37, 33-42 (2007).

121. Kao, W. J., McNally, A. K., Hiltner, A. \& Anderson, J. M. Role for interleukin-4 in foreign-body giant cell formation on a poly(etherurethane urea) in vivo. J. Biomed. Mater. Res. 29, 1267-75 (1995).

122. DeFife, K. M., Jenney, C. R., McNally, A. K., Colton, E. \& Anderson, J. M. Interleukin13 induces human monocyte/macrophage fusion and macrophage mannose receptor expression. J. Immunol. 158, 3385-90 (1997).

123. McNally, A. K., DeFife, K. M. \& Anderson, J. M. Interleukin-4-induced macrophage fusion is prevented by inhibitors of mannose receptor activity. Am. J. Pathol. 149, 975-85 (1996).

124. McNally, A. K. \& Anderson, J. M. $\beta 1$ and $\beta 2$ Integrins Mediate Adhesion during Macrophage Fusion and Multinucleated Foreign Body Giant Cell Formation. Am. J. Pathol. 160, 621-630 (2002). 
125. Yagi, M. et al. DC-STAMP is essential for cell-cell fusion in osteoclasts and foreign body giant cells. J. Exp. Med. 202, 345-51 (2005).

126. Helming, L. \& Gordon, S. Molecular mediators of macrophage fusion. Trends Cell Biol. 19, 514-22 (2009).

127. Yasuda, H. et al. Osteoclast differentiation factor is a ligand for osteoprotegerin/osteoclastogenesis-inhibitory factor and is identical to TRANCE/RANKL. Proc. Natl. Acad. Sci. U. S. A. 95, 3597-602 (1998).

128. Vignery, A. Macrophage fusion: the making of osteoclasts and giant cells. J. Exp. Med. 202, 337-40 (2005).

129. Kyriakides, T. R. et al. The CC chemokine ligand, CCL2/MCP1, participates in macrophage fusion and foreign body giant cell formation. Am. J. Pathol. 165, 2157-66 (2004).

130. Tsai, A. T. et al. The role of osteopontin in foreign body giant cell formation. Biomaterials 26, 5835-43 (2005).

131. Jones, J. A. et al. Macrophage behavior on surface-modified polyurethanes. J. Biomater. Sci. Polym. Ed. 15, 567-84 (2004).

132. McNally, A. K., Jones, J. A., Macewan, S. R., Colton, E. \& Anderson, J. M. Vitronectin is a critical protein adhesion substrate for IL-4-induced foreign body giant cell formation. $J$. Biomed. Mater. Res. A 86, 535-43 (2008).

133. Wieland, M., Chehroudi, B., Textor, M. \& Brunette, D. M. Use of Ti-coated replicas to investigate the effects on fibroblast shape of surfaces with varying roughness and constant chemical composition. J. Biomed. Mater. Res. 60, 434-44 (2002).

134. Schuler, M. et al. Fabrication of TiO2-coated epoxy replicas with identical dual-type surface topographies used in cell culture assays. J. Biomed. Mater. Res. A 88, 12-22 (2009).

135. Salitsky, A. The Raw 264.7 Cell Line: A Valid Candidate for Studying Macrophage Activation. (1983).

136. Wong, A. T. T. The Effect of Surface Topography on Gene Expression of Macrophages. (University of British Columbia, 2013).

137. Menzies, F. M., Henriquez, F. L., Alexander, J. \& Roberts, C. W. Sequential expression of macrophage anti-microbial/inflammatory and wound healing markers following innate, alternative and classical activation. Clin. Exp. Immunol. 160, 369-79 (2010).

138. Nolan, T., Hands, R. E. \& Bustin, S. A. Quantification of mRNA using real-time RT-PCR. 1, 1559-1582 (2006).

139. Abe, T. et al. Key role of CD36 in Toll-like receptor 2 signaling in cerebral ischemia. Stroke. 41, 898-904 (2010).

140. Villani, G. R. D. et al. Cytokines, neurotrophins, and oxidative stress in brain disease from mucopolysaccharidosis IIIB. J. Neurosci. Res. 85, 612-22 (2007). 
141. Carvalho-Gaspar, M., Billing, J. S., Spriewald, B. M. \& Wood, K. J. Chemokine gene expression during allograft rejection: comparison of two quantitative PCR techniques. $J$. Immunol. Methods 301, 41-52 (2005).

142. Cambien, B. et al. CCL5 neutralization restricts cancer growth and potentiates the targeting of PDGFR $\beta$ in colorectal carcinoma. PLoS One 6, e28842 (2011).

143. Michalec, L. et al. CCL7 and CXCL10 orchestrate oxidative stress-induced neutrophilic lung inflammation. J. Immunol. 168, 846-52 (2002).

144. Schmittgen, T. D. \& Livak, K. J. Analyzing real-time PCR data by the comparative C(T) method. Nat. Protoc. 3, 1101-8 (2008).

145. Esche, C., Stellato, C. \& Beck, L. A. Chemokines: key players in innate and adaptive immunity. J. Invest. Dermatol. 125, 615-28 (2005).

146. Charo, I. F. \& Ransohoff, R. M. The many roles of chemokines and chemokine receptors in inflammation. N. Engl. J. Med. 354, 610-21 (2006).

147. Kjeldsen, L., Johnsen, a H., Sengeløv, H. \& Borregaard, N. Isolation and primary structure of NGAL, a novel protein associated with human neutrophil gelatinase. J. Biol. Chem. 268, 10425-10432 (1993).

148. Oakley, C. \& Brunette, D. M. Topographic compensation: guidance and directed locomotion of fibroblasts on grooved micromachined substrata in the absence of microtubules. Cell Motil. Cytoskeleton 31, 45-58 (1995).

149. Oakley, C., Jaeger, N. A. \& Brunette, D. M. Sensitivity of fibroblasts and their cytoskeletons to substratum topographies: topographic guidance and topographic compensation by micromachined grooves of different dimensions. Exp. Cell Res. 234, 413-24 (1997).

150. Curtis, A. S. \& Wilkinson, C. D. Reactions of cells to topography. J. Biomater. Sci. Polym. Ed. 9, 1313-29 (1998).

151. Meyle, J., Gültig, K. \& Nisch, W. Variation in contact guidance by human cells on a microstructured surface. J. Biomed. Mater. Res. 29, 81-8 (1995).

152. Elsdale, T. \& Bard, J. Cellular Interactions in Mass Cultures of Human Diploid Fibroblasts. Nature 236, 152-155 (1972).

153. Mosser, D. M. The many faces of macrophage activation. J. Leukoc. Biol. 73, 209-212 (2003).

154. Martinez, F. O., Helming, L. \& Gordon, S. Alternative activation of macrophages: an immunologic functional perspective. Annu. Rev. Immunol. 27, 451-83 (2009).

155. Mosser, D. M. \& Edwards, J. P. Exploring the full spectrum of macrophage activation. Nat. Rev. Immunol. Immunol. 8, 958-969 (2008).

156. Giancotti, F. G. \& Ruoslahti, E. Integrin signaling. Science 285, 1028-32 (1999). 
157. Yan, L., Borregaard, N., Kjeldsen, L. \& Moses, M. A. The high molecular weight urinary matrix metalloproteinase (MMP) activity is a complex of gelatinase B/MMP-9 and neutrophil gelatinase-associated lipocalin (NGAL). Modulation of MMP-9 activity by NGAL. J. Biol. Chem. 276, 37258-65 (2001).

158. Jay, S. M., Skokos, E., Laiwalla, F., Krady, M.-M. \& Kyriakides, T. R. Foreign Body Giant Cell Formation Is Preceded by Lamellipodia Formation and Can Be Attenuated by Inhibition of Rac1 Activation. Am. J. Pathol. 171, 632-640 (2007).

159. MacKinnon, A. C. et al. Regulation of Alternative Macrophage Activation by Galectin-3. J. Immunol. 180, 2650-2658 (2008).

160. Henderson, N. C. et al. CD98hc (SLC3A2) interaction with beta 1 integrins is required for transformation. J. Biol. Chem. 279, 54731-41 (2004).

161. Rintoul, R. C. et al. Cross-linking CD98 promotes integrin-like signaling and anchorageindependent growth. Mol. Biol. Cell 13, 2841-52 (2002).

162. Keselowsky, B. G. et al. Role of plasma fibronectin in the foreign body response to biomaterials. Biomaterials 28, 3626-3631 (2007).

163. Lück, M., Paulke, B. R., Schröder, W., Blunk, T. \& Müller, R. H. Analysis of plasma protein adsorption on polymeric nanoparticles with different surface characteristics. $J$. Biomed. Mater. Res. 39, 478-85 (1998).

164. Urbani, A. et al. Proteomic analysis of protein adsorption capacity of different haemodialysis membranes. Mol. Biosyst. 8, 1029-39 (2012).

165. Baharloo, B., Textor, M. \& Brunette, D. M. Substratum roughness alters the growth, area, and focal adhesions of epithelial cells, and their proximity to titanium surfaces. J. Biomed. Mater. Res. A 74, 12-22 (2005).

166. Leng, X. et al. Inhibition of lipocalin 2 impairs breast tumorigenesis and metastasis. Cancer Res. 69, 8579-84 (2009).

167. Bouchet, S. \& Bauvois, B. Neutrophil Gelatinase-Associated Lipocalin (NGAL), ProMatrix Metalloproteinase-9 (pro-MMP-9) and Their Complex Pro-MMP-9/NGAL in Leukaemias. Cancers (Basel). 6, 796-812 (2014). 


\section{Appendix}

\section{Appendix A}

\section{A.1 Preliminary Study on the Effect of Surface Topography on Canonical Wnt/ß- catenin Pathway in Macrophage-Role of E-cadherin/P120 (CTNND1) Complex in Macrophage-like cell RAW264.7}

Rationale: A previous study by Barth et al. (2013) showed polarization of RAW 264.7 macrophages cultured on rough surface topography SLA more towards an M2-like phenotype compared to smooth control Pol surface. In addition, whole genome microarray studies from Wong et al. (Wong A. T. T. MSc Thesis 2013) indicated an up-regulated expression of P120 (CTNND1) gene in RAW 264.7 macrophages cultured on SLA surface relative to Pol surface. Hence, it was of interest to investigate whether the M2 polarization of macrophages cultured on rough surface SLA is achieved via E-cadherin/P120 (CTNND1) complex mediated canonical wnt/ $\beta$-catenin signaling pathway as previous studies have shown that canonical wnt $/ \beta$-catenin pathway induces an anti-inflammatory phenotype in macrophages (Schaale et al. 2011).

Hypothesis: Surface roughness can drive macrophage cells' activation more towards an M2-like phenotype through E-cadherin/P120 complex by modulating higher level of canonical wnt/ $\beta$ catenin signaling pathway. 


\begin{abstract}
Aim: The effect of rough surface topography on the elicitation of canonical wnt $/ \beta$-catenin pathway through the membrane associated E-cadherin/P120 complex is studied.
\end{abstract}

Hypothesized signaling pathway: Upon the presence of an appropriate signal, E-cadherin acts as a mediator between the wnt receptor and $\mathrm{CK} 1 \varepsilon$, with the help of a docking protein P120, and prevents GSK $\beta$ from phosphorylating $\beta$-catenin for ubiquitination. This in turn causes translocation of cytoplasmic $\beta$-catenin that induces macrophage cells to exhibit an antiinflammatory phenotype. P120 also plays a role in translocation of cytoplasmic $\beta$-catenin by activating Rac1-GTPase as well as interacts with transcriptional repressor Kaiso to derepress its target genes, some of which are shared with wnt target genes (see Figure A-1) (based on previous studies Casagolda et al. 2010; Valls et al. 2012; Bossche et al. 2013) 


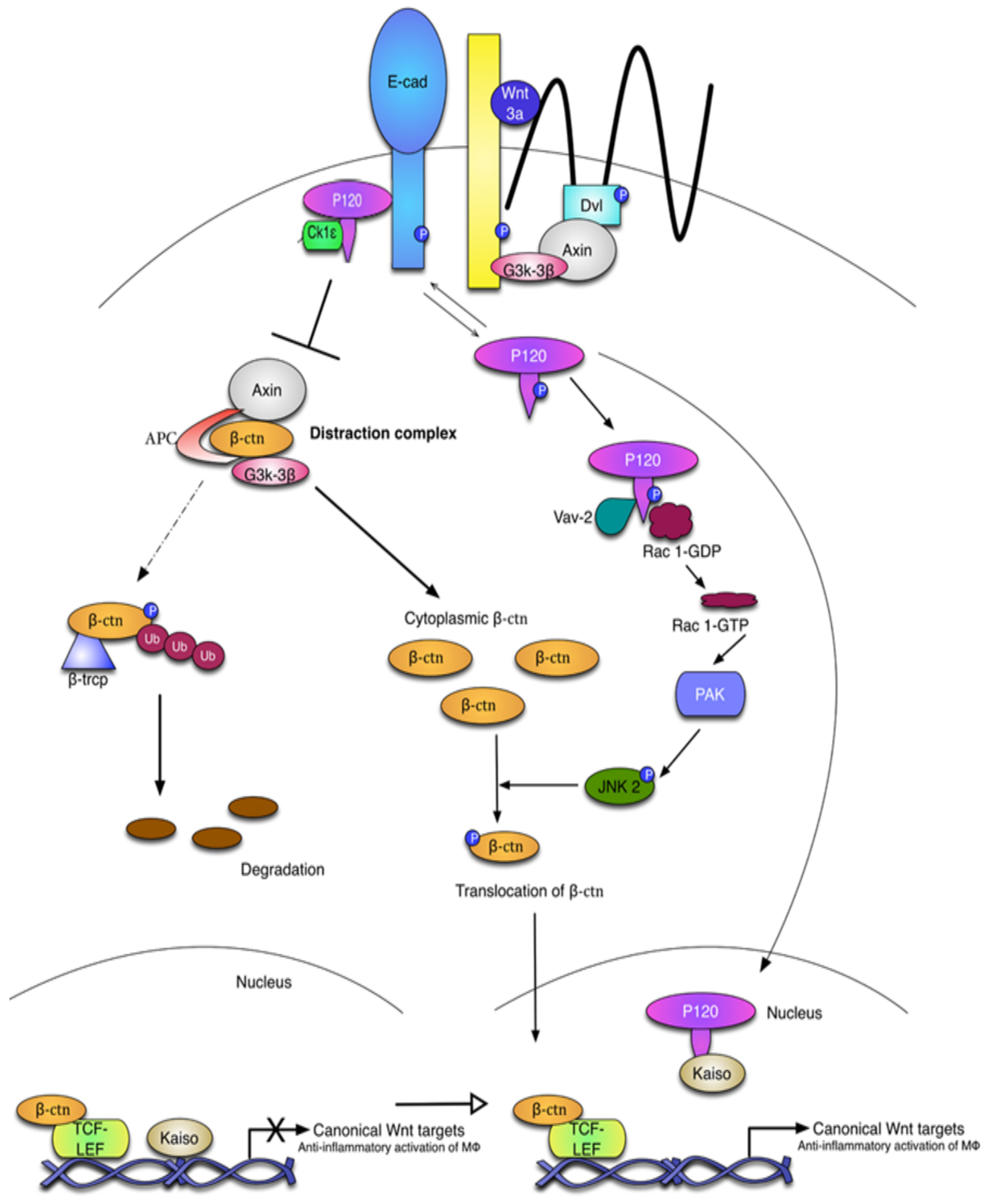

Figure A-1. Cartoon of E-cadherin /P120 complex mediated canonical wnt//-catenin signaling pathway

Canonical wnt/ $\beta$-catenin induces an anti-inflammatory phenotype in macrophages. 


\section{Material and Methods:}

\section{Preparation of Replica Surfaces}

Epoxy replicas were prepared as previously mention in section 3.2 Preparation of Replica Surfaces of this thesis. Sandblasted large-grit acid-etched (SLA) titanium disks (15 mm in diameter and $1 \mathrm{~mm}$ in thickness) were provided by Institute Straumann (Basel, Switzerland).

\section{Cell Culture}

Cells were culture as previously mentioned in section 3.3 Cell Culture of this thesis. Cells were plated onto the epoxy replicas of Pol and SLA at a population density of $2 \times 10^{5}$ cells $/ \mathrm{mL} / \mathrm{well}$

(Corning Costar; VWR International, ON, Canada) for 1-day and 2 x 10 4 cells $/ \mathrm{mL} /$ well for 5-day experiments.

\section{Immunofluorescence}

Immunofluorescence staining was used to study the E-cadherin and P120 proteins' distribution and amount at Day 1 and Day 5. Cells were fixed with 4\% formaldehyde (Fisher Scientific, MA, USA) for $10 \mathrm{~min}$ and permeabilized with $0.1 \%$ Triton X-100 (Fisher Scientific, MA, USA) for 3 min at room temperature. Non-specific biding sites were blocked by $1 \%$ bovine serum albumin (Sigma-Aldrich, MO, USA) in PBS (Sigma-Aldrich, MO, USA) for $30 \mathrm{~min}$.

For E-cadherin staining, cells were incubated with primary rabbit anti-mouse E-cadherin (Abcam, Cambridge, UK) (1:100 dilution) overnight at $4{ }^{\circ} \mathrm{C}$. For P120 staining, cells were incubated with primary rabbit anti-mouse P120 (Abcam, Cambridge, UK) (1:20) at $37{ }^{\circ} \mathrm{C}$ for $1 \mathrm{~h}$. 
After primary antibody application, cells were then rinsed with PBS before incubated in Alexa Fluor 488 goat anti-rabbit secondary antibody (Invitrogen, NY, USA) for $1 \mathrm{~h}$ at room temperature. All samples were counter-stained with DAPI prepared at $5 \mu \mathrm{g} / \mathrm{mL}$ (Sigma-Aldrich, MO, USA) for 30 min at room temperature. Following PBS washing 5times 2 min each, samples were mounted on microscope slides with Fluoromount ${ }^{\circledR}$ (SouthernBiotech, AL, USA). Then samples were observed with Nikon Confocal Microscope C1 and EZ-C1 3.50 software version 1.0.

Quantification of fluorescence intensity was done using Image J (version 1.48x, Image J, MD, USA) using a formula:

CTCF $($ corrected total cell fluorescence $)=$ Integrated Density $-($ Area of selected cell $\mathrm{x}$ Mean Fluorescence of background readings) (Burgess et al. 2010)

\section{Western Blotting}

Western Blotting of samples harvested on Day 1 and Day 5 was performed to study the changes in E-cadherin and P120 expression. Results were quantified using Image J. The measurements were used to assess the different levels of E-Cadherin and P120 protein production on different surface topographies.

\section{Sample Preparation:}

Cells were harvested and lysed on Day 1 and Day 5 with 100mM EDTA (Sigma-Aldrich, MO, USA), 100mM PMSF (Sigma-Aldrich, MO, USA), and Protease inhibitor (Sigma-Aldrich, MO, USA) in RIPA buffer (Sigma-Aldrich, MO, USA). Total protein concentration of each sample 
was measured using the BCA Protein Assay kit (Pierce Biotechnology Inc, IL, USA).

\section{Electrophoresis, membrane staining and gel quantification:}

An equal concentration of protein samples $(30 \mu \mathrm{g})$ in Laemmli sample buffer (Bio-Rad

Laboratories, CA, USA) was loaded and resolved on 10\% SDS-PAGE gel and transferred to polyvinylidene fluoride (PVDF) membrane (Bio-Rad Laboratories, CA, USA) for western blotting using PowerPac Basic ${ }^{\mathrm{TM}}$ (Bio-Rad Laboratories, CA, USA). Fifteen $\mu \mathrm{L}$ of the molecular weight marker Precison Plus Protein ${ }^{\mathrm{TM}}$ all blue standards (Bio-Rad Laboratories, CA, USA) was loaded to the first left lane of the gel.

The samples on the membranes were blocked with 10\% goat serum (Sigma-Aldrich, MO, USA) prepared in [1\% BSA (Sigma-Aldrich, MO, USA) in 0.05\% Tween20 TBS (Bio-Rad

Laboratories, CA, USA)] for $1 \mathrm{~h}$ at room temperature. After blocking, membranes were washed twice with TTBS for 10 min each and incubated in primary antibody (1:1000 dilution in TTBS) for overnight at $4{ }^{\circ} \mathrm{C}$. Followed by $10 \mathrm{~min}$ TTBS washing twice, alkaline phosphataseconjugated goat anti-rabbit secondary antibody (1:3000 diluted in TTBS) (Bio-Rad Laboratories, CA, USA) was applied for $1 \mathrm{~h}$ at room temperature. Then the membranes were immersed in the colour development buffer until visible purple bands appeared. Once purple bands were visible, the colour development process was stopped by immersing the membranes in distilled water for 10 min. The membranes were then dried overnight and scanned with Epson Perfection V700 Photo Scanner (Epson, NGN, Japan). The quantification of the purple bands on the membranes was done using Image J (version 1.48x, Image J, MD, USA). 
Results:

Immunofluorescent labeling of P120

Day 1

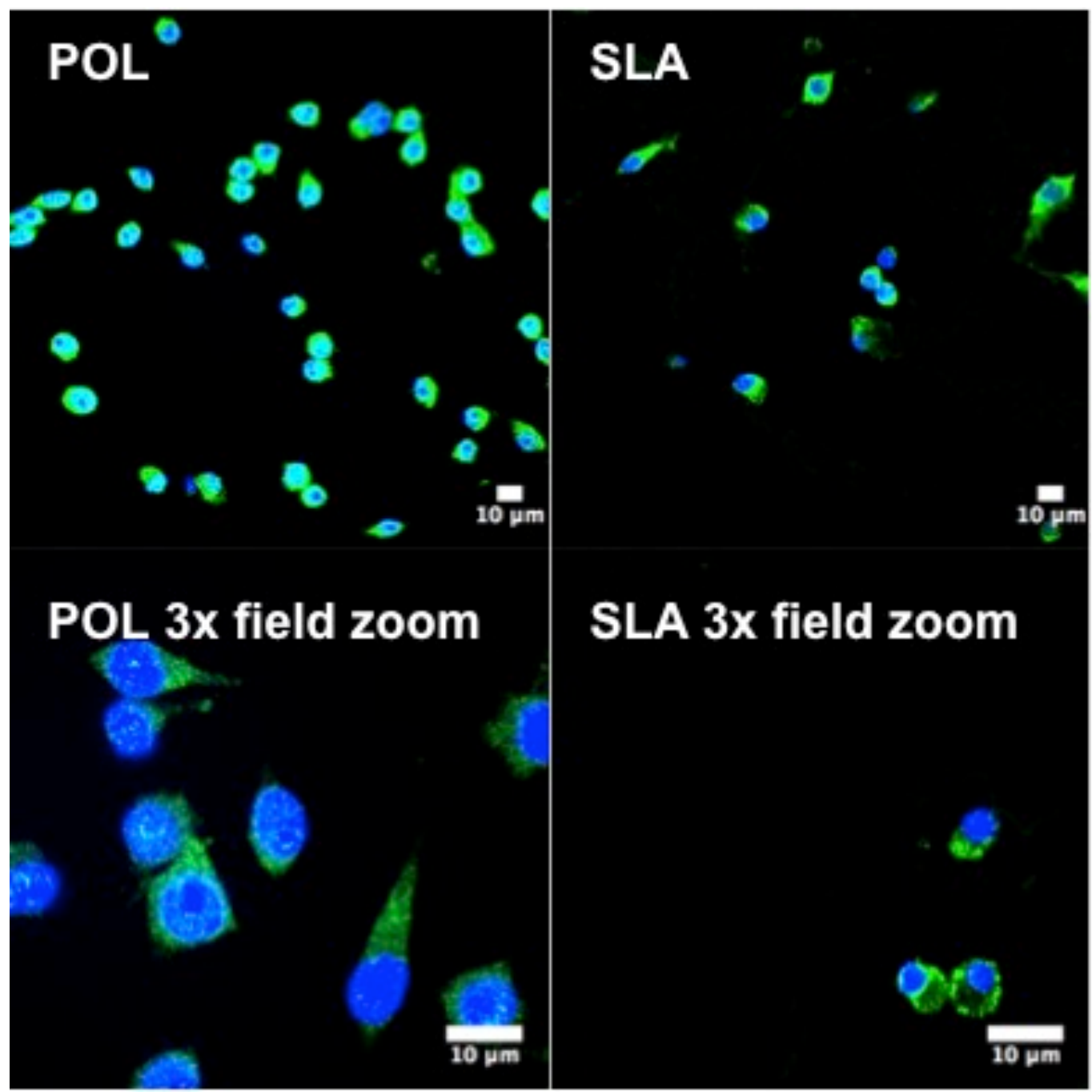

Figure A-2. Immunofluorescent labeling of macrophages cultured on Pol and SLA for Day1

Fluorescence images of topographical effects on the expression and distribution of P120 proteins expressed by RAW 264.7 macrophage cells cultured on Pol and SLA surfaces for Day 1. Cells were stained for P120 (green) and nucleus (blue). 


\section{Day 5}

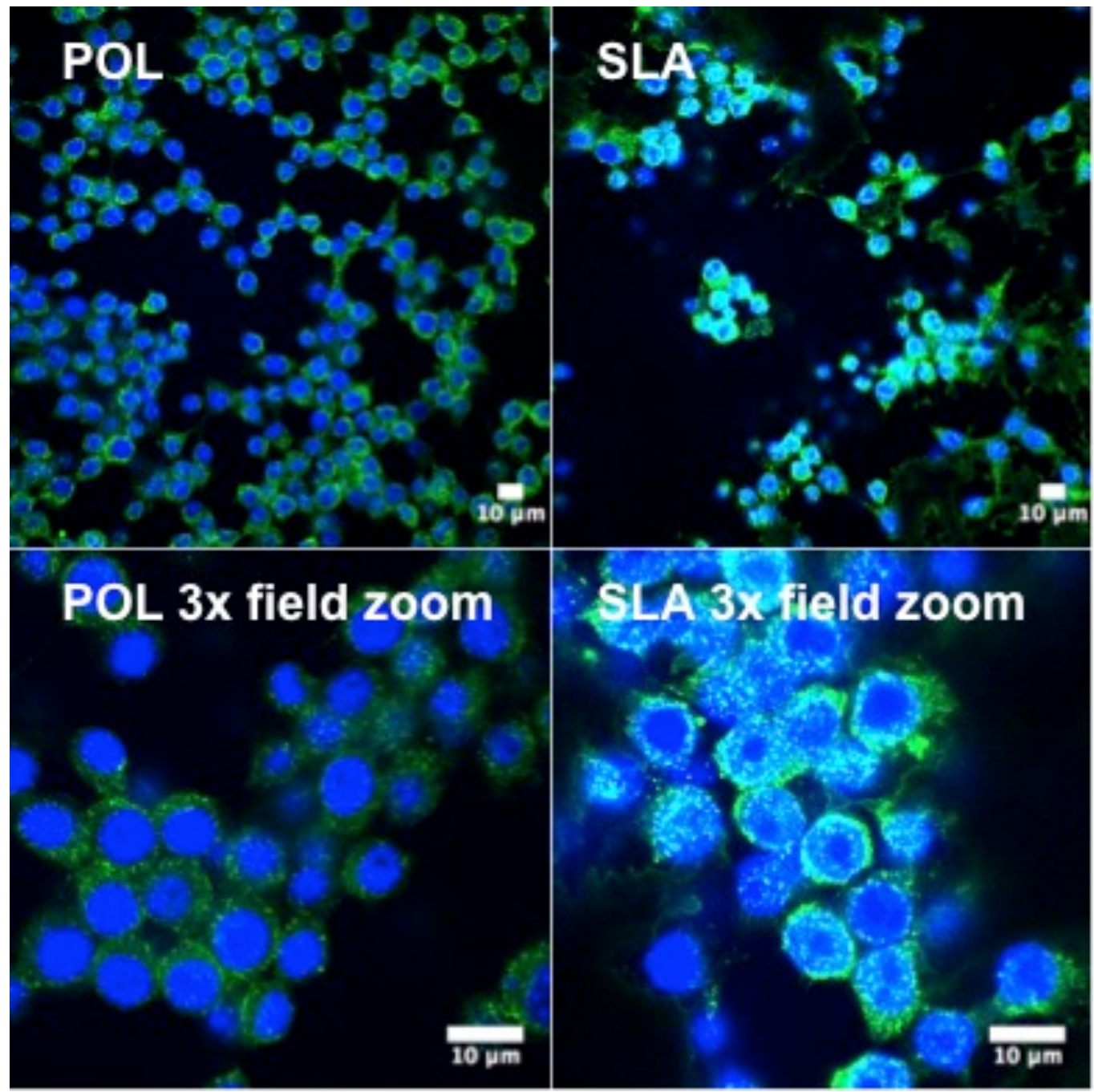

Figure A-3. Immunofluorescent labeling of macrophages cultured on Pol and SLA for Day5

Fluorescence images of topographical effects on the expression and distribution of P120 proteins expressed by RAW 264.7 macrophage cells cultured on Pol and SLA surfaces for Day 5. Cells were stained for P120 (green) and nucleus (blue). 


\section{Quantification of Fluorescence}

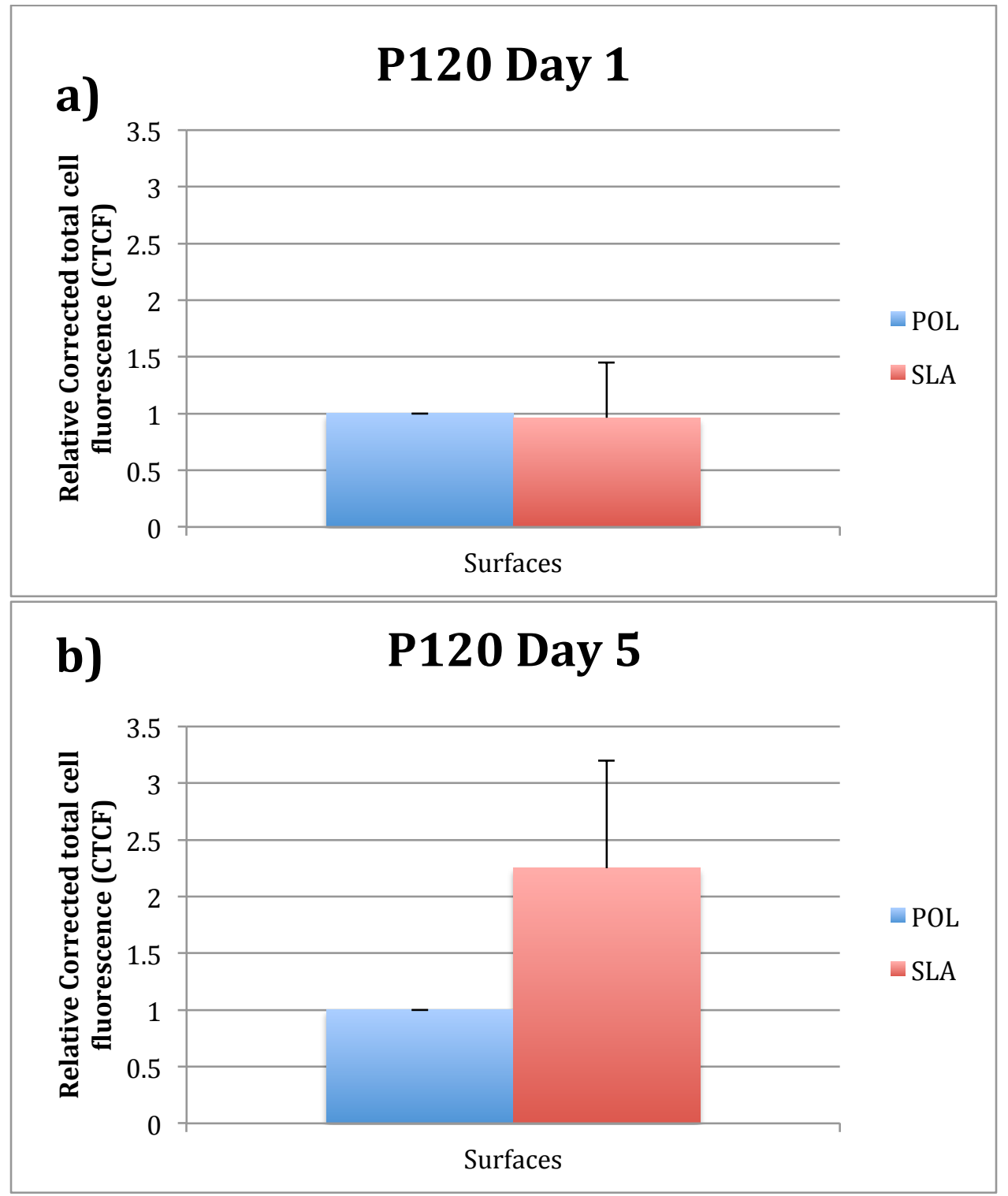

Figure A-4. Quantification of Fluorescence for P120 on Day 1 and Day 5

Quantification of corrected total cell fluorescence (CTCF) value normalized to POL's CTCF value for Day 1 (a) and for Day 5 (b). When CTCF values of the surfaces were compared, for Day 1, Pol expressed higher CTCF value only by 1.1-fold compared to SLA. For Day 5, SLA expressed higher CTCF value by 2.3-fold compared to Pol. The analysis was performed with two independent sample sets from different cultures showing similar results. 


\section{Western Blot}

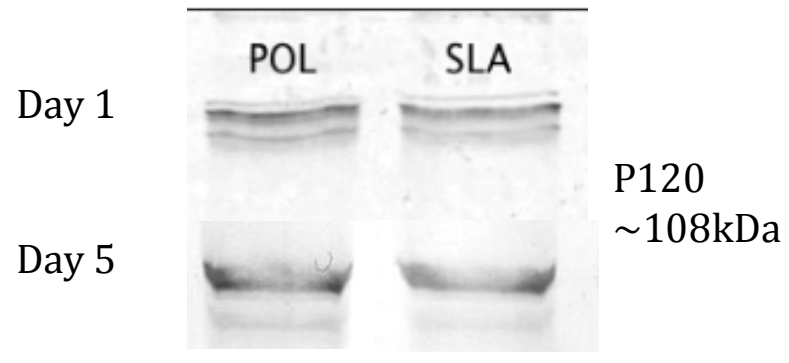

Figure A-5. Representative Western bolts of the amount of P120 in lysates prepared from RAW264.7 macrophages cultured on Pol and SLA for Day 1 and Day 5

\section{Quantification of Western Blot Results}

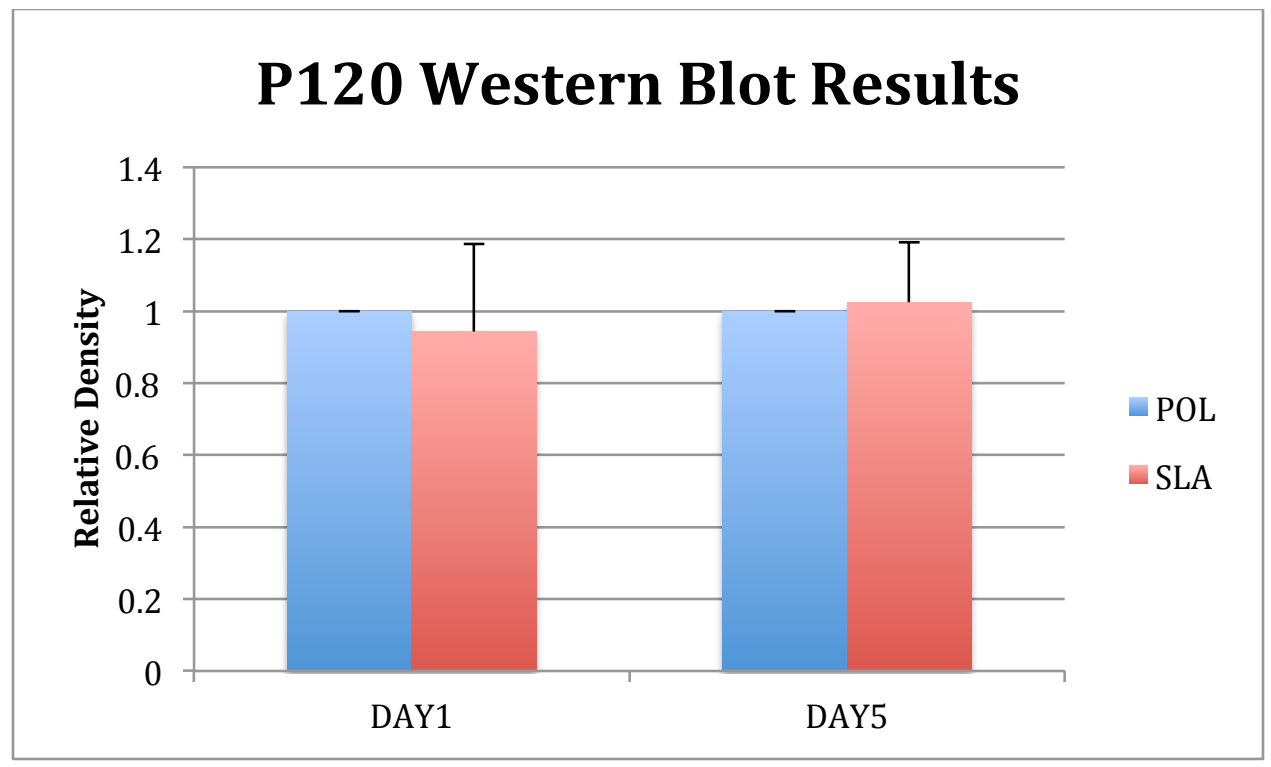

Figure A-6. Quantification of Western Blot Results for P120

Quantification of the amount of P120 in lysates prepared from RAW264.7 macrophages cultured on Pol and SLA for Day 1 and Day 5 determined by the Western Blot. The analysis was performed with two independent sample sets from different cultures showing similar results. 


\section{Discussion and Conclusions:}

The discrepancies observed between the analyses of immunofluorescent data and western blotting data at Day 5 for SLA surface might have been due to the variability in fluorescence measurements caused by the fluorescence properties of the epoxy resin substrata.

From the preliminary results, it appears that surface topography does not have a large influence on the expression of P120 proteins. However, the methods employed may not be sensitive enough to detect small differences. 